\title{
Evaluation of the Impact of EISA Federal Project Investments
}

KS Judd

EM Wendel

SL Morris

JL Williamson
MA Halverson

OV Livingston

SA Loper

December 2012

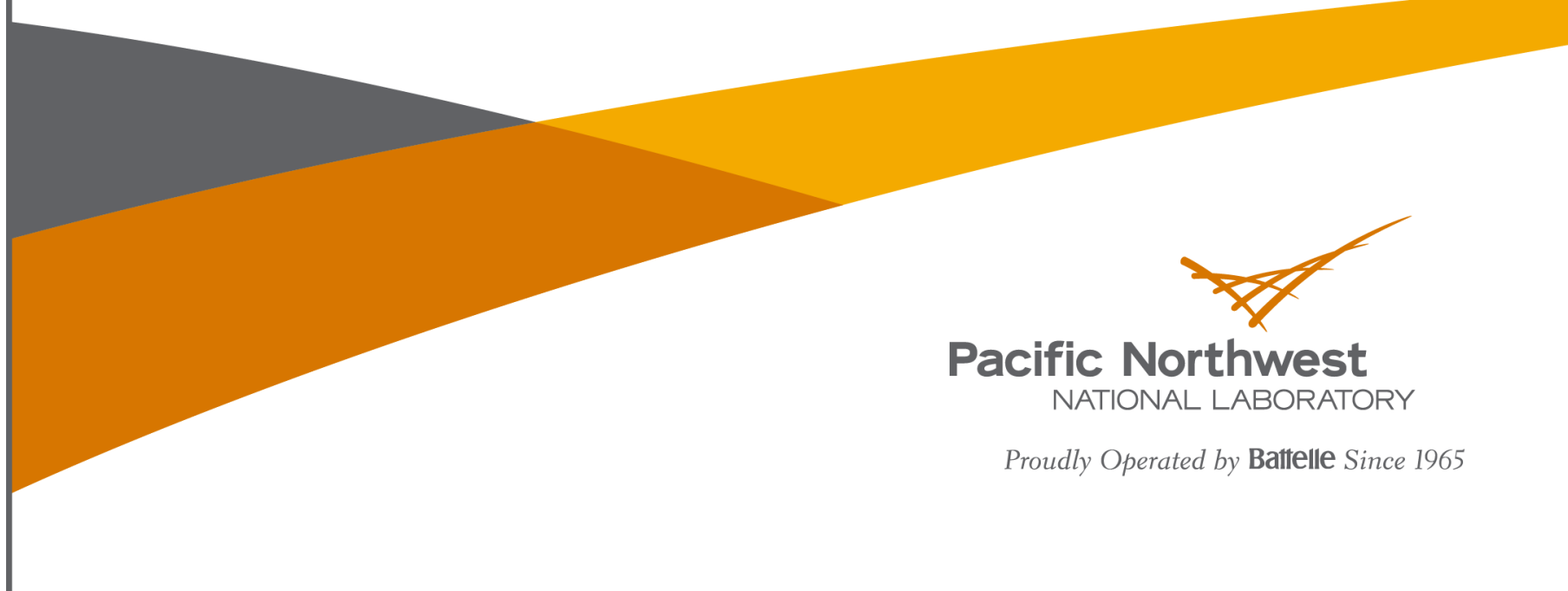




\title{
DISCLAIMER
}

This report was prepared as an account of work sponsored by an agency of the United States Government. Neither the United States Government nor any agency thereof, nor Battelle Memorial Institute, nor any of their employees, makes any warranty, express or implied, or assumes any legal liability or responsibility for the accuracy, completeness, or usefulness of any information, apparatus, product, or process disclosed, or represents that its use would not infringe privately owned rights. Reference herein to any specific commercial product, process, or service by trade name, trademark, manufacturer, or otherwise does not necessarily constitute or imply its endorsement, recommendation, or favoring by the United States Government or any agency thereof, or Battelle Memorial Institute. The views and opinions of authors expressed herein do not necessarily state or reflect those of the United States Government or any agency thereof.

\author{
PACIFIC NORTHWEST NATIONAL LABORATORY \\ operated by \\ BATTELLE \\ for the \\ UNITED STATES DEPARTMENT OF ENERGY \\ under Contract DE-AC05-76RL01830 \\ Printed in the United States of America
Available to DOE and DOE contractors from the
Office of Scientific and Technical Information,
P.O. Box 62, Oak Ridge, TN 37831-0062;
ph: (865) 576-8401
fax: $(865) 576-5728$ \\ email: reports@adonis.osti.gov \\ Available to the public from the National Technical Information Service \\ 5301 Shawnee Rd., Alexandria, VA 22312 \\ ph: (800) 553-NTIS (6847) \\ email: orders@ntis.gov <http://www.ntis.gov/about/form.aspx> \\ Online ordering: http://www.ntis.gov
}

This document was printed on recycled paper.

(8/2010) 


\title{
Evaluation of the Impact of EISA Federal Project Investments
}

\author{
KS Judd \\ MA Halverson \\ EM Wendel \\ SL Morris \\ OV Livingston \\ JL Williamson \\ SA Loper
}

December 2012

Prepared for

the U.S. Department of Energy

under Contract DE-AC05-76RL01830

Pacific Northwest National Laboratory

Richland, Washington 99352 



\section{Executive Summary}

This study evaluates the energy, economic, and environmental impacts of investments in energy and water conservation projects that were made by federal agencies as a result of the Energy Independence and Security Act (EISA) of 2007. The Department of Energy's (DOE's) Federal Energy Management Program (FEMP) led this effort in response to a request from the Office of Management and Budget to evaluate the savings and carbon emissions reductions from federal energy management investments.

As the agency responsible for tracking federal agency progress toward the various energy and water management and monitoring requirements under EISA, FEMP designed the EISA Compliance Tracking System (CTS) to capture the data associated with agency compliance. The analyses in this study are based on the data reported in the CTS by federal agencies starting in fiscal year (FY) 2008 through FY 2012. These data include:

- annual energy and water use in facilities covered under EISA,

- potential energy and water savings and cost savings based on evaluations of these facilities,

- estimated savings from investments in energy and water conservation measures, and

- benchmark data for select buildings within the covered facilities.

As of the end of FY 2012, the CTS contained annual energy use and the corresponding gross building area data for over 7,000 covered facilities across the federal government, more than half of which were U.S. Postal Service (USPS) facilities. A covered facility in CTS may include a single building or multiple buildings at a site (e.g., a military installation). Forty-eight percent of all covered facilities have been completely evaluated as of the end of FY 2012, although these evaluated facilities represent $57 \%$ of the energy use in covered facilities. The government-wide energy-savings potential identified through these covered facility evaluations is estimated to be 33,274.6 billion British thermal units (Btus).

The focus of this study is on the project-level investments that have been entered into CTS. It should be noted that these investments do not provide a comprehensive view of efficiency efforts currently funded by the federal government because agency reporting in CTS has been somewhat selective to date. The $\$ 1.35$ billion of project investments reported in CTS represent just $14 \%$ of the total spending on efficiency reported by agencies in their annual energy reports since FY 2008. Just one-third of the known Energy Savings Performance Contract (ESPC) funding and less than 10\% of direct capital and Utility Energy Service Contract (UESC) investments have been entered in CTS to date. While not comprehensive, the data provides useful insights into the comparative impacts that agency investments in different types of energy conservation measures are having at the site level and across agencies.

The largest funding sources for projects in CTS have come from ESPCs and the American Recovery \& Reinvestment Act of 2009 (ARRA). ESPCs represent 43\% of all project investments, and projects that relied on this funding source have the largest average project size of \$7.6 million. ARRA funds provided $33 \%$ of the total investment in projects and also supported larger projects on average as shown in Figure ES.1. In contrast, agency direct decentralized operations and maintenance budgets and centralized capital budgets fund significantly smaller projects on average. This suggests that without ARRA funds supporting efficiency investments in the future, it may be even more important to continue to find ways to make ESPCs and UESCs work as a mechanism for supporting large-scale improvements. 


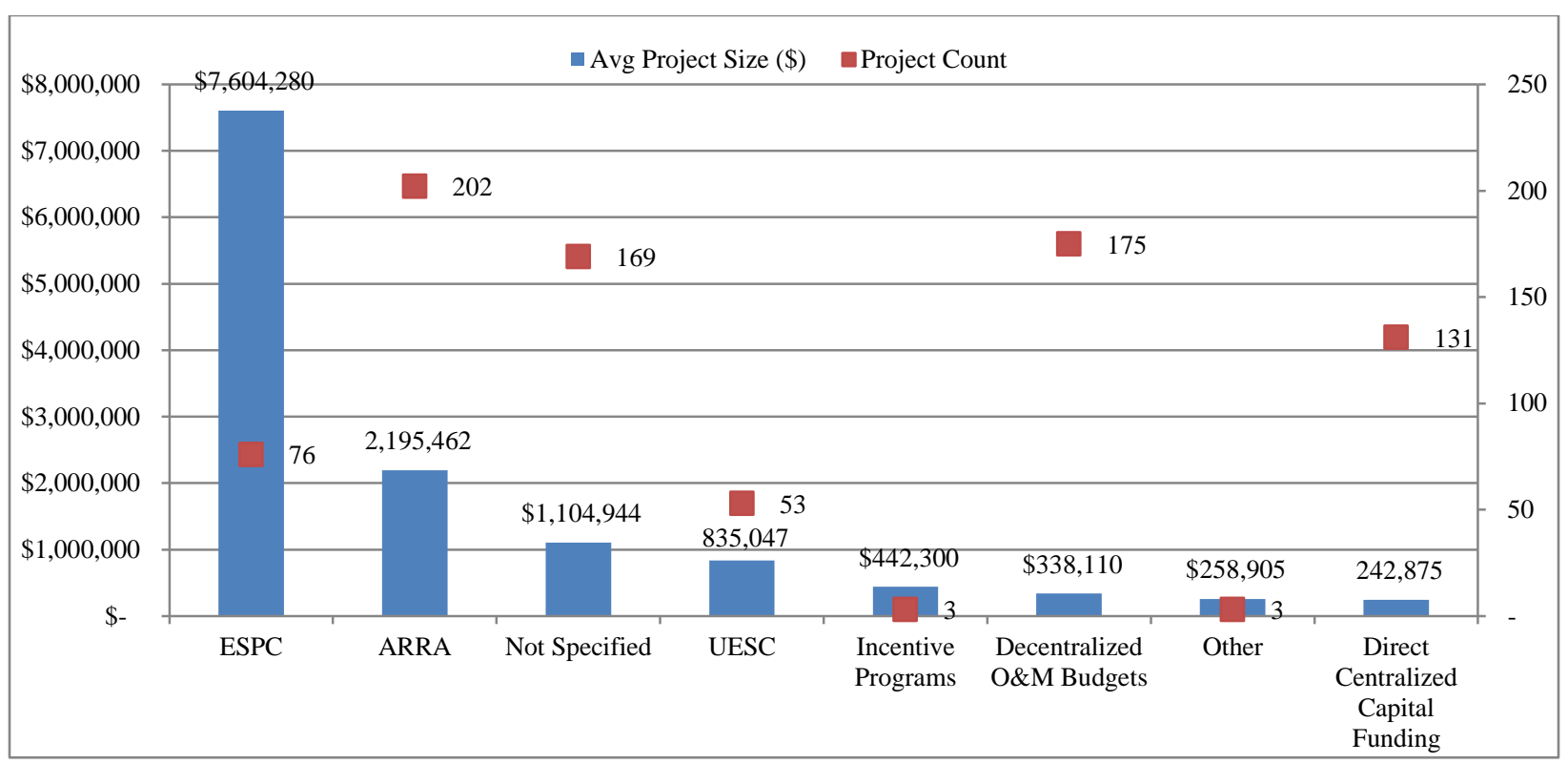

Figure ES.1. Average Project Size and Count of Projects by Funding Source

The 794 projects reported in CTS resulted in government-wide estimated energy savings of 4,078,279 million Btu (MMBtu) and water savings of 1.1 billion gallons coming from a broad set of energy and water conservation measures (ECMs). Agencies identified over 2,800 ECMs in these projects with Lighting; Heating, Ventilation and Air Conditioning (HVAC); and Energy Management and Control Systems (EMCS) being the most common ECM types implemented (see Figure ES.2).

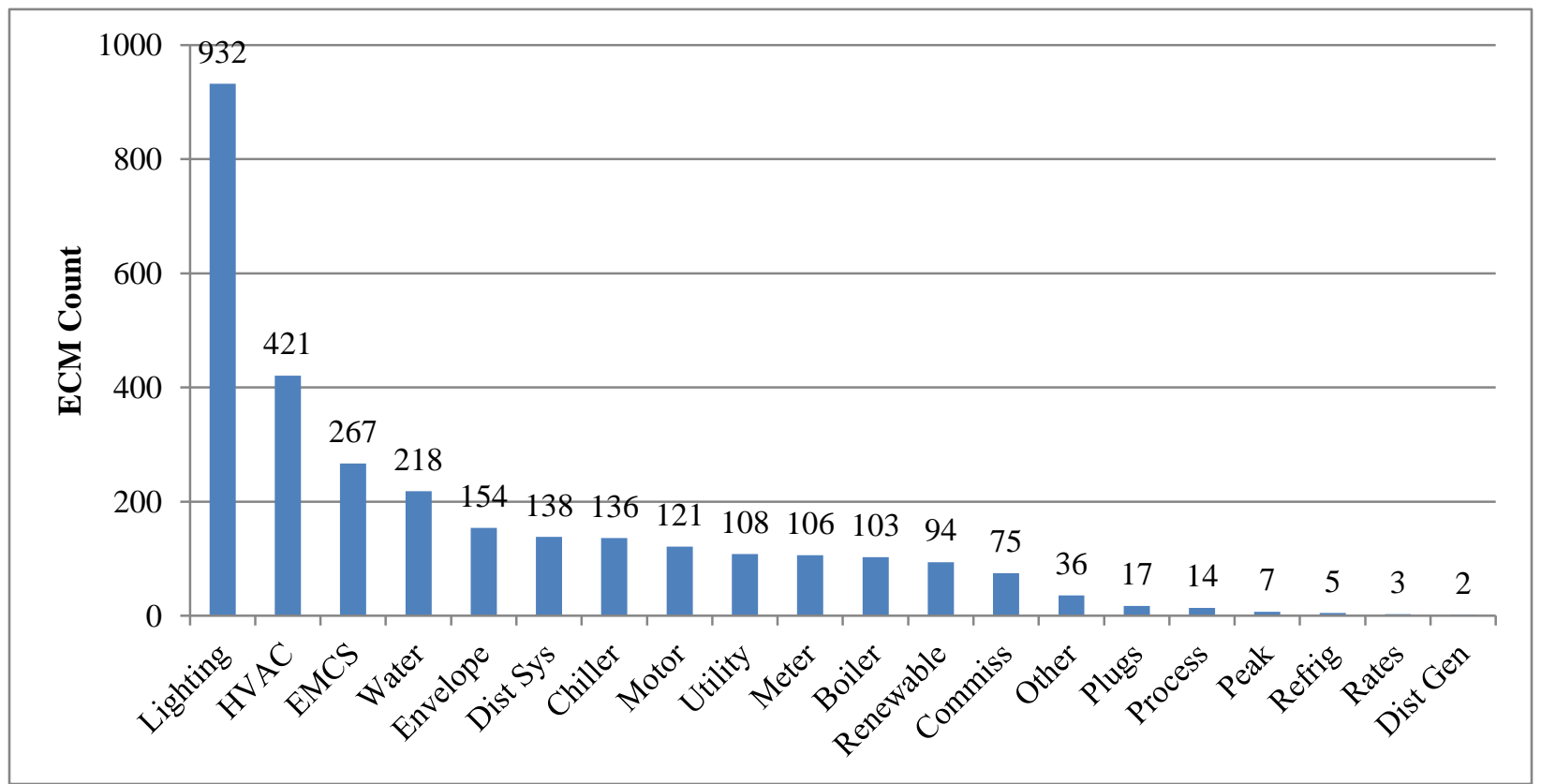

Figure ES.2. Sum of ECMs Implemented by Category 
As illustrated by the dark green shading in Table ES.1, Lighting ECMs were among the most frequently implemented ECM types for several agencies, and represented the majority ECMs implemented for the Department of Defense (72\% of its ECMs) and USPS (67\% of its ECMs).

Table ES.1. Percent of Agency's Total Count of ECMs for the Top 10 ECM Categories ${ }^{1}$

\begin{tabular}{lrrrrrrrrrr}
\hline Agency* & Lighting & HVAC & EMCS & Envelope & Water & Chiller & Boiler & Commiss & Meter & Motor \\
\hline GSA & $24 \%$ & $16 \%$ & $9 \%$ & $3 \%$ & $3 \%$ & $8 \%$ & $5 \%$ & $7 \%$ & $7 \%$ & $10 \%$ \\
NASA & $39 \%$ & $11 \%$ & $9 \%$ & $1 \%$ & $16 \%$ & $2 \%$ & $2 \%$ & $0 \%$ & $6 \%$ & $0 \%$ \\
USPS & $67 \%$ & $4 \%$ & $19 \%$ & $1 \%$ & $3 \%$ & $1 \%$ & $1 \%$ & $0 \%$ & $0 \%$ & $2 \%$ \\
DOD & $72 \%$ & $7 \%$ & $7 \%$ & $4 \%$ & $2 \%$ & $1 \%$ & $1 \%$ & $1 \%$ & $1 \%$ & $0 \%$ \\
DOL & $12 \%$ & $35 \%$ & $2 \%$ & $39 \%$ & $3 \%$ & $1 \%$ & $4 \%$ & $0 \%$ & $0 \%$ & $0 \%$ \\
DOI & $16 \%$ & $23 \%$ & $3 \%$ & $11 \%$ & $4 \%$ & $2 \%$ & $8 \%$ & $0 \%$ & $1 \%$ & $4 \%$ \\
DOJ & $13 \%$ & $10 \%$ & $16 \%$ & $0 \%$ & $13 \%$ & $7 \%$ & $4 \%$ & $0 \%$ & $0 \%$ & $2 \%$ \\
DOT & $16 \%$ & $18 \%$ & $3 \%$ & $6 \%$ & $29 \%$ & $10 \%$ & $3 \%$ & $1 \%$ & $1 \%$ & $2 \%$ \\
DHS & $12 \%$ & $21 \%$ & $12 \%$ & $21 \%$ & $3 \%$ & $2 \%$ & $9 \%$ & $0 \%$ & $0 \%$ & $0 \%$ \\
DOE & $16 \%$ & $11 \%$ & $9 \%$ & $2 \%$ & $9 \%$ & $7 \%$ & $9 \%$ & $0 \%$ & $7 \%$ & $2 \%$ \\
\hline
\end{tabular}

* Abbreviations are defined in the Acronyms and Abbreviations list, which follows the Executive Summary.

While EISA encourages bundling of ECMs to optimize energy saving opportunities while promoting cost-effectiveness, just $28 \%$ of projects were found to have bundled ECMs, although these represent $68 \%$ of total project investment. Three agencies - Department of Justice, State Department, and General Services Administration - bundled ECMs for almost all of their implemented projects. Agencies that bundled ECMs appear to be taking advantage of the cost-effectiveness of Lighting to make more costly improvements, such as Boiler, Chiller, and other HVAC upgrades (Table ES.2). However Building Envelope improvements, which often are not cost-effective when implemented alone, were not among the most commonly bundled ECMs.

Table ES.2. Top 25 Most Commonly Bundled ECMs

\begin{tabular}{ccccccccc}
\hline & EMCS & HVAC & Commiss & Meter & Boiler & Chiller & Motor & Water \\
\hline Lighting & 118 & 93 & 51 & 49 & 39 & 50 & 48 & 46 \\
HVAC & 88 & & 61 & 55 & 45 & 57 & 47 & \\
EMCS & & & 57 & 53 & 43 & 55 & 49 & 36 \\
Chiller & & & 39 & & 39 & & 37 & \\
Commiss & & & & 54 & & & 36 & \\
\hline
\end{tabular}

The energy savings from the energy efficiency investments reported in CTS since FY 2008 have resulted in an estimated 485,070 metric tons of Scope 1 and $2^{2}$ carbon dioxide equivalent $\left(\mathrm{MTCO}_{2} \mathrm{e}\right)$ emissions avoided by federal agencies. This represents approximately one percent of government-wide greenhouse gas (GHG) emissions. GHG emissions avoided by fuel source are presented in Figure ES.3

\footnotetext{
${ }^{1}$ Table ES.1 only includes 10 agencies with the highest number of ECMs reported. Information on ECMs reported by all agencies is included in the main body of the report.

${ }^{2}$ Scope 1 refers to direct emissions from onsite fuel combustion. Scope 2 refers to indirect emissions resulting from purchased electricity, heating, or steam.
} 
for the $70 \%$ of projects in which agencies specified the fuel source that was saved. Most of these emissions avoided for these projects came from reductions in electricity use (67\%) and natural gas (16\%), followed by coal (7\%), and other sources.

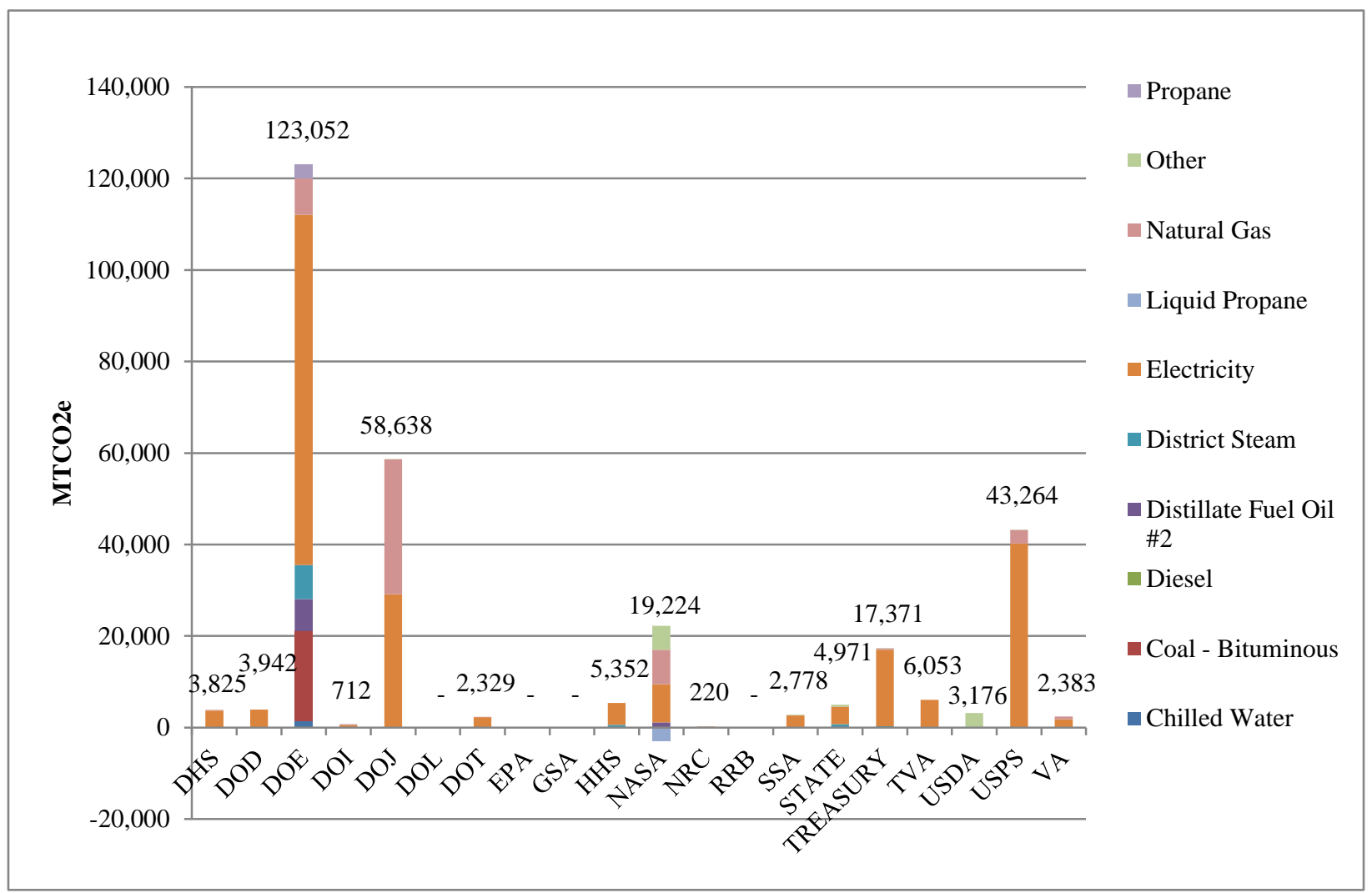

Figure ES.3. GHG Emissions Avoided by Agency for Projects with Known Savings by Fuel Source Only

The estimated annual energy and water savings per dollar invested provides one useful measure of return on investment for energy efficiency and water savings projects. The average savings per dollar invested for projects in which a single ECM was implemented was 5,340 Btu per dollar with over 90\% of projects showing a return of less than 10,000 Btu per dollar.

As illustrated in Figure ES.4 below, single-ECM projects focused on Commissioning, EMCS, and Metering have the highest average energy savings per dollar invested, whereas Chiller, Building Envelope and Energy-Related Process improvement projects had the lowest average savings per dollar. ECM types with a high number of projects and lower relative variability, such as Chiller and Lighting improvements, are more likely to accurately characterize the energy savings per dollar and may be more useful to use as a basis for estimating savings levels for future projects when making general estimates prior to conducting a more rigorous energy saving audit. In contrast, ECMs such as Metering and Plug Loads, which have few observations and more variability in CTS, are less likely to accurately characterize energy savings per dollar invested. 


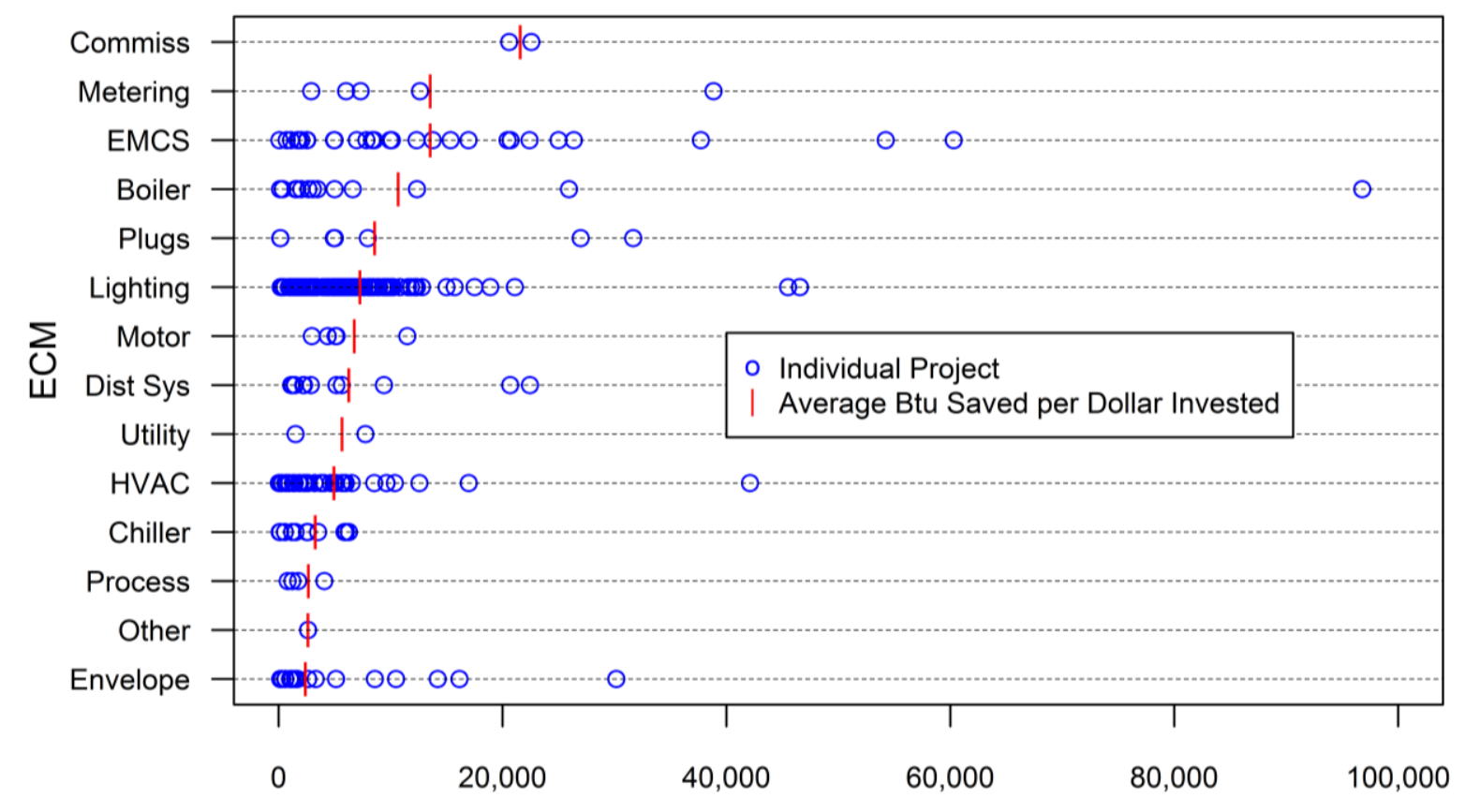

Btu Saved per Dollar Invested

Figure ES.4. Savings per Dollar Invested by ECM Type (circles represent individual projects)

Estimates of water savings per dollar invested were more difficult to draw meaningful conclusions from based on the data currently reported in CTS. Just 31 projects included both water savings estimates and implementation costs and limited information was provided on the nature of the water projects implemented, which could have ranged from water-efficient irrigation to interior plumbing improvements. As water metering becomes more prevalent among federal agencies and details about the types of the water conservation measures implemented are added, there will be greater opportunity to gauge the impact of water projects entered in CTS.

Finally, life-cycle cost (LCC) analysis was used to calculate several economic performance measures for evaluation of projects in which a single ECM was implemented. Seven of 16 types of ECMs evaluated were cost-effective on average based on net savings, savings-to-investment ratio, and adjusted internal rate of return, as illustrated in Table ES.3 when financing costs were included as part of the total investment. Excluding the financing costs from the total cost calculation resulted in the three ECMs highlighted in red - Distribution Systems, Motor, and Chiller improvements - switching from costineffective to cost-effective based on both the savings-to-investment ratio and adjusted internal rate of return. When not bundled with other ECMs, HVAC, Energy-Related Process, Boiler, Envelope, and PlugLoad ECMs were not cost-effective on average whether or not financing costs were included. 
Table ES.3. Average Economic Performance Indicators by ECM Type, Financing Cost Included

\begin{tabular}{lrrrrr}
\hline ECM Type & $\begin{array}{c}\text { Life-cycle } \\
\text { Benefit }(\$)\end{array}$ & $\begin{array}{r}\text { Location-Adjusted } \\
\text { Investment }(\$)\end{array}$ & $\begin{array}{c}\text { Net Savings } \\
(\$)\end{array}$ & $\begin{array}{c}\text { Savings-to- } \\
\text { Investment Ratio }\end{array}$ & $\begin{array}{c}\text { Adjusted Internal } \\
\text { Rate of Return }\end{array}$ \\
\hline Commiss & $8,441,711$ & $2,053,604$ & $6,388,107$ & 4.11 & $19 \%$ \\
EMCS & $4,423,204$ & $1,322,088$ & $3,101,117$ & 3.35 & $11 \%$ \\
Renewable & $134,663,627$ & $25,272,100$ & $109,391,572$ & 5.33 & $11 \%$ \\
Dist Gen & $1,140,968$ & 197,665 & 943,304 & 5.77 & $10 \%$ \\
Lighting & 632,577 & 332,605 & 299,972 & 1.90 & $7 \%$ \\
Meter & $8,472,775$ & $4,046,647$ & $4,426,128$ & 2.09 & $7 \%$ \\
Utility & 267,073 & 149,999 & 117,074 & 1.78 & $6 \%$ \\
Other & 4,987 & 5,358 & $(\$ 370)$ & 0.93 & $2 \%$ \\
Dist Sys & $16,171,604$ & $21,397,510$ & $(\$ 5,225,906)$ & 0.76 & $1 \%$ \\
Motor & $1,668,115$ & $2,284,258$ & $(\$ 616,143)$ & 0.73 & $-1 \%$ \\
Chiller & $2,793,226$ & $6,008,089$ & $(\$ 3,214,863)$ & 0.46 & $-4 \%$ \\
HVAC & 267,765 & 826,706 & $(\$ 558,940)$ & 0.32 & $-4 \%$ \\
Process & 874,087 & $5,578,280$ & $(\$ 4,704,193)$ & 0.16 & $-5 \%$ \\
Plugs & 15,707 & 49,117 & $(\$ 33,410)$ & 0.32 & $-6 \%$ \\
Envelope & 127,103 & 528,727 & $(\$ 401,625)$ & 0.24 & $-10 \%$ \\
Boiler & 536,381 & $5,476,869$ & $(\$ 4,940,489)$ & 0.10 & $\mathbf{1 0 . 4 \%}$ \\
\hline Totals & $\mathbf{4 , 5 3 6 , 8 8 2 , 1 2 0}$ & $\mathbf{1 , 4 8 6 , 6 0 1 , 4 4 3}$ & $\mathbf{3 , 0 5 0 , 2 8 0 , 6 7 7}$ & $\mathbf{3 . 0 5}$ & \\
\hline
\end{tabular}




\section{Acronyms and Abbreviations}

\begin{tabular}{|c|c|}
\hline AIRR & adjusted internal rate of return \\
\hline ARRA & American Recovery and Reinvestment Act \\
\hline ASCC & Alaska Systems Coordinating Council \\
\hline BMP & Best Management Practices \\
\hline Boiler & Boiler Plant Improvements \\
\hline CBECS & Commercial Building Energy Consumption Survey \\
\hline CDD & cooling degree days \\
\hline Chiller & Chiller Plant Improvements \\
\hline Commiss & Commissioning Measures \\
\hline CTS & Compliance Tracking System \\
\hline DHS & Department of Homeland Security \\
\hline Dist Gen & Distributed Generation \\
\hline Dist Sys & Chilled Water, Hot Water, and Steam Distribution Systems \\
\hline DOC & Department of Commerce \\
\hline DOD & Department of Defense \\
\hline DOE & Department of Energy \\
\hline DOI & Department of the Interior \\
\hline DOJ & Department of Justice \\
\hline DOL & Department of Labor \\
\hline DOT & Department of Transportation \\
\hline ECM & energy conservation measure \\
\hline EISA & Energy Independence and Security Act \\
\hline EMCS & Building Automation System/Energy Management and Control System \\
\hline Envelope & Building Envelope Modifications \\
\hline EPA & Environmental Protection Agency \\
\hline ERCOT & Electric Reliability Council of Texas \\
\hline ESPC & Energy Savings Performance Contract \\
\hline EUI & energy use intensity \\
\hline FEMP & Federal Energy Management Program \\
\hline FRCC & Florida Reliability Coordinating Council \\
\hline FY & fiscal year \\
\hline GSA & General Services Administration \\
\hline GHG & greenhouse gas \\
\hline HDD & heating degree days \\
\hline HHS & Department of Health and Human Services \\
\hline HICC & Hawaiian Islands Coordinating Council \\
\hline HUD & Department of Housing and Urban Development \\
\hline
\end{tabular}


HVAC

LCC

$\mathrm{LCB}$

Lighting

Meter

MMBtu

Motor

MRO

$\mathrm{MTCO}_{2} \mathrm{e}$

NARA

NASA

NIST

NPCC

NRC

OPM

O\&M

Peak

Plugs

PNNL

PPA

Process

Rates

Refrig

Renewable

RFC

RRB

SERC

SI

SIR

SPP

SSA

STATE

TMY

TREASURY

TVA

UESC

USACE

USDA
Heating, Ventilating, and Air Conditioning

life-cycle cost

life-cycle benefit

Lighting Improvements

Advanced Metering Systems

Million British thermal units

Electric Motors and Drives

Midwest Reliability Organization

Metric Tons of Carbon Dioxide Equivalent

National Archives and Records Administration

National Aeronautics and Space Administration

National Institute of Standards and Technology

Northeast Power Coordinating Council

Nuclear Regulatory Commission

Office of Personnel Management

operations and maintenance

Electrical Peak Shaving/Load Shifting

Appliance/Plug-Load reductions

Pacific Northwest National Laboratory

Power Purchase Agreements

Energy Related Process Improvements

Energy Cost Reduction through Rate Adjustments

Refrigeration

Renewable Energy Systems

ReliabilityFirst Corporation

Railroad Retirement Board

SERC Reliability Corporation

Smithsonian Institution

savings-to-investment ratio

Southwest Power Pool

Social Security Administration

Department of State

typical meteorological year

Department of the Treasury

Tennessee Valley Authority

Utility Energy Service Contract

Army Corps of Engineers

Department of Agriculture 
USPS

Utility

VA

Water

WECC
United States Postal Service

Energy/Utility Distribution Systems

Department of Veterans Affairs

Water and Sewer Conservation Systems

Western Electricity Coordinating Council 



\section{Contents}

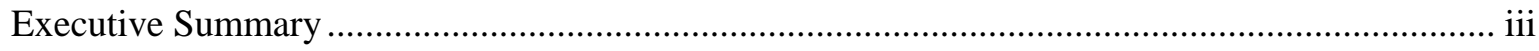

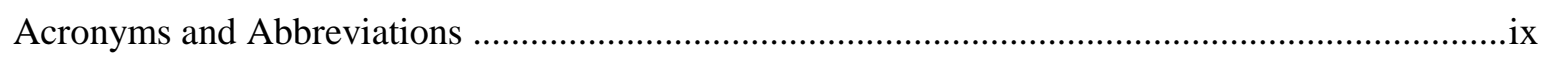

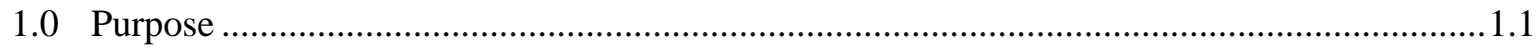

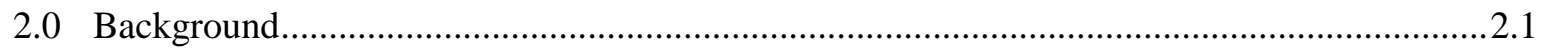

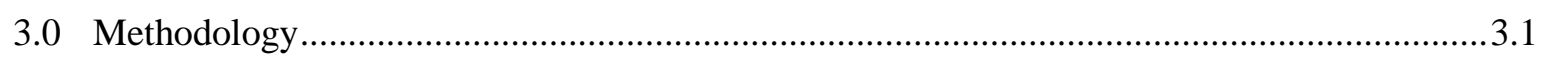

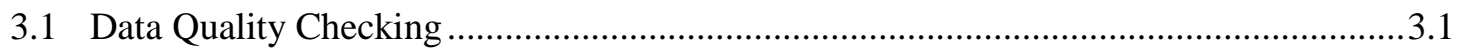

3.2 Working with Agencies to Address Data Quality Issues .............................................

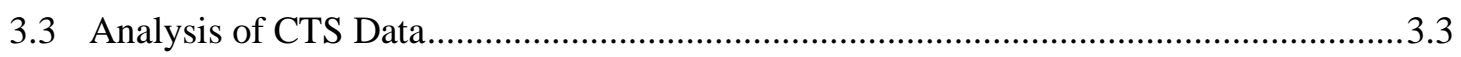

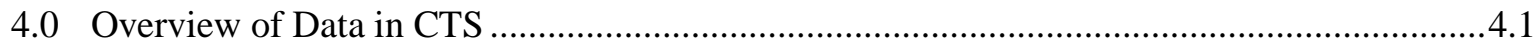

4.1.1 Covered Facility Footprint ….........................................................................

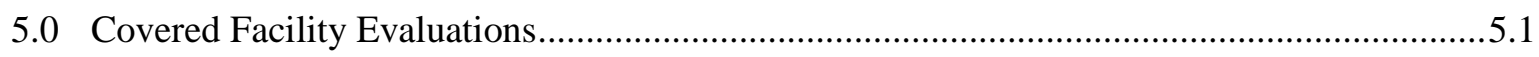

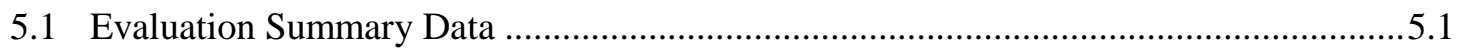

5.2 ECM Types Identified in Evaluations .................................................................... 5.3

5.3 Potential Savings from ECMs Evaluated .................................................................

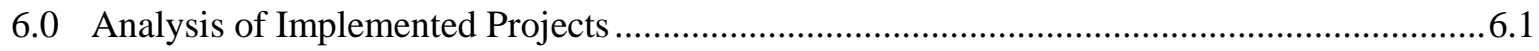

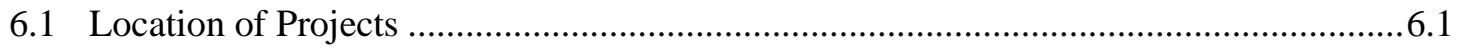

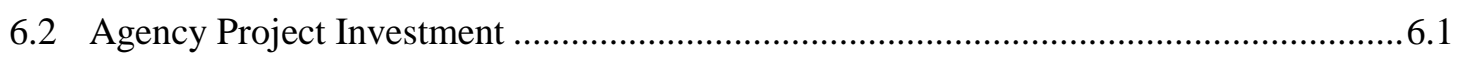

6.2.1 Average and Total Project Investment ........................................................... 6.2

6.2.2 Project Investment by Funding Source …......................................................6.5

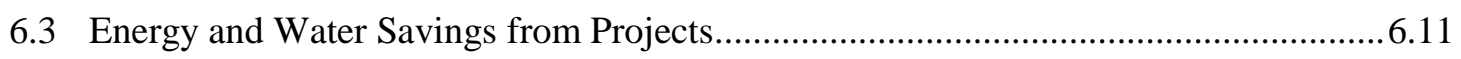

6.4 Energy Conservation Measures Implemented ............................................................6.11

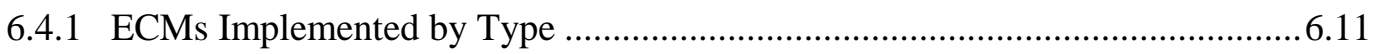

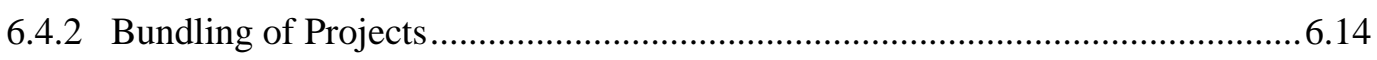

6.4.3 Energy Savings by Implemented ECM .........................................................6.16

6.4.4 Renewable Energy Output by Implemented ECM ...........................................6.18

6.4.5 Cost of Implementing ECMs by Type ......................................................6.19

6.4.6 Water Conservation Measures Implemented....................................................6.20

6.4.7 Energy and Water Evaluation Estimate Relative to Implemented Projects .......6.21

6.5 Annual Savings per Dollar Invested.........................................................................2.

6.5.1 Annually Recurring Energy Savings per Dollar Invested ................................6.22

6.5.2 Energy Savings per Dollar Invested by ECM ................................................6.22

6.5.3 Energy Savings per Dollar Invested by Agency.............................................6.25

6.5.4 Energy Savings per Dollar Invested by Funding Source....................................6.26

6.5.5 Water Savings per Dollar Invested...............................................................27

6.6 Savings Relative to Annual Energy and Water Use .....................................................28

6.6.1 Energy Savings as a Percent of Annual Energy Use .......................................6.28 
6.6.2 Energy Savings Relative to Annual Energy Use by ECM ...............................6.30

6.6.3 Energy Savings Relative to Annual Energy Use by Agency.............................6.31

6.6.4 Water Savings Relative to Annual Water Use.................................................6.33

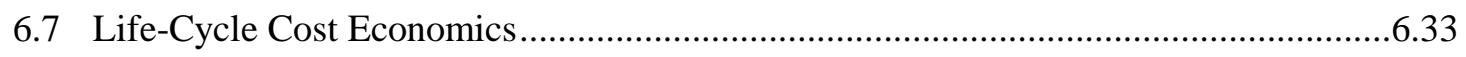

6.7.1 Economic Performance Indicators by ECM ................................................6.34

6.7.2 Economic Performance Indicators by Agency …............................................6.37

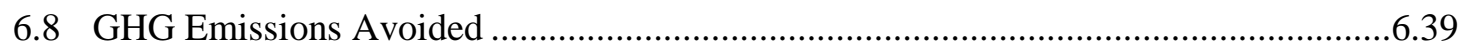

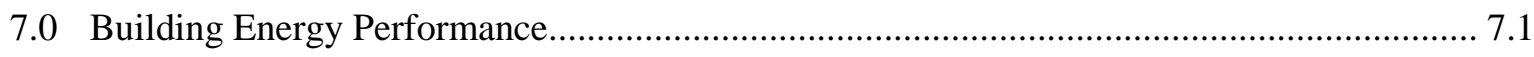

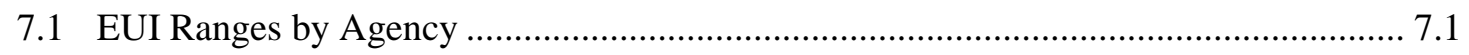

7.2 Covered Facility EUI Changes Over Time............................................................... 7.3

7.3 Energy Savings per Square Foot for Evaluated ECMs............................................... 7.5

7.4 Energy Reduction per Square Foot for Implemented Projects .................................... 7.5

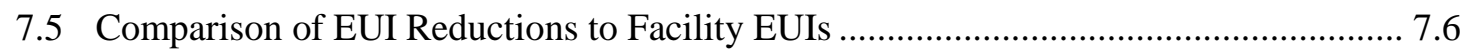

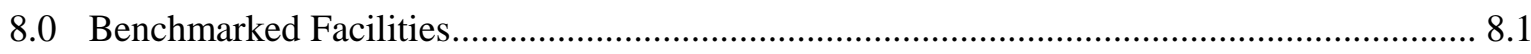

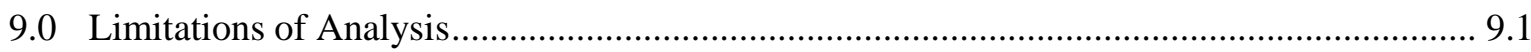

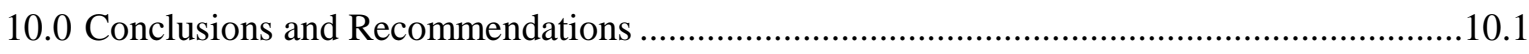

Appendix A PNNL Program Plan for Savings Evaluation of EISA Federal Project Investments..A.1 Appendix B List of ECM Types and Subtypes in CTS ..............................................................

Appendix C High and Low LCC Results by ECM and Agency ................................................. 1 


\section{Figures}

Figure 4.1. Reporting Structure for Covered Facilities and Individual Buildings in CTS .............4.1

Figure 5.1. Sum of ECMs Evaluated by Category .......................................................................5.4

Figure 5.2. Distribution of Savings per Dollar Invested by ECM for Evaluations ........................5.5

Figure 5.3. Projected Evaluated Water Savings Relative to Baseline Use ..................................5.7

Figure 6.1. Locations of Projects Reported in CTS and Project Density by State ........................6.1

Figure 6.2. Number of Implemented Projects by Agency and Level of Investment (\$M) .............6.2

Figure 6.3. Average (blue bar) and Range of Individual Project Investments by Agency ............6.3

Figure 6.4. Average Project Cost Relative to Number of Projects ...............................................6.4

Figure 6.5. Percent of Dollars Invested in Efficiency per Dollar Spent on Energy Utility Bills as

Reported in CTS (red) and Agency Annual Energy Reports (blue) ........................................ 6.5

Figure 6.6. Percent of Total Project Investment Reported in CTS by Source ..............................6.7

Figure 6.7....... Value (\$M) and Percent of Total Efficiency Investments Reported in Annual Energy

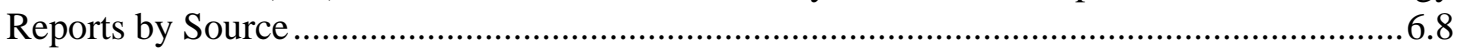

Figure 6.8. Total Project Investment by Agency and Funding Source .......................................6.9

Figure 6.9. Average Size and Count of Implemented Projects by Funding Source .....................6.10

Figure 6.10. Average Project Size by Agency and Funding Source ........................................6.10

Figure 6.11. Sums of ECMs Implemented by Category ..........................................................6.12

Figure 6.12. Type of ECMs Implemented by Agency ….......................................................6.13

Figure 6.13. Number of Projects with One or More ECM Types............................................6.14

Figure 6.14. Number of Projects, Number of Single Parent ECM Projects, and Sum of ECMs by

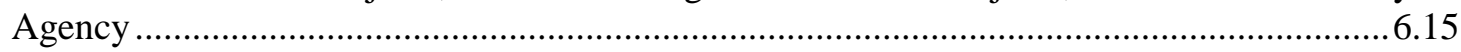

Figure 6.15. ECM Savings by Category for Projects with a Single ECM Type .........................6.18

Figure 6.16. Total Implementation Cost by Category for Projects with a Single ECM Type .......6.20

Figure 6.17. Average Implementation Cost per ECM for Projects with a Single ECM Type ......6.20

Figure 6.18. Annual Energy Savings (Btu) per Dollar Invested for All Energy Projects ..............6.22

Figure 6.19. Distribution of Savings per Dollar Invested by ECM Type ..................................6.23

Figure 6.20. Distribution of Savings per Dollar Invested by Agency.......................................6.26

Figure 6.21. Distribution of Savings per Dollar Invested by Funding Source for Projects with One

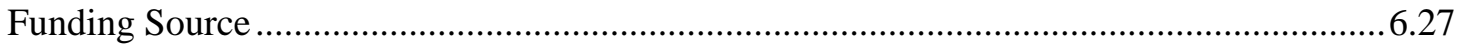

Figure 6.22. Number of Projects versus Range of Gallons Saved per Dollar Invested ...............6.28

Figure 6.23. Energy Savings Relative to Annual Baseline (left) and Weather-Normalized (right)

Energy Use for All Energy Projects.................................................................................6.29

Figure 6.24. Distribution of the Ratio of Energy Savings to Energy Use by ECM Type ............6.30

Figure 6.25. Distribution of Energy Savings Relative to Annual Normalized Baseline Energy Use,

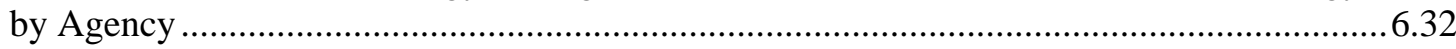

Figure 6.26. Water Savings Relative to Baseline Use .............................................................6.33

Figure 6.27. Estimated Annual Government-wide GHG Emissions Avoided by Fuel Source.....6.41 
Figure 6.28. Estimated Proportion of Annual Government-wide GHG Emissions Avoided by Fuel Type

Figure 6.29. GHG Emissions Avoided by Agency for Projects with Known Fuel Sources. Red arrows indicate agencies with complete estimates of all avoided GHG emissions due to reporting by fuel type.

Figure 6.30. Comparison of Annual Estimated Energy Savings (left) and GHG Emissions Avoided (right) by Fuel Type as a Percentage of Total Annual Savings and Emissions Avoided (estimates are for savings reported by fuel source only).

Figure 6.31. Government-wide GHG Emissions Avoided from Electricity Savings by eGRID Subregion 6.44

Figure 7.1. Comparison of EUI Changes from 2008 to 2011 by Agency ..................................... 7.4

Figure 7.2. Comparison of EUI Changes from 2010 to 2011 by Agency ................................... 7.4

Figure 7.3. Average Projected EUI Reduction Estimates by Agency for Evaluated ECMs .......... 7.5

Figure 7.4. Average Projected EUI Reduction Estimates for Agencies for Active Projects .......... 7.6

\section{Tables}

Table 4.1. Covered Facility Annual Footprint for FY 2011 .................................................... 4.2

Table 5.1. Covered Facility Evaluation Summary Table .......................................................... 5.2

Table 5.2. ECM Types and Abbreviations for Evaluations...................................................... 5.3

Table 5.3. Number of Facilities with Evaluations within Simple Payback Ranges ...................... 5.5

Table 5.4. Potential Energy Savings Ranges of Evaluated Projects per Dollar Invested for

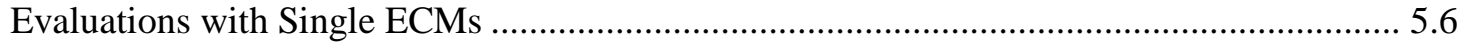

Table 5.5. Water Savings per Dollar Invested for Evaluations with Only Water ECMs .............. 5.6

Table 6.1. Federal Project Total Investment in CTS by Funding Source and Agency (\$M) ........ 6.8

Table 6.2. Total Annual Energy Savings and Renewable Output from Projects in CTS .............6.11

Table 6.3. Percent of Agency's Total Count of ECMs for the Top 10 ECM Categories ..............6.13

Table 6.4. Bundling of ECMs in Projects by Agency ................................................................6.16

Table 6.5. Top 25 Most Commonly Bundled ECMs .................................................................6.16

Table 6.6. Energy Savings Grouped by Number of ECM Types per Project .............................6.17

Table 6.7. Energy Savings per ECM Group by Number of ECMs ............................................6.17

Table 6.8. Annual Renewable Energy Output Summary ….......................................................18

Table 6.9. Renewable Energy Output by Project Type ..............................................................6.19

Table 6.10. Implementation Costs Grouped by Number of ECM Types per Project...................6.19

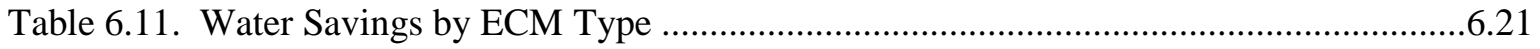

Table 6.12. Btus Saved per Dollar Invested for Single-ECM Projects ......................................6.24

Table 6.13. Btus Saved per Dollar Invested for Bundled Projects by ECM Presence within Project 6.24

Table 6.14. Btus Saved per Dollar Invested by Agency 6.26 
Table 6.15. Btus Saved per Dollar Invested by Funding Source

Table 6.16. ...... Comparison of Average Annual Savings Relative to Non-Normalized and WeatherNormalized Energy Use 6.29

Table 6.17. Energy Savings as a Percentage of Normalized Baseline Use for Single-ECM Projects 6.31

Table 6.18. Percentage of Energy Savings Relative to Normalized Baseline Energy Use, by Agency

Table 6.19. Average Economic Performance Indicators by ECM Type, Including Financing Cost 6.35

Table 6.20. Average Economic Performance Indicators by ECM Type, Excluding Financing Cost 6.35

Table 6.21. Comparative AIRR Ranking by ECM Type with and without Financing 6.36

Table 6.22. Average Economic Performance Indicators by Agency, Including Financing Cost..6.37

Table 6.23. Average Economic Performance Indicators by Agency, Excluding Financing Cost 6.38

Table 6.24. Estimated Annual Energy Savings (MMBtu) by Agency with Known and Unspecified Fuel Sources 6.40

Table 7.1. Simplified Version of Table 3.1.9 of DOE's Building Energy Data Book—Commercial Building EUIs $\left(\mathrm{kBtu} / \mathrm{ft}^{2}\right)$ 7.1

Table 7.2. Minimum, Average, and Maximum EUI (kBtu/ft $\left.{ }^{2}\right)$ Reported in FY 2011 by Agency..7.2

Table 7.3. Average EUI $\left(\mathrm{kBtu} / \mathrm{ft}^{2}\right)$ and Average EUI Reduction for Evaluations and Projects

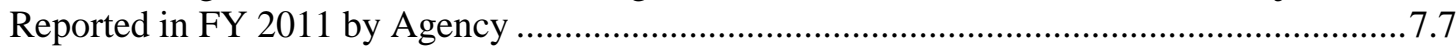

Table 8.1. Benchmarked Buildings in CTS (FY 2011 data) ....................................................... 8.1 



\subsection{Purpose}

Section 432 of the Energy Independence and Security Act (EISA) of $2007^{3}$ establishes the expectation that federal agencies will implement energy and water efficiency projects in federal buildings and monitor the performance of those buildings over time. The Department of Energy's (DOE's) Federal Energy Management Program (FEMP) has been charged by the Office of Management and Budget to conduct "an evaluation on actual and verifiable energy savings and carbon emissions reductions from federal energy management investments" made across the federal government as a result of this statute. This study presents the findings from that evaluation, which was conducted by Pacific Northwest National Laboratory (PNNL) during fiscal year (FY) 2012.

The specific goals of this study were to:

1. Evaluate the accuracy of data reported in the EISA Compliance Tracking System (CTS) and assist agencies in addressing inaccuracies.

2. Characterize energy, water, and greenhouse gas (GHG) savings from the implemented energy and water efficiency projects.

3. Assess cost-effectiveness of various types of energy and water conservation measures (ECMs) that were implemented across the federal government.

\footnotetext{
${ }^{3}$ The Energy Independence and Security Act of 2007, 42 USC 17001 et seq., is summarized on the FEMP website at http://www1.eere.energy.gov/femp/regulations/eisa.html. The complete text of the Act may be found at http://www.gpo.gov/fdsys/pkg/BILLS-110hr6enr/pdf/BILLS-110hr6enr.pdf
} 



\subsection{Background}

FEMP is responsible for tracking federal agency progress toward the various energy and water management and monitoring requirements under EISA. The EISA Section $432 \mathrm{CTS}$ was designed to capture the data associated with agency compliance with the Facility Energy Management Guidelines and Criteria for Energy and Water Evaluations in Covered Facilities, Subsection (f), Use of Energy and Water Efficiency Measures in Federal Buildings (42 U.S.C. 8253(f)).

Specific EISA requirements of top-tier agencies include:

- Designate "covered facilities" that comprise at least 75\% of the agency's facility energy use.

- Assign energy managers to $100 \%$ of those covered facilities.

- Conduct comprehensive energy and water evaluations for covered facilities (25\% per year with all completed by June 2012), including energy and water audits and a commissioning assessment for the purpose of identifying $\mathrm{ECM}^{4}$ opportunities.

- Prioritize potential ECMs for implementation and bundle them into projects that optimize energysaving and/or environmental benefits and align with available funding.

- Report progress in implementing energy and water efficiency projects and follow up to confirm persistence of savings.

In December 2011, agencies began reporting data into CTS on initial implemented energy- and water-saving projects. The information in CTS is not only useful for assessing compliance with these EISA requirements, but can help agencies understand the real and comparative impacts that their investments in ECMs are having at the site level and across the agency as a whole. Analysis of CTS data can be used to direct and justify investment in ECMs to help achieve agency energy and water efficiency goals.

It is the intent of this study to assess the overall effectiveness of these investments and help agencies to learn from these past investments, rather than to evaluate agency compliance with specific requirements under the statute.

\footnotetext{
${ }^{4}$ For consistency with language in EISA Section 432(f)(3)-(8) and the CTS, the acronym ECM represents both water and energy efficiency measures.
} 



\subsection{Methodology}

This analysis of the impact of investments in energy and water conservation projects in the CTS consisted of three major steps:

1. data quality checking of the CTS database entries

2. working with agencies to address any data quality issues identified

3. conducting a final analysis of the revised data in CTS.

Each of these steps is discussed below. A more detailed description of the methodology is contained in the Program Plan found in Appendix A.

\subsection{Data Quality Checking}

The CTS database contains data on energy and water use at over 7,000 facilities, as well as evaluation or audit results for those facilities and data on projects implemented at those facilities. FEMP has provided guidelines for data entry and supported agencies with biweekly meetings on the development and use of CTS to help provide consistency in how each data element is reported. Because the data has been entered by many individuals at many agencies over a period of two years, data-entry and calculation errors are inevitable.

The first step in the analysis was to make sure that the data was of sufficient quality to be analyzed. The entire database was examined for missing data, internal inconsistencies between multiple years of data for the same facility, and anomalies based on comparisons to the expected or "typical" performance ranges. Data quality checking focused on covered facility footprint and implemented project data, but also included a high-level review of covered facility evaluation data to identify obvious errors.

Specific checks undertaken include: ${ }^{5}$

1. number of ECMs per facility

2. missing data on implementation cost, facility area, and energy and water savings estimates

3. energy use intensity compared to expected ranges for commercial buildings

4. energy savings per square foot

5. renewable energy production relative to energy use

6. energy savings per dollar invested

7. energy and water savings reported relative to estimated baseline usage

8. evaluated area relative to gross covered facility area

9. other anomalies (e.g., unusually high increases or decreases in energy use at a facility in a single year).

\footnotetext{
${ }^{5}$ See Appendix A, PNNL Program Plan for Savings Evaluation of EISA Federal Project Investments, Task 6 for more details on these checks.
} 
The most common problems identified and addressed in the database included:

1. missing required project data (i.e., implementation costs, energy or water savings estimates)

2. projects and evaluations with energy or water savings higher than (or an extremely high proportion of) total facility energy or water use

3. unusually high/low reported energy use in a single year, often due to poor quality source data

4. projects identified as a renewable energy ECM with no renewable energy generation estimates, or vice versa

5. projects identified as a Water and Sewer Conservation ECM with no water savings estimates, or vice versa

6. energy or water usage or savings estimates entered in the wrong units

7. evaluations with an evaluated facility area greater than the gross covered facility area

8. ECMs bundled as part of larger maintenance projects and "additional" costs for the ECM could not be easily separated out, resulting in unusually low energy savings-to-investment ratios.

Over 500 issues were identified as part of the data quality check. Some issues were resolved by reviewing the project notes and other details. Agencies were contacted for follow-up on issues that could not be resolved.

It should be emphasized that the CTS database is continually growing and changing as agencies add new facilities and projects to the database. The data quality issues identified and addressed in this analysis were from versions of the database reviewed in the summer of 2012 and there is a potential for additional data quality issues as new data is added. The research team recommended a set of automated quality checks that may be built into CTS to flag potential data-entry issues for agencies.

\subsection{Working with Agencies to Address Data Quality Issues}

For each issue identified during data quality checking, the research team reviewed the project details in CTS to help resolve or narrow down the problem. For those issues that could not be resolved, the research team contacted the agency-designated Facility Energy Manager to determine whether there was an actual data quality concern to be addressed or the data point was simply an outlier. Based on these interactions, corrections were made in the CTS database, either by the agency or by PNNL when requested by the agency. PNNL staff also assisted in the development of energy-savings estimates when requested.

It should be noted that all data quality issues were not resolved through this process. As of the end of September 2012, all agencies had been notified of outstanding issues; however over 100 potential issues had not been resolved. The data associated with these issues was evaluated on a case-by-case basis and pulled from the analyses where it could potentially skew the results. For this reason, the number of observations used in analyses throughout this report will vary. 


\subsection{Analysis of CTS Data}

After all agencies were contacted about potential data quality issues and given an opportunity to correct these issues, final analysis of the database was undertaken. The results of that analysis are shown in this report. Specific analyses undertaken include: ${ }^{6}$

1. ECMs evaluated and implemented

2. energy savings by ECM type and by agency

3. project investment by ECM type, agency and funding source

4. energy and water savings relative to total agency energy and water use

5. energy and water savings per dollar invested

6. life-cycle cost economics

7. GHG emissions avoided

8. energy savings from implemented projects relative to evaluated energy savings potential

9. facility energy-use intensity changes.

As part of the final analysis, energy use data was normalized to account for the fact that the evaluation and measurement occurred in a particular year and reflects weather-specific patterns of that year. This normalized data was used in the analysis of energy savings relative to energy use described in Section 6.0.

\footnotetext{
${ }^{6}$ See Appendix A, PNNL Program Plan for Savings Evaluation of EISA Federal Project Investments, Task 10 for more details on these analyses.
} 



\subsection{Overview of Data in CTS}

The CTS is a FEMP-administered, Web-based reporting system to track agency compliance with EISA Section 432 requirements to conduct energy and water evaluations, implement projects, monitor and verify savings from those projects, and benchmark building performance. This section provides an overview of the data entered into CTS by federal agencies as of the end of FY 2012 for the years 2008 to 2011. ${ }^{7}$ The following sections provide analysis of facility evaluations (Section 5.0) and implemented projects (Section 6.0).

As depicted in Figure 4.1, CTS contains data reported at the covered facility level for project management tracking, and at the individual building level for performance monitoring. Most of the data reported in CTS and analyzed for this report is examined at the covered facility level, which may include a single building or multiple buildings at a site (e.g., a military installation). This represents more breadth and depth of energy and water savings potential and achievements than has previously been available across federal facilities. However, because covered facilities can include multiple buildings and there is not enough information in CTS to group covered facilities by building type or age, the findings on facility energy performance must be interpreted carefully and may not be relevant for building-level comparisons.

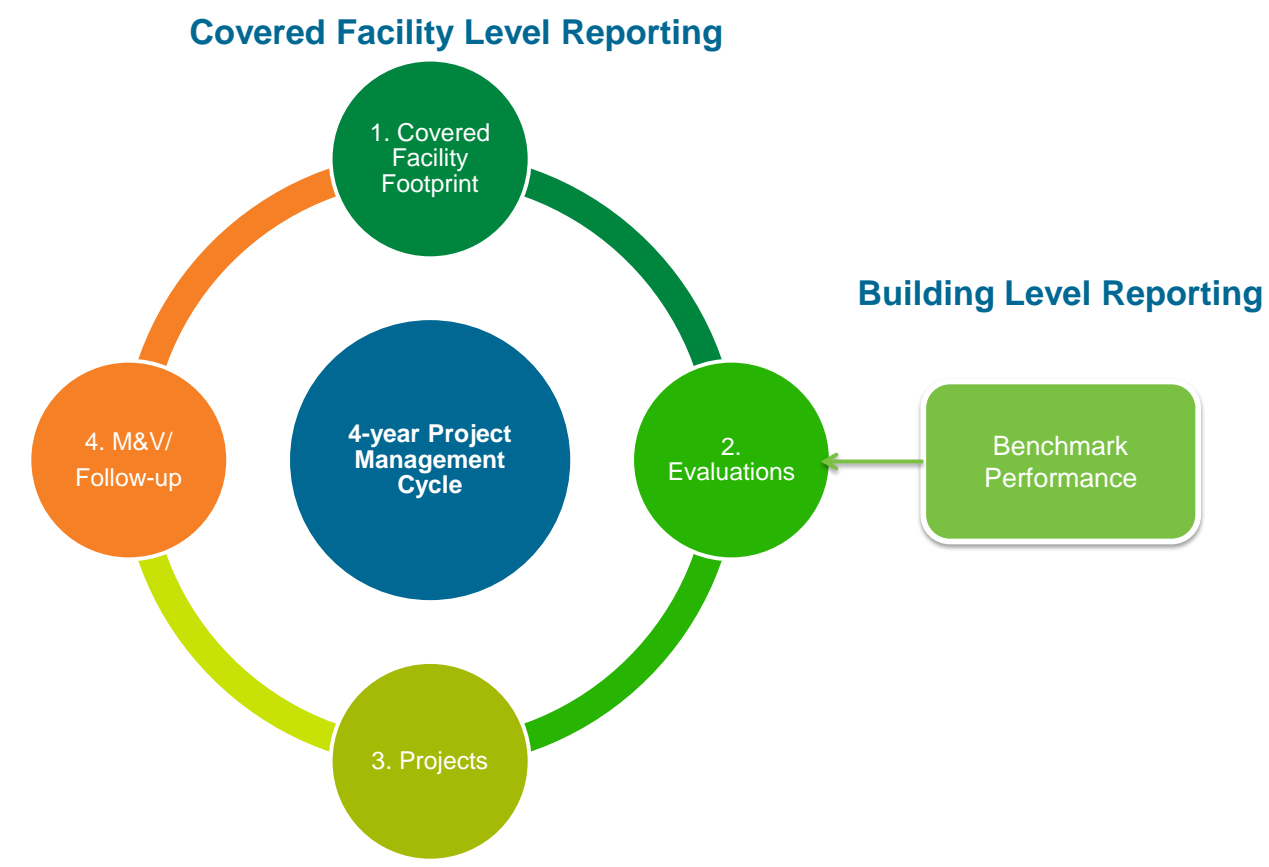

Figure 4.1. Reporting Structure for Covered Facilities and Individual Buildings in CTS

\subsubsection{Covered Facility Footprint}

Covered facility data in CTS includes floor area, energy use and water use for FY 2008 through FY 2011. As of the end of FY 2012, the CTS contains annual energy use and the corresponding gross

\footnotetext{
${ }^{7}$ While 2008 is the first year of reporting in CTS, EISA allows agencies to include in CTS projects implemented up to two years prior.
} 
building area data for 7,001 covered facilities across the federal government. ${ }^{8}$ The U.S. Postal Service (USPS) accounts for the greatest number of active covered facilities in CTS, with 59\% of all covered facilities by number. While the Department of Defense (DOD) manages just $9 \%$ of the active covered facilities, those facilities comprise $68 \%$ of total energy use and covered facility gross square footage in CTS. This is because DOD covered facilities typically represent multiple buildings managed as part of an integrated operation at large site (e.g., installation).

Water-use reporting for covered facilities in CTS is currently optional for agencies as water metering is not required under EISA and has not yet been widely adopted. As a result, the total water use reported is likely to be significantly lower than actual use for many agencies. Just 11 of the 20 agencies reported water use for all covered facilities in FY 2011. Table 4.1 below indicates which agencies have incomplete reporting of water use.

Table 4.1. Covered Facility Annual Footprint for FY 2011

\begin{tabular}{|c|c|c|c|c|c|}
\hline Agency* & $\begin{array}{l}\text { Total \# of } \\
\text { Active } \\
\text { Covered } \\
\text { Facilities } \\
\end{array}$ & $\begin{array}{l}\text { Covered Facility } \\
\text { Gross Square Feet } \\
\text { (Thousands) }\end{array}$ & $\begin{array}{l}\text { \# of Metered } \\
\text { Buildings }\end{array}$ & $\begin{array}{c}\text { Total FY } 2011 \\
\text { Covered Facility } \\
\text { Energy Use } \\
\text { (Million Btu) } \\
\end{array}$ & $\begin{array}{l}\text { Total FY } 2011 \\
\text { Water Use } \\
\text { (Thou. Gallon) }\end{array}$ \\
\hline All Agencies & $\mathbf{7 , 0 0 1}$ & $2,796,600$ & 22,263 & $334,541,205$ & $122,621,089$ \\
\hline DHS & 180 & 37,051 & 4,855 & $3,571,053$ & 198,643 \\
\hline $\mathrm{DOC}$ & 7 & 11,694 & 64 & $2,112,833$ & 376,962 \\
\hline DOD & 606 & $1,906,670$ & 4,935 & $194,868,101$ & $95,973,019$ \\
\hline DOE & 49 & 87,559 & 1,695 & $24,653,294$ & $6,987,428$ \\
\hline DOI & 505 & 46,518 & 2,821 & $3,842,382$ & $1,948,956$ \\
\hline DOJ & 74 & 53,087 & 76 & $7,364,236$ & $8,369,165$ \\
\hline DOL & 59 & 17,495 & 119 & $1,771,832$ & 744,013 \\
\hline DOT & 623 & 16,457 & 894 & $2,812,184$ & 285,317 \\
\hline EPA & 16 & 2,840 & 16 & 989,170 & 102,355 \\
\hline GSA & 197 & 139,207 & 230 & $13,888,553$ & $2,275,446$ \\
\hline HHS & 80 & 22,133 & 129 & $9,165,243$ & $1,442,536$ \\
\hline HUD & 1 & 1,441 & 1 & 106,300 & 21,039 \\
\hline NARA & 7 & 3,492 & 7 & 413,600 & 65,490 \\
\hline NASA & 12 & 32,327 & 844 & $5,964,147$ & $2,053,370$ \\
\hline NRC & 2 & 763 & 2 & 90,246 & 26,336 \\
\hline OPM & 3 & 1,014 & 3 & 77,038 & 29,500 \\
\hline RRB & 1 & 347 & 1 & 33,600 & 4,480 \\
\hline SI & 10 & 6,105 & - & $1,012,700$ & - \\
\hline SSA & 8 & 6,320 & 8 & 820,695 & 127,613 \\
\hline STATE & 10 & 4,656 & 16 & 556,162 & 83,299 \\
\hline TREASURY & 13 & 8,721 & 10 & $1,485,521$ & 185,540 \\
\hline TVA & 53 & 19,456 & 9 & $1,267,880$ & 98,423 \\
\hline USACE & 46 & 7,052 & 48 & $1,389,877$ & 116,679 \\
\hline USDA & 165 & 17,968 & 265 & $3,302,941$ & $1,097,793$ \\
\hline USPS & 4,105 & 191,568 & 4,105 & $24,117,258$ & - \\
\hline VA & 169 & 154,661 & 1,110 & $28,864,360$ & 7,688 \\
\hline
\end{tabular}

\footnotetext{
${ }^{8}$ Because agencies do not report the number of buildings that constitute a covered facility, it is not possible to specify what proportion of total federal buildings these 7,001 covered facilities represent. Based on annual energy use reporting, however, these facilities represented $87 \%$ of the total annual federal facility energy use in 2011.
} 


\subsection{Covered Facility Evaluations}

This section provides an overview of the potential savings identified by agencies through their required evaluations, or audits, of covered facilities. It also examines the types of ECMs identified through those evaluations to support comparisons to implemented ECMs in the next section.

\subsection{Evaluation Summary Data}

Comprehensive evaluations of covered facilities are required to identify potential life-cycle cost-effective ECMs that can be implemented separately or as bundled projects. Evaluations also identify estimated implementation costs and estimated energy and water savings or energy production. Just under half of the 7,001 covered facilities that have been entered into the CTS by federal agencies have been completely evaluated as of the end of FY 2012. This represents $57 \%$ of covered facility energy use and $49 \%$ of government-wide energy use. Findings from these evaluations are summarized in Table 5.1 below.

The number of ECMs identified through evaluations varies substantially across agencies and does not have a strong correlation with estimated potential energy savings. There appears to be a lack of consistency in how agencies count ECMs. Over 50\% of all potential ECMs identified were in DOD facilities, yet these represent just $28 \%$ of the total energy-savings potential identified in CTS. Similarly, DOI accounts for $16 \%$ of the potential ECMs identified, but those represent just $2 \%$ of total energy savings across all agencies. Both Treasury and DOE have identified very few ECMs $(0.2 \%$ and $2 \%$, respectively) yet these represent a substantial portion of total federal agency energy savings potential ( $16 \%$ and $13 \%$, respectively). This may be due to DOI reporting on a number of comparatively small covered facilities and DOE reporting ECMs for larger covered facilities with multiple buildings.

The estimated investment required to implement all life-cycle-cost-effective ECMs identified in the most recent evaluation of each covered facility exceeds $\$ 9.3$ billion, with an annual estimated cost savings potential of $\$ 689.4$ million. The corresponding potential energy savings of 33,274,578 million British thermal units (MMBtu) represents $18 \%$ of the total annual energy used by those covered facilities. Because the most recent evaluation may have been in 2008, it should be noted that some of these conservation measures may have already been implemented as projects so no longer represent the full potential. 
Table 5.1. Covered Facility Evaluation Summary Table

\begin{tabular}{|c|c|c|c|c|c|c|c|c|c|}
\hline Agency & $\begin{array}{c}\text { \# of } \\
\text { Covered } \\
\text { Facilities } \\
\text { Evalu- } \\
\text { ated }\end{array}$ & $\begin{array}{c}\text { Gross } \\
\text { Square Feet } \\
\text { Evaluated } \\
\text { (Thousands) }\end{array}$ & $\begin{array}{c}\text { Annual } \\
\text { Energy Use } \\
\text { of Evaluated } \\
\text { Facilities } \\
\text { (MMBtu) }\end{array}$ & $\begin{array}{l}\text { Potential } \\
\text { Annual } \\
\text { Energy } \\
\text { Savings } \\
\text { (MMBtu) }\end{array}$ & $\begin{array}{c}\text { Annual Water } \\
\text { Use of } \\
\text { Evaluated } \\
\text { Facilities } \\
\text { (Thou. } \\
\text { Gallons) }\end{array}$ & $\begin{array}{c}\text { Potential } \\
\text { Annual Water } \\
\text { Savings } \\
\text { (Thou. } \\
\text { Gallons) }\end{array}$ & $\begin{array}{c}\text { Total ECMs } \\
\text { Identified }\end{array}$ & $\begin{array}{l}\text { Total Potential } \\
\text { Implementation } \\
\text { Cost }(\$ M)\end{array}$ & $\begin{array}{c}\text { Total Potential } \\
\text { Annual Cost } \\
\text { Savings (\$M) }\end{array}$ \\
\hline All & 3,203 & $1,478,018$ & $189,130,701$ & $33,274,578$ & $38,213,884$ & $14,510,524$ & 68,454 & $\$ 9,323$ & $\$ 689.4$ \\
\hline DHS & 92 & 26,564 & $2,709,049$ & 579,616 & 140,118 & $1,934,819$ & 1,125 & $\$ 144.32$ & $\$ 18.39$ \\
\hline DOC & 5 & 9,643 & $1,961,270$ & 88,903 & 384,781 & 6,515 & 57 & $\$ 19.92$ & $\$ 3.10$ \\
\hline DOD & 355 & 791,179 & $85,167,819$ & $11,064,530$ & $23,318,119$ & $3,807,033$ & 35,350 & $\$ 1,338.84$ & $\$ 196.16$ \\
\hline DOE & 40 & 53,332 & $17,192,886$ & $5,088,224$ & $4,359,494$ & $1,005,471$ & 1,504 & $\$ 3,375.86$ & $\$ 90.09$ \\
\hline DOI & 372 & 42,990 & $3,590,150$ & 639,329 & $1,862,241$ & 131,499 & 11,138 & $\$ 210.56$ & $\$ 13.17$ \\
\hline DOJ & 4 & 2,527 & 314,006 & 148,672 & 479,620 & 174,419 & 25 & $\$ 31.48$ & $\$ 3.31$ \\
\hline DOL & 59 & 17,911 & $1,950,151$ & 86,880 & 576,930 & 96,530 & 225 & $\$ 11.28$ & $\$ 3.06$ \\
\hline DOT & 79 & 3,029 & 464,032 & 58,669 & 34,706 & 58,785 & 636 & $\$ 27.00$ & $\$ 4.18$ \\
\hline EPA & 16 & 2,827 & 987,322 & 317,010 & 83,263 & 27,022 & 378 & $\$ 109.62$ & $\$ 4.33$ \\
\hline GSA & 196 & 136,816 & $13,868,938$ & $1,874,378$ & $2,118,633$ & $5,241,735$ & 2,085 & $\$ 1,881.48$ & $\$ 94.15$ \\
\hline HHS & 68 & 20,629 & $6,968,972$ & 567,758 & $1,178,077$ & 82,184 & 872 & $\$ 52.16$ & $\$ 14.09$ \\
\hline NARA & 7 & 3,492 & 432,600 & 27,440 & 67,400 & 2,868 & 69 & $\$ 42.28$ & $\$ 0.83$ \\
\hline NASA & 9 & 25,433 & $3,922,085$ & 723,731 & $1,463,500$ & 61,355 & 1,053 & $\$ 156.85$ & $\$ 13.27$ \\
\hline $\mathrm{NRC}^{10}$ & 2 & 763 & 90,246 & 314,540 & 26,336 & - & 2 & $\$ 0.23$ & $\$ 0.12$ \\
\hline OPM & 1 & 86 & 8,508 & 1,145 & 4,800 & 2,973 & 3 & $\$ 0.20$ & $\$ 0.05$ \\
\hline RRB & 1 & 347 & 30,596 & 100 & 4,608 & 1,152 & 5 & $\$ 0.12$ & $\$ 0.07$ \\
\hline SI & 6 & 4,171 & 616,600 & 99,904 & - & 13,956 & 60 & $\$ 24.13$ & $\$ 4.30$ \\
\hline SSA & 6 & 5,705 & 574,825 & 105,841 & 62,538 & 6,254 & 89 & $\$ 45.41$ & $\$ 3.04$ \\
\hline STATE & 9 & 4,543 & 460,141 & 38,402 & - & 13,529 & 43 & $\$ 24.71$ & $\$ 4.32$ \\
\hline TREASURY & 9 & 6,100 & $1,023,308$ & 377,560 & 152,130 & 22,051 & 148 & $\$ 103.99$ & $\$ 11.34$ \\
\hline TVA & 46 & 18,751 & $1,263,388$ & 227,752 & 10,173 & 19,279 & 280 & $\$ 34.98$ & $\$ 7.62$ \\
\hline USACE & 1 & 64 & 7,833 & 839 & 3,415 & - & 173 & $\$ 0.17$ & $\$ 0.02$ \\
\hline USDA & 164 & 17,633 & $2,978,021$ & 321,281 & $1,881,294$ & 77,450 & 1,400 & $\$ 56.20$ & $\$ 5.68$ \\
\hline USPS & 1487 & 139,825 & $14,501,367$ & $3,901,772$ & - & 490,679 & 7,191 & $\$ 1,050.00$ & $\$ 104.20$ \\
\hline VA & 169 & 143,658 & $28,046,590$ & $6,620,302$ & 1,707 & $1,232,967$ & 4,543 & $\$ 580.87$ & $\$ 90.51$ \\
\hline
\end{tabular}

\footnotetext{
${ }^{9}$ The three agencies with evaluated annual water savings greater than annual water use (DHS, TVA, and VA) are all agencies with substantially incomplete reporting of water use data as noted in Table 1.

${ }^{10}$ Data reported from audits of two NRC facilities each showed energy-savings potential higher than energy use, but could not be resolved by the agency.
} 


\subsection{ECM Types Identified in Evaluations}

Over 78,000 ECMs were identified in the 3,203 fully completed facility evaluations reported in CTS. Another 241 facility evaluations were "in progress" at the time of this report and are included in the charts and tables in this section. These evaluations were examined for trends by the types of ECMs evaluated and the savings potential identified. Evaluations entered into CTS had 20 different parent ECM types available to characterize the activities. Table 5.2 below lists these categories with a corresponding short name used in this analysis and subsequent graphs and tables.

Table 5.2. ECM Types and Abbreviations for Evaluations

\begin{tabular}{lc}
\hline ECM Type & ECM Short Name \\
\hline Advanced Metering Systems & Meter \\
Appliance/Plug-Load Reductions & Plugs \\
Boiler Plant Improvements & Boiler \\
Building Automation Systems/Energy Management Control Systems & EMCS \\
Building Envelope Modifications & Envelope \\
Chilled Water, Hot Water, and Steam Distribution Systems & Dist Sys \\
Chiller Plant Improvements & Chiller \\
Commissioning Measures & Commiss \\
Distributed Generation & Dist Gen \\
Electric Motors and Drives & Motor \\
Electrical Peak Shaving/Load Shifting & Peak \\
Energy Cost Reduction Through Rate Adjustments & Rates \\
Energy Related Process Improvements & Process \\
Energy/Utility Distribution Systems & Utility \\
Lighting Improvements & Lighting \\
Other & Other \\
Other Heating, Ventilating, and Air Conditioning & Other HVAC \\
Refrigeration & Refrig \\
Renewable Energy Systems & Renewable \\
Water and Sewer Conservation Systems & Water \\
\hline
\end{tabular}

Lighting was the most common ECM included in the facility evaluations next to Water and Sewer projects, Other HVAC and Energy Management and Control Systems (EMCS) upgrades. These four project types accounted for two-thirds of the total ECM count for federal facilities. Figure 5.1 shows the total number of ECMs identified in the evaluation by type. 


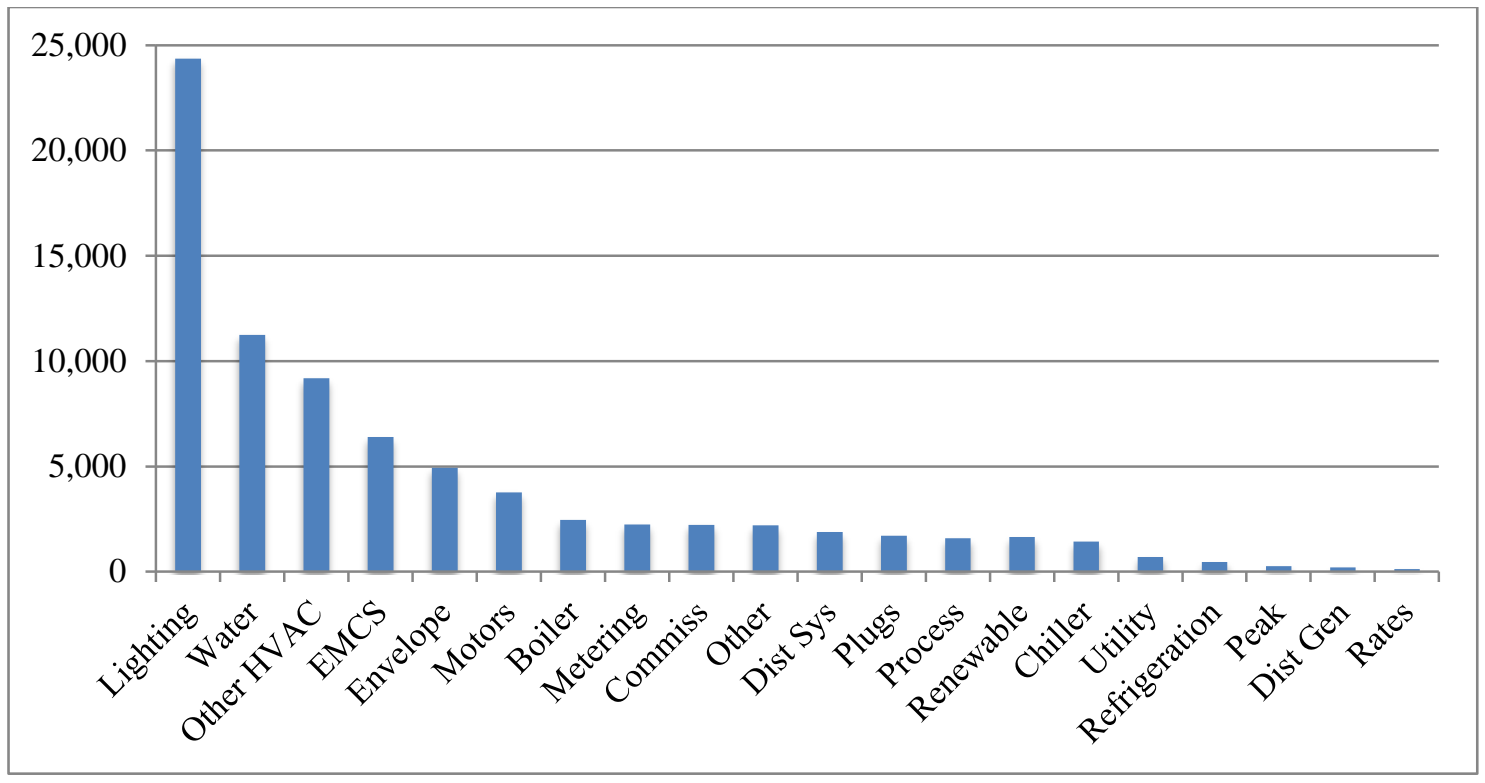

Figure 5.1. Sum of ECMs Evaluated by Category

The majority of evaluations identified more than one ECM type and 18\% of facilities identified savings potential from all $20 \mathrm{ECM}$ types in their evaluations. Because covered facility evaluations are intended to be comprehensive, it is expected the evaluations would have multiple ECMs.

\subsection{Potential Savings from ECMs Evaluated}

The ECMs identified through covered facility evaluations in CTS have an average simple payback of 12.5 years when all ECMs are considered, and 8.4 years when evaluations with Water ECMs are removed from the analysis and only energy ECMs are considered. Sixty-five percent (65\%) of facility evaluations had a less than 10-year payback and $14 \%$ had a payback of over 20 years (see Table 5.3). The trend is similar with evaluations with Water ECMs are removed from the analysis. This suggests that facility evaluations may include ECMs that are not all cost-effective. The longer-payback projects tended to include more renewable energy and distributed-generation ECMs. The simple payback ranges were calculated using all three cost types associated with the evaluations (water cost savings, energy cost savings, and ancillary cost savings). 
Table 5.3. Number of Facilities with Evaluations within Simple Payback Ranges

\begin{tabular}{lrrrr}
\hline $\begin{array}{c}\text { Payback Range } \\
\text { (Years) }\end{array}$ & $\begin{array}{c}\text { Number of Facility } \\
\text { Evaluations within } \\
\text { Range (All ECMs) }\end{array}$ & $\begin{array}{c}\text { Percent of } \\
\text { Evaluations } \\
\text { (All ECMs) }\end{array}$ & $\begin{array}{c}\text { Number of Facility } \\
\text { Evaluations within } \\
\text { Range (Without } \\
\text { Water ECMs) }\end{array}$ & $\begin{array}{c}\text { Percent of } \\
\text { Evaluations } \\
\text { (Without } \\
\text { Water ECMs) }\end{array}$ \\
\hline 0 to 5 & 1035 & $30 \%$ & 547 & $31 \%$ \\
5 to 10 & 1220 & $35 \%$ & 605 & $35 \%$ \\
10 to 15 & 397 & $12 \%$ & 188 & $11 \%$ \\
15 to 20 & 179 & $5 \%$ & 91 & $5 \%$ \\
20 to 25 & 106 & $3 \%$ & 47 & $3 \%$ \\
$>25$ & 378 & $11 \%$ & 115 & $7 \%$ \\
None Identified & 129 & $4 \%$ & 156 & $9 \%$ \\
Grand Total & $\mathbf{3 4 4 4}$ & $\mathbf{1 0 0 \%}$ & $\mathbf{1 7 4 9}$ & $\mathbf{1 0 0 \%}$ \\
\hline
\end{tabular}

The estimated potential annual energy savings per dollar of investment required was also analyzed to illustrate the relative energy saving impact that the different ECMs are projected to have. Because implementation costs and savings are attributed to a project and not individual ECMs, only facility evaluations that identify a single ECM type can be analyzed for their relative savings impact. Of the 287 evaluations with a single ECMs identified, Other HVAC, Refrigeration and Electric Motors and Drives had the highest potential energy savings per dollar invested. ${ }^{11}$ Figure 5.2 and Table 5.4 below show the average potential energy savings for each ECM type with the minimum and maximum values included. In many cases the evaluated ECMs show a wide variance (standard deviation) in potential savings.

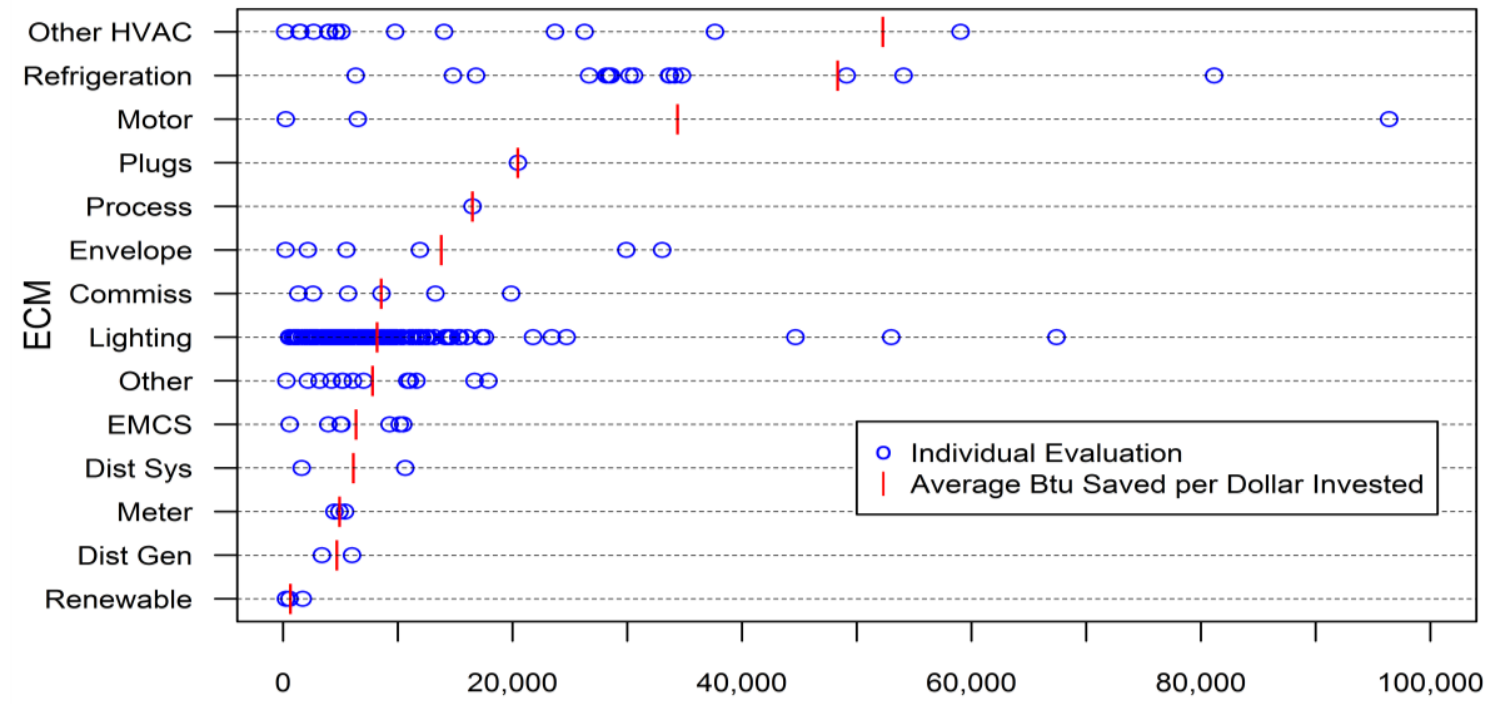

Btu Saved per Dollar Invested

Figure 5.2. Distribution of Savings per Dollar Invested by ECM for Evaluations ${ }^{12}$

\footnotetext{
${ }^{11} 82$ of the evaluations were removed from this analysis because they had incomplete values or obviously incorrect values (e.g., implementation costs or savings of $\$ 1$ ).

${ }^{12}$ Values above 100,000 Btus per Dollar Invested are not shown on this graph but are included in the average calculation.
} 
Table 5.4. Potential Energy Savings Ranges of Evaluated Projects per Dollar Invested for Evaluations with Single ECMs

\begin{tabular}{llrrrr}
\hline \multirow{2}{*}{ ECM Type } & Number of & \multicolumn{3}{c}{ Potential Btus Saved per Dollar Invested } \\
& Evaluations & Minimum & Maximum & Average & Standard Deviation \\
& 18 & 179 & 419,667 & 52,267 & 104,749 \\
\hline Other HVAC & 18 & 6,316 & 194,450 & 48,337 & 47,732 \\
Refrigeration & 3 & 219 & 96,400 & 34,373 & 53,809 \\
Motor & 3 & 20,465 & 20,465 & 20,465 & N.A. \\
Plugs & 1 & 16,505 & 16,505 & 16,505 & N.A. \\
Process & 1 & 215 & 33,031 & 13,785 & 14,297 \\
Envelope & 6 & 1,326 & 19,864 & 8,547 & 7,015 \\
Commiss & 6 & 0.8 & 182,696 & 8,191 & 14,304 \\
Lighting & 203 & 281 & 17,895 & 7,789 & 5,440 \\
Other & 13 & 573 & 10,451 & 6,351 & 3,708 \\
EMCS & 7 & 1,604 & 10,631 & 6,118 & 6,383 \\
Dist Sys & 2 & 4,466 & 5,385 & 4,915 & 460 \\
Meter & 3 & 3,376 & 6,001 & 4,689 & 1,856 \\
Dist Gen & 2 & 48 & 1,705 & 638 & 740 \\
Renewable & 4 & & & & \\
\hline
\end{tabular}

Just five evaluations identified Water ECMs only and could be analyzed to show their impact in terms of the potential water saved per dollar invested (Table 5.5). The expected average savings was over 2,200 gallons per dollar invested however the variance in these evaluations was significant as indicated by the large standard deviation.

Table 5.5. Water Savings per Dollar Invested for Evaluations with Only Water ECMs

\begin{tabular}{lrrrrr}
\hline & & \multicolumn{4}{c}{ Gallons Avoided per Dollar Invested } \\
ECM Type & Number & Minimum & Maximum & Average & Standard Deviation \\
\hline Water & 5 & 230 & 5,059 & 2,288 & 1,738 \\
\hline
\end{tabular}

A total of 489 facilities identified water savings potential in their evaluations. This broader set of evaluations was analyzed to determine the projected water savings over baseline water use. Over half of the evaluations (54\%) projected water savings representing more than $10 \%$ of their total water use (Figure $5.3)$. 


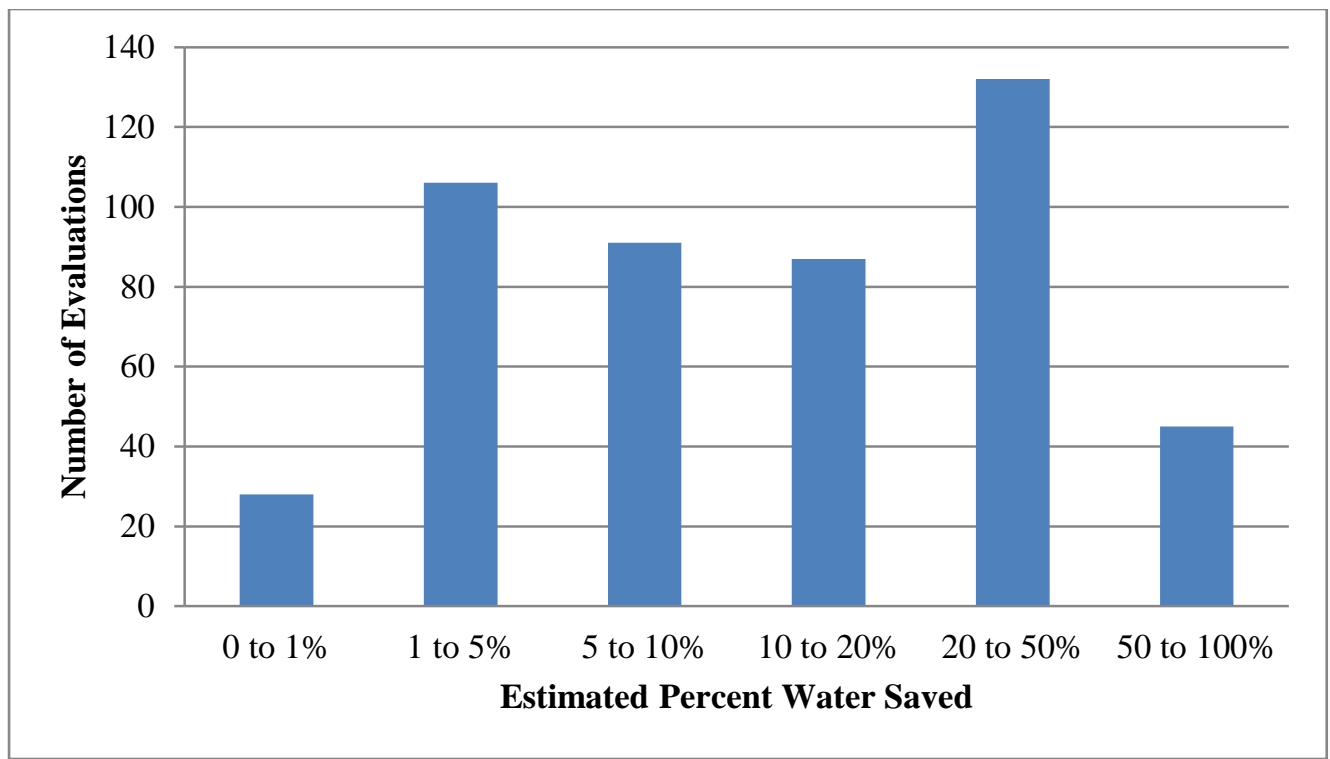

Figure 5.3. Projected Evaluated Water Savings Relative to Baseline Use 



\subsection{Analysis of Implemented Projects}

Agencies may implement any energy or water-saving ECMs identified in the evaluations that are life-cycle cost-effective. Projects can include single ECMs or multiple ECMs with varying paybacks bundled to help make their implementation cost-effective. This section presents findings from the analysis of project investments reported in CTS.

\subsection{Location of Projects}

From FYs 2008 through 2011, agencies reported 794 projects in CTS. As shown in Figure 6.1, states with the highest density of implemented projects were California, Pennsylvania, and Georgia.

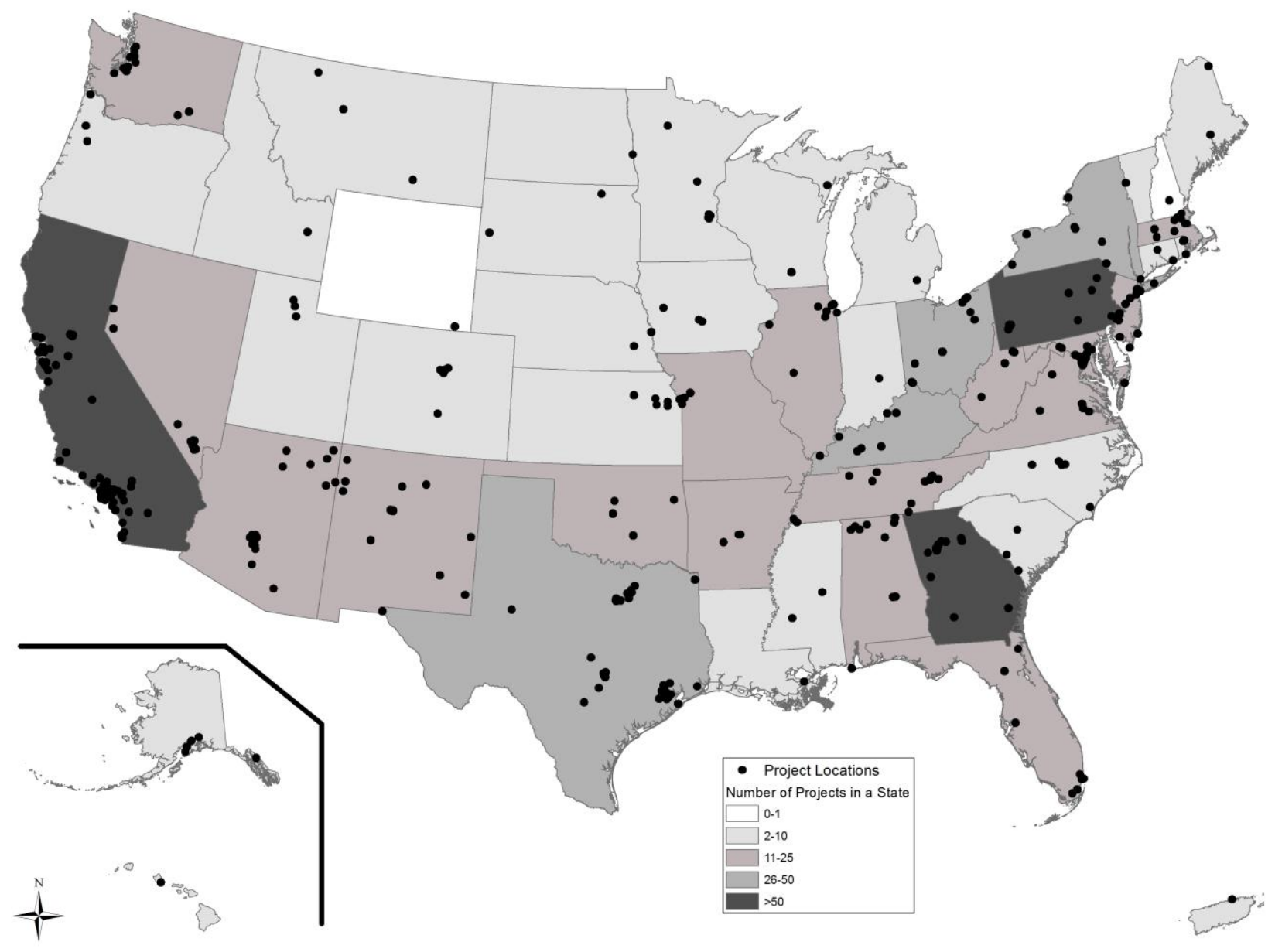

Figure 6.1. Locations of Projects Reported in CTS and Project Density by State

\subsection{Agency Project Investment}

The projects reported in CTS represent a subset of total agency spending on efficiency each year. Total agency investment through both direct and third-party funding sources between FY 2008 and 
FY 2011 was $\$ 9.89$ billion, based on annual agency energy reporting to the DOE. While CTS represents an important source of information on what agencies are investing in at the project level, it does not yet provide a comprehensive picture of agency investments in efficiency and renewables.

\subsubsection{Average and Total Project Investment}

The 794 implemented projects reported in CTS by federal agencies as of the end of FY 2012 represent $\$ 1.35$ billion of total investment and $\$ 2.5$ billion in total awarded contract values, which include financing costs. The total investment comprises just $14 \%$ of the $\$ 9.89$ billion of total spending on efficiency reported by agencies since the period FY 2008 through FY 2011. ${ }^{13}$ As illustrated in Figure 6.2, GSA, DOE, and DOJ represent nearly three-quarters of all federal project funding reported in CTS.

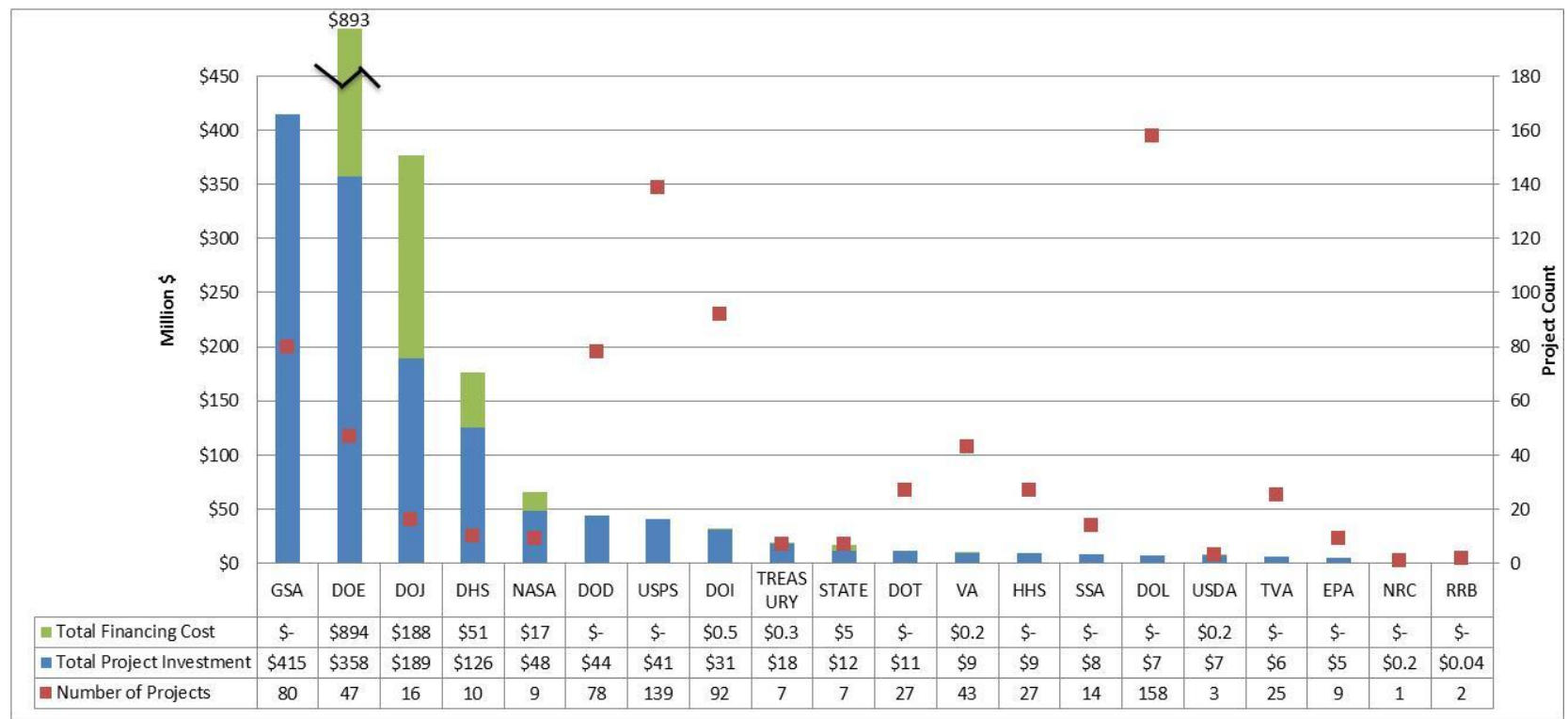

Figure 6.2. Number of Implemented Projects by Agency and Level of Investment (\$M)

Analysis of the project data in CTS shows a wide range of investment levels, with individual energy and water projects ranging in size from $\$ 0$ to $\$ 137$ million and the average project costing $\$ 1.69$ million to implement. ${ }^{14}$ (See Figure 6.3) The difference in total investments and average project sizes by agency are in part a function of agency budget levels. Another factor is the type of funding sources the agency has used for project investments. It is also possible that there is some data-entry bias in CTS toward larger projects. Agencies may be less likely to enter small project investments in CTS, because energy and water savings values may be more difficult to estimate without the robust analysis of a third party leading a performance contract. Furthermore, the requirement to do measurement and verification on all project investments entered in CTS may not be cost-effective for all small projects.

\footnotetext{
${ }^{13}$ FY 2012 spending data was not available at the time of this report.

${ }^{14}$ Agencies may have indicated $\$ 0$ project cost if ECMs are being incorporated into larger maintenance projects that would be carried out anyway and they are unable to attribute a specific dollar amount to the efficiency upgrade. In other cases, agencies reported the total cost of maintenance projects, which would result in artificially high project costs because all dollars are not directly supporting ECMs.
} 


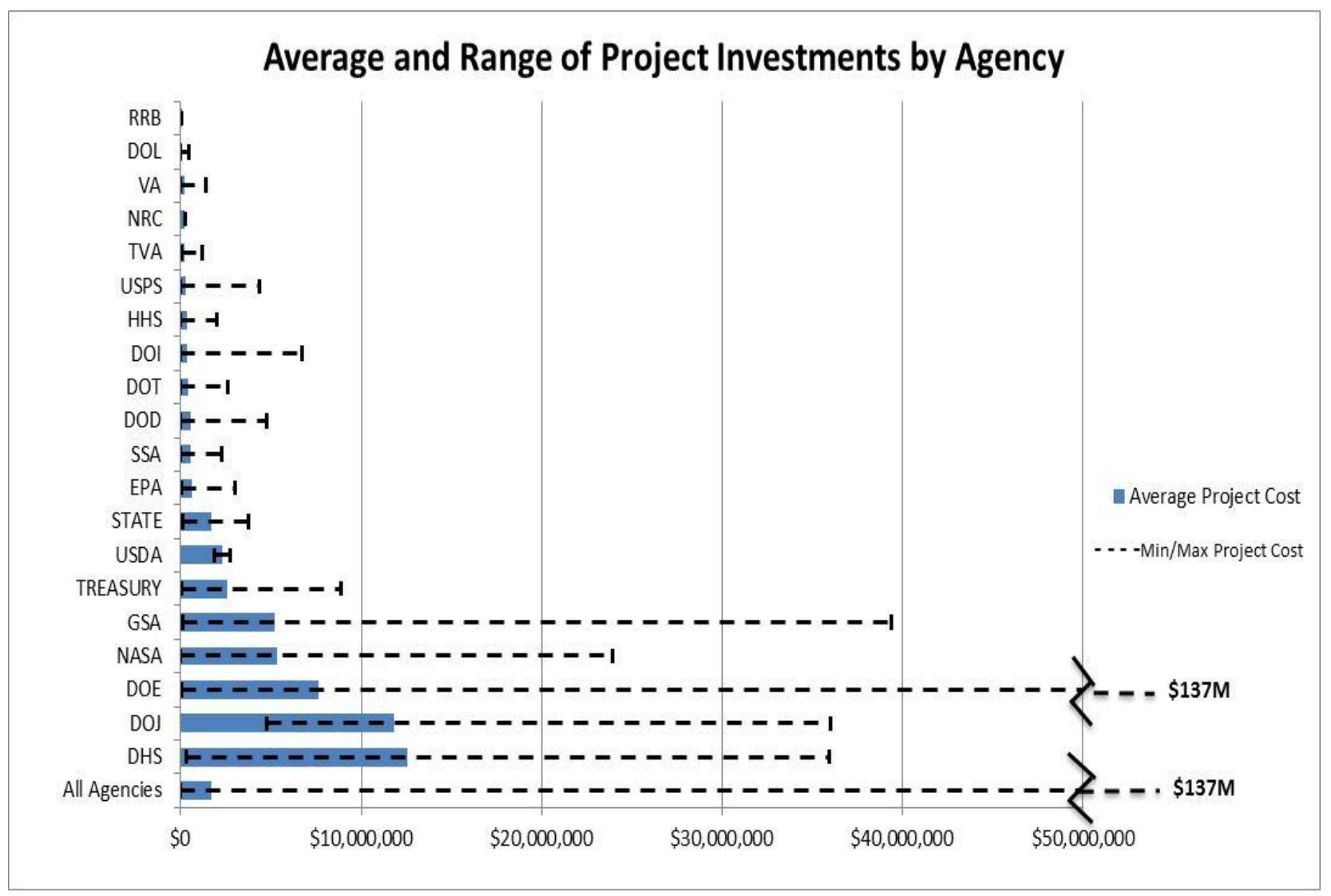

Figure 6.3. Average (blue bar) and Range of Individual Project Investments by Agency

The $\$ 137$ million DOE investment is for the development of a biomass plant. Without this project in the analysis, the maximum implementation cost becomes $\$ 59$ million, which is for another DOE biomass project.

Figure 6.4 illustrates the wide range in the count and average size of projects across agencies for projects entered in CTS through 2012. About half of these 794 projects have been implemented by three agencies: DOL, USPS, and DOI. These agencies may have a higher number of projects because they tend to have smaller, single-building facilities. 


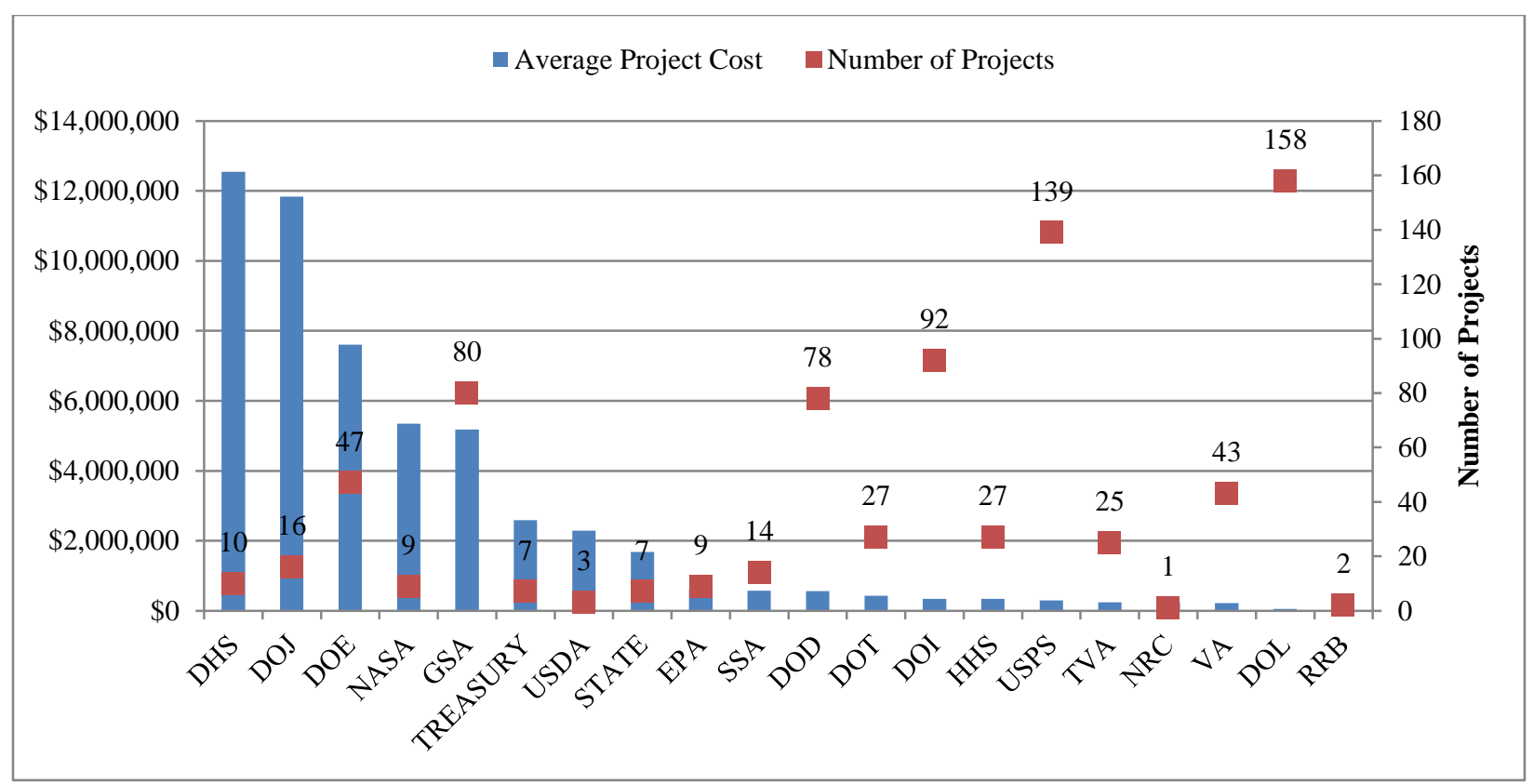

Figure 6.4. Average Project Cost Relative to Number of Projects

To help normalize project investments across agencies, Figure 6.5 presents ECM investments reported in CTS as a proportion of each agency's annual facility energy costs. This figure also shows efficiency investments reported in annual energy reports from 2008 through 2011 as a proportion of the agency's annual energy costs. ECM investments reported in CTS represent between $0 \%$ and $25 \%$ of agency annual facility energy costs, whereas total energy efficiency investments from annual energy reports represent between $0 \%$ and $366 \%$ of energy costs. Based on project reporting in the CTS, DHS, DOJ, and GSA are spending the largest proportion of their energy costs on ECMs, at 25\%, 25\%, and 24\% respectively. Based on top-down reporting of agency efficiency investments, HUD and GSA are spending the greatest proportion of their energy costs on efficiency projects, at 366\% and $189 \%$ respectively. This may be due to one-time ARRA investments.

Comparing energy investments reported in CTS to those reported in the annual energy reports helps to illustrate how comprehensive project reporting in CTS has been. Agencies on left side of this figure have a greater proportion of the agency's total efficiency investment entered in CTS. ${ }^{15}$

\footnotetext{
${ }^{15}$ CTS project investments to date have been predominantly in energy conservation measures but also include some water conservation measures. Because a single investment value is reported for projects, these investments include some water ECMs as well.
} 


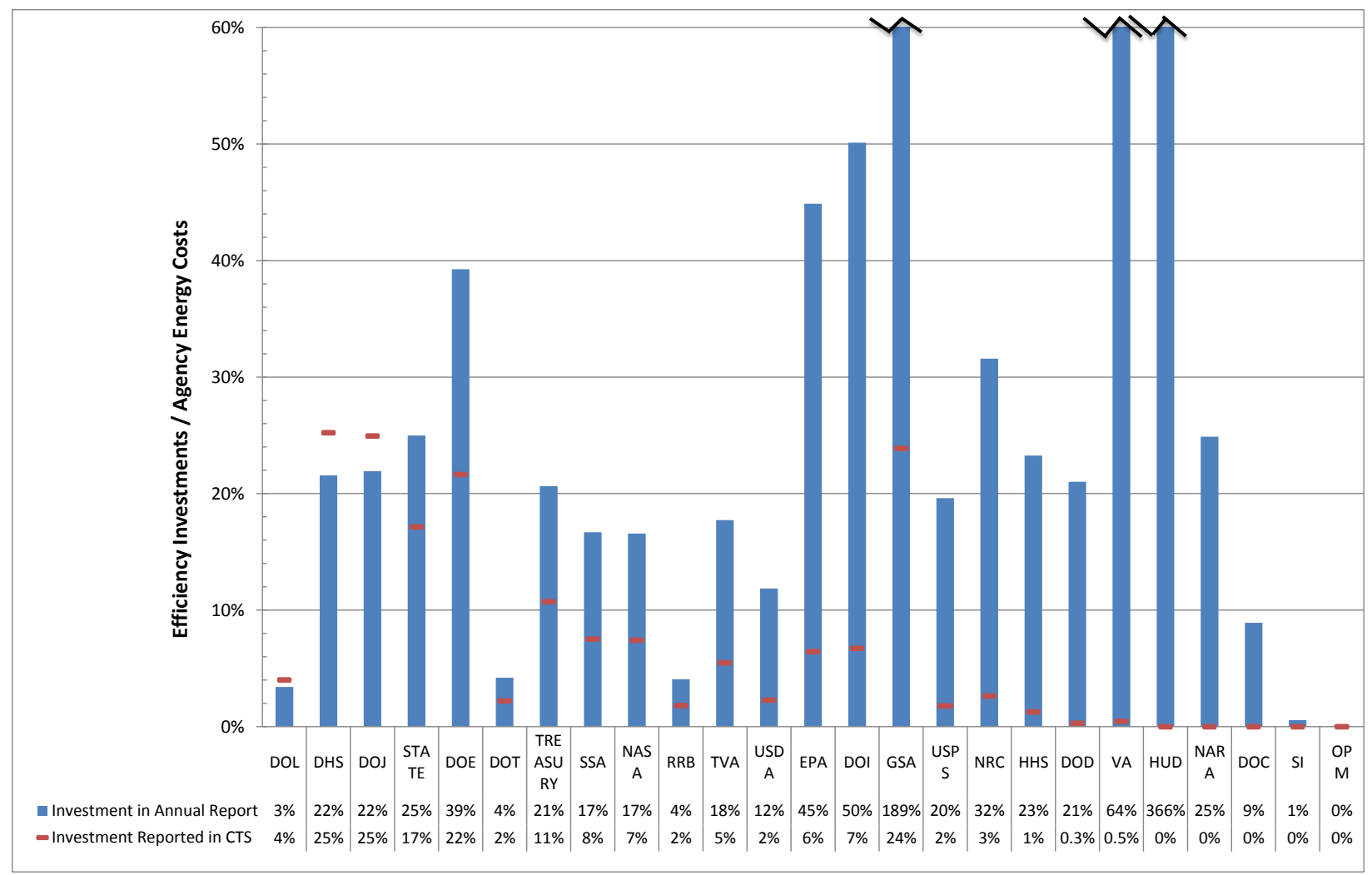

Figure 6.5. Percent of Dollars Invested in Efficiency per Dollar Spent on Energy Utility Bills as Reported in CTS (red) and Agency Annual Energy Reports (blue)

As noted above, this provides a snapshot of the CTS database as of the end of FY 2012 and it underrepresents the total actual investment in efficiency measures identified by agencies in their agency annual energy reports to DOE. For example, while DOD's investments in CTS appear relatively small as a proportion of total energy costs $(0.3 \%)$, no Army project investments have been entered into CTS at this time. The Army's Energy Conservation Investment Program (ECIP) is funded at approximately $\$ 30$ million per year and would increase DOD's percentage to $0.5 \%$ if included in CTS. Other sources of Army project funding (e.g., ESPCs, UESCs, and direct sustainment, restoration and modernization funds) would increase this further. This is probably the case with other agencies as well.

\subsubsection{Project Investment by Funding Source}

An analysis of funding sources provides an indication of the extent to which agencies are leveraging third-party funding to support their energy- and water-saving measures versus using internal resources to support those measures. This provides an opportunity to evaluate the comparative impact of investments made through different funding sources. Analysis of the investment by funding source can also help to assess the potential volatility of investment, and whether such levels are likely to be sustained.

For each project investment, agencies must identify funding sources from the categories below and may include multiple funding sources for a single project:

- Direct Centralized Capital Funding - In general, direct funding includes appropriations or other funding from centralized agency funding accounts for larger capital-intensive projects. 
- Decentralized Operations and Maintenance (O\&M) Budgets - Funding is provided from decentralized operations and maintenance budgets.

- ARRA - Funding is provided from the American Recovery and Reinvestment Act.

- Energy Savings Performance Contract (ESPC) - An ESPC is a contract between a federal agency and a third party (e.g., a task order awarded to an energy service company) that provides for the performance of services for the design, acquisition, financing, installation, testing, operation, maintenance and repair of an identified energy, water conservation, or renewable energy measure or series of measures, at one or more locations.

- Utility Energy Service Contract (UESC) - A UESC is a contract between a federal agency and a local utility providing energy or water services, as well as provision of technical services and/or up-front project financing for energy efficiency, water conservation, and renewable energy investments, allowing federal agencies to pay for the services with the savings generated from improvement projects over time, either on their utility bill or through a separate agreement.

- Power Purchase Agreements (PPA) - A PPA is funded through an agreement between an agency and developer of a renewable or other energy system project. Under a PPA, a developer installs the energy system on agency property and the agency purchases the power generated by the system. The agency pays for the system through these power payments over the life of the contract. After installation, the developer owns, operates, and maintains the system for the life of the contract.

- Incentive Programs - Funding is provided from state and utility incentive programs that help offset energy costs while promoting energy and water efficiency and renewable energy technologies.

- Enhanced Use Lease (EUL) - An Enhanced Use Lease is an authority by which some federal agencies can lease underutilized real property to the public or private sector as a means of obtaining services, facilities, revenue, space, etc., that enhance their mission.

- Other - Funding is provided by a source other than those listed above.

- Not Specified - Indicates the agency did not document the funding source in CTS.

As indicated in Figure 6.6 below, funding from ESPCs (43\%) and ARRA (33\%) have provided the greatest proportion of total investment in energy and water projects reported in CTS over the past four years. End-use leases and PPAs have not been used at all by agencies based on entries in CTS. Direct funding through annual operating budgets - either from decentralized O\&M budgets or centralized capital funding sources - represent just 7\% of all investments entered into CTS over the past four years. 


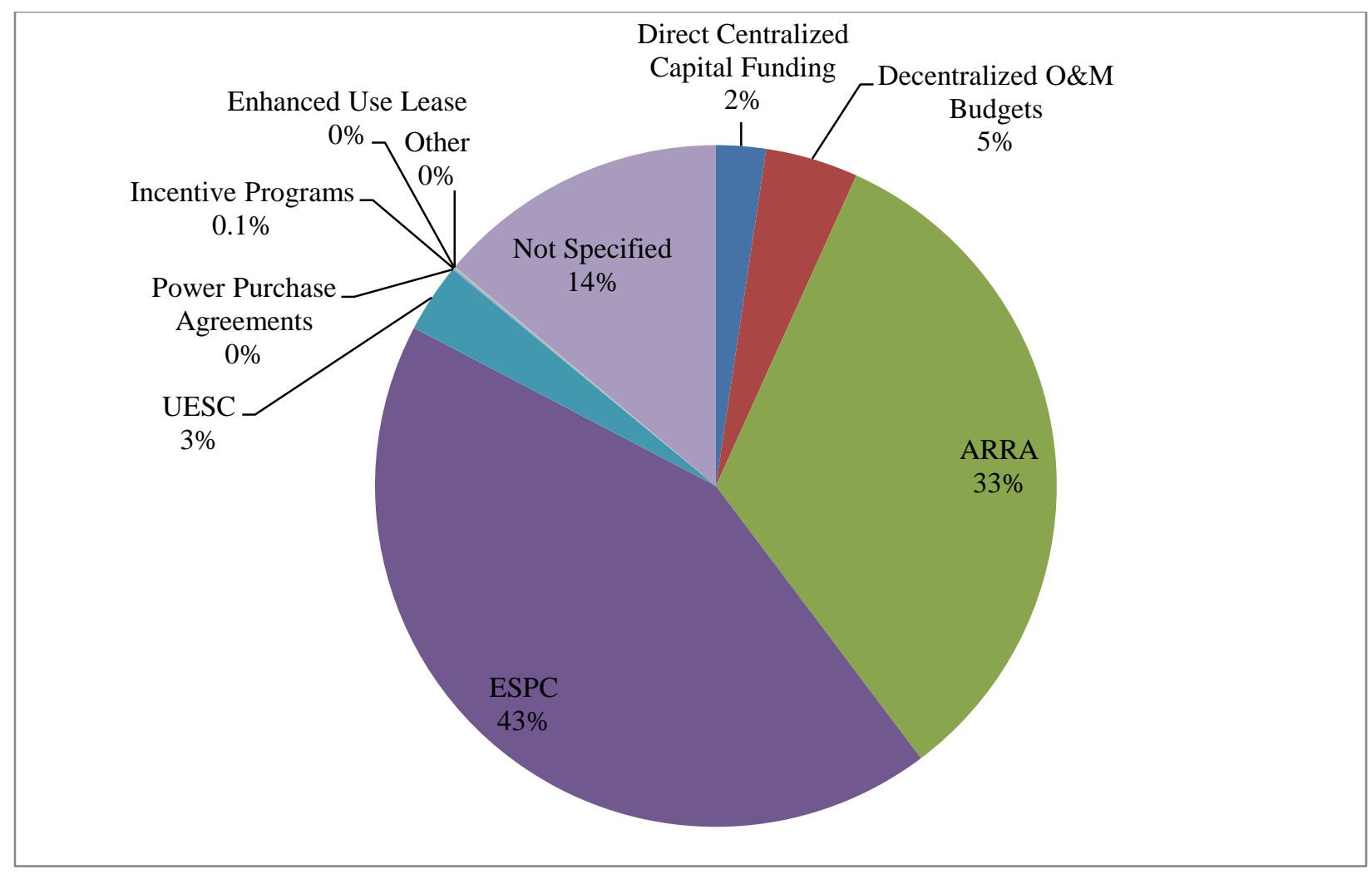

Figure 6.6. Percent of Total Project Investment Reported in CTS by Source

A comparison to agency top-down reporting of efficiency investments by funding source suggests that while all funding areas are being under-reported in CTS, projects funded through direct obligations appear to be under-reported at a much higher rate. The \$577 million of ESPC funding reported in CTS represents $33 \%$ of total ESPC funding reported by agencies in their annual energy reports, whereas the $\$ 534$ million of direct funding from centralized capital, decentralized O\&M, and ARRA funding together represent just $7 \%$ of the total direct obligations reported in Figure 6.7. 


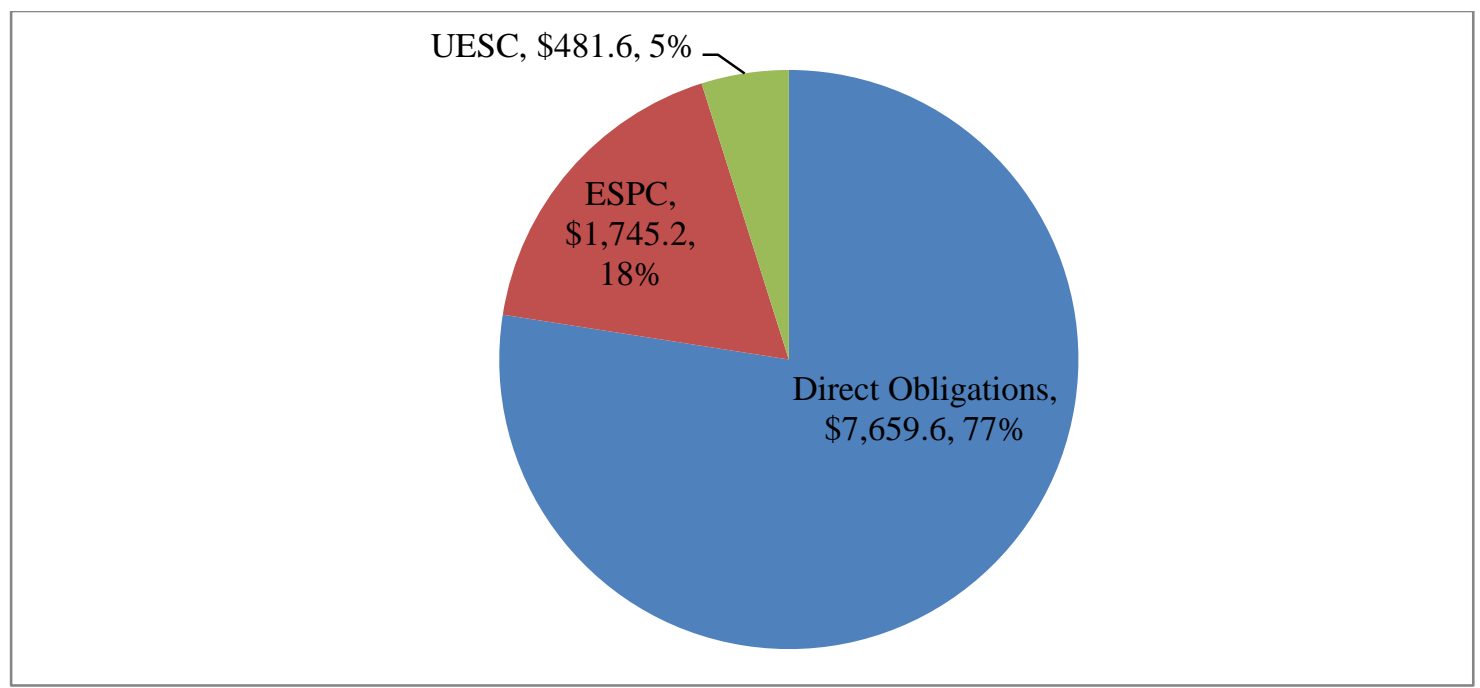

Figure 6.7. Value $(\$ M)$ and Percent of Total Efficiency Investments Reported in Annual Energy Reports by Source

While ESPCs are the predominant source of funding for projects reported in CTS government-wide, only one-third of agencies reported ESPC projects (see Table 6.1). Projects implemented by DOE and DOJ represent $94 \%$ of government-wide ESPC project investment.

Table 6.1. Federal Project Total Investment in CTS by Funding Source and Agency ( $\$ M)$

\begin{tabular}{|c|c|c|c|c|c|c|c|c|c|}
\hline Agency & $\begin{array}{c}\text { Direct } \\
\text { Central- } \\
\text { ized } \\
\text { Capital } \\
\text { Funding }\end{array}$ & $\begin{array}{c}\text { Decentral- } \\
\text { ized O\&M } \\
\text { Budgets }\end{array}$ & ARRA & ESPC & UESC & $\begin{array}{l}\text { Incent- } \\
\text { ive } \\
\text { Prog- } \\
\text { rams }\end{array}$ & Other & $\begin{array}{c}\text { Not } \\
\text { Specified }\end{array}$ & Total \\
\hline All Agencies & $\$ 31.8$ & $\$ 59.2$ & $\$ 443.5$ & $\$ 577.9$ & $\$ 44.3$ & $\$ 1.3$ & $\$ 0.8$ & $\$ 186.7$ & $\$ 1,345.5$ \\
\hline DHS & - & - & - & - & - & - & - & $\$ 125.5$ & $\$ 125.5$ \\
\hline DOD & $\$ 3.7$ & $\$ 10.1$ & - & - & - & - & - & $\$ 30.2$ & $\$ 44.0$ \\
\hline DOE & - & - & - & $\$ 357.6$ & - & - & - & - & $\$ 357.6$ \\
\hline DOI & $\$ 1.3$ & $\$ 0.4$ & $\$ 15.9$ & - & $\$ 3.5$ & - & $\$ 0.03$ & $\$ 10.0$ & $\$ 31.2$ \\
\hline DOJ & - & $\$ 4.4$ & - & $\$ 185.0$ & - & - & - & - & $\$ 189.4$ \\
\hline DOL & $\$ 3.5$ & - & $\$ 3.8$ & - & - & - & - & - & $\$ 7.4$ \\
\hline DOT & - & $\$ 2.2$ & - & - & - & - & - & $\$ 9.3$ & $\$ 11.5$ \\
\hline EPA & - & - & - & - & - & - & - & $\$ 5.5$ & $\$ 5.5$ \\
\hline GSA & $\$ 1.9$ & - & $\$ 412.8$ & - & - & - & - & - & $\$ 414.7$ \\
\hline HHS & $\$ 4.4$ & - & - & - & $\$ 4.6$ & - & - & - & $\$ 9.1$ \\
\hline NASA & $\$ 2.7$ & $\$ 0.5$ & - & $\$ 19.7$ & $\$ 23.2$ & $\$ 1.3$ & $\$ 0.7$ & - & $\$ 48.2$ \\
\hline NRC & - & $\$ 0.2$ & - & - & - & - & - & - & $\$ 0.2$ \\
\hline RRB & - & $\$ 0.04$ & - & - & - & - & - & - & $\$ 0.04$ \\
\hline SSA & $\$ 4.9$ & $\$ 0.1$ & - & $\$ 2.0$ & $\$ 0.7$ & - & - & $\$ 0.2$ & $\$ 7.9$ \\
\hline STATE & - & - & - & $\$ 11.7$ & - & - & - & - & $\$ 11.7$ \\
\hline TREASURY & $\$ 9.3$ & - & $\$ 6.0$ & - & $\$ 2.8$ & - & - & - & $\$ 18.1$ \\
\hline TVA & - & - & - & - & - & - & - & $\$ 5.9$ & $\$ 5.9$ \\
\hline USDA & - & - & $\$ 5.0$ & $\$ 1.9$ & - & - & - & - & $\$ 6.9$ \\
\hline USPS & - & $\$ 41.3$ & - & - & - & - & - & - & $\$ 41.3$ \\
\hline VA & - & - & - & - & $\$ 9.4$ & - & - & - & $\$ 9.4$ \\
\hline
\end{tabular}


Figure 6.8 helps to illustrate the predominant funding sources used by each agency. For example, GSA's primary source of project investment in CTS has been ARRA funding, and only a portion of this has been entered into CTS. This suggests that the unusually high level of investment (which was noted above to represent $189 \%$ of GSA's energy costs over four years) is short-term and not likely to be sustained. DOE's and DOJ's investments in CTS are dominated by ESPC projects. NASA used predominantly UESC funding; of the six agencies using UESC as a funding source, NASA represents $52 \%$ of this investment. USPS has relied exclusively on decentralized operating budgets to fund its ECMs reported in CTS. Overall, third-party project financing is used by about half of agencies and represents $\$ 1.16$ billion of funding to the private sector, or $46 \%$ of the total investment in projects.

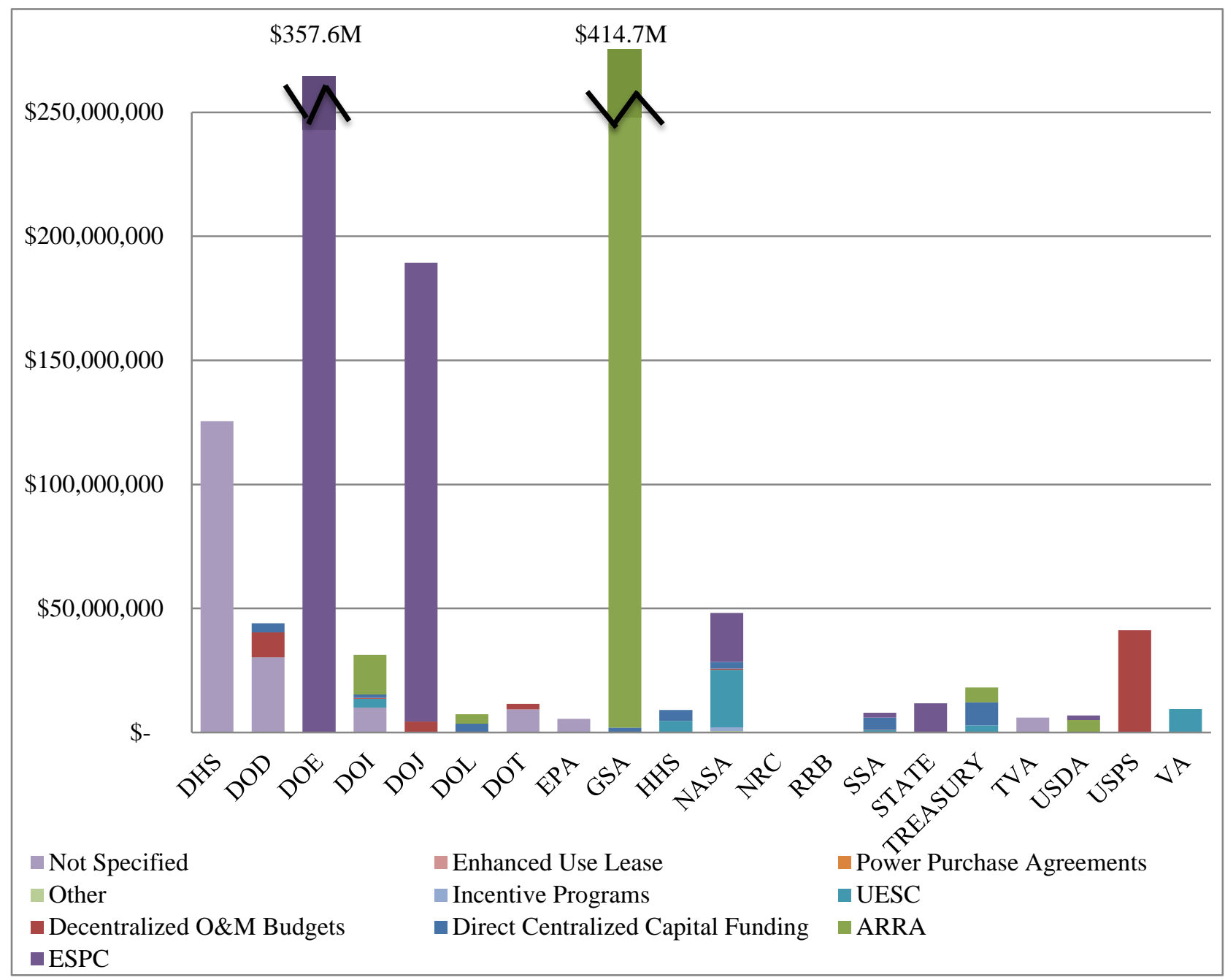

Figure 6.8. Total Project Investment by Agency and Funding Source

In addition to representing the predominant total funding sources, ESPC projects have the largest average project size, at $\$ 7.6$ million. ARRA projects are the next largest on average, at $\$ 2.2$ million (see Figure 6.9). All other projects with funding sources specified are under $\$ 1$ million on average. Projects funded through direct centralized capital funding have the smallest average project size, at $\$ 252,513$. In terms of frequency of use, the greatest number of projects in the database used ARRA as a full or partial funding source. While projects funded with decentralized O\&M budgets and centralized capital together 
represent just $7 \%$ of total agency investment reported in CTS, these are among the most frequently used funding sources in terms of number of individual projects funded.

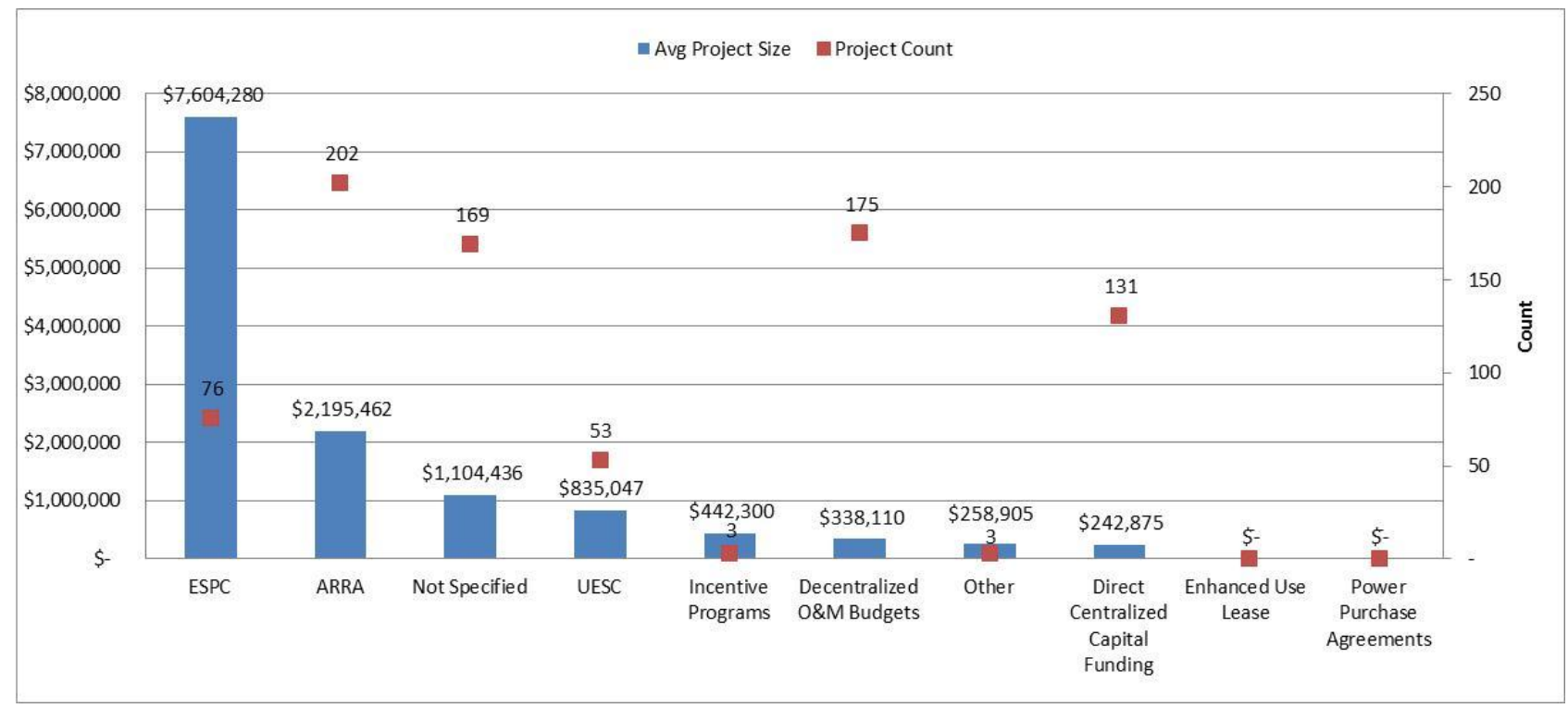

Figure 6.9. Average Size and Count of Implemented Projects by Funding Source

Figure 6.10 illustrates variation in the average project size by funding source and agency. For most agencies using UESCs, the average project size was under \$3.5 million; NASA was the exception with a single UESC project valued at over \$23 million. Most agencies reporting ARRA projects in CTS had average project sizes under $\$ 3$ million; GSA's average project size for ARRA projects was slightly higher than other agencies at $\$ 5.3$ million.

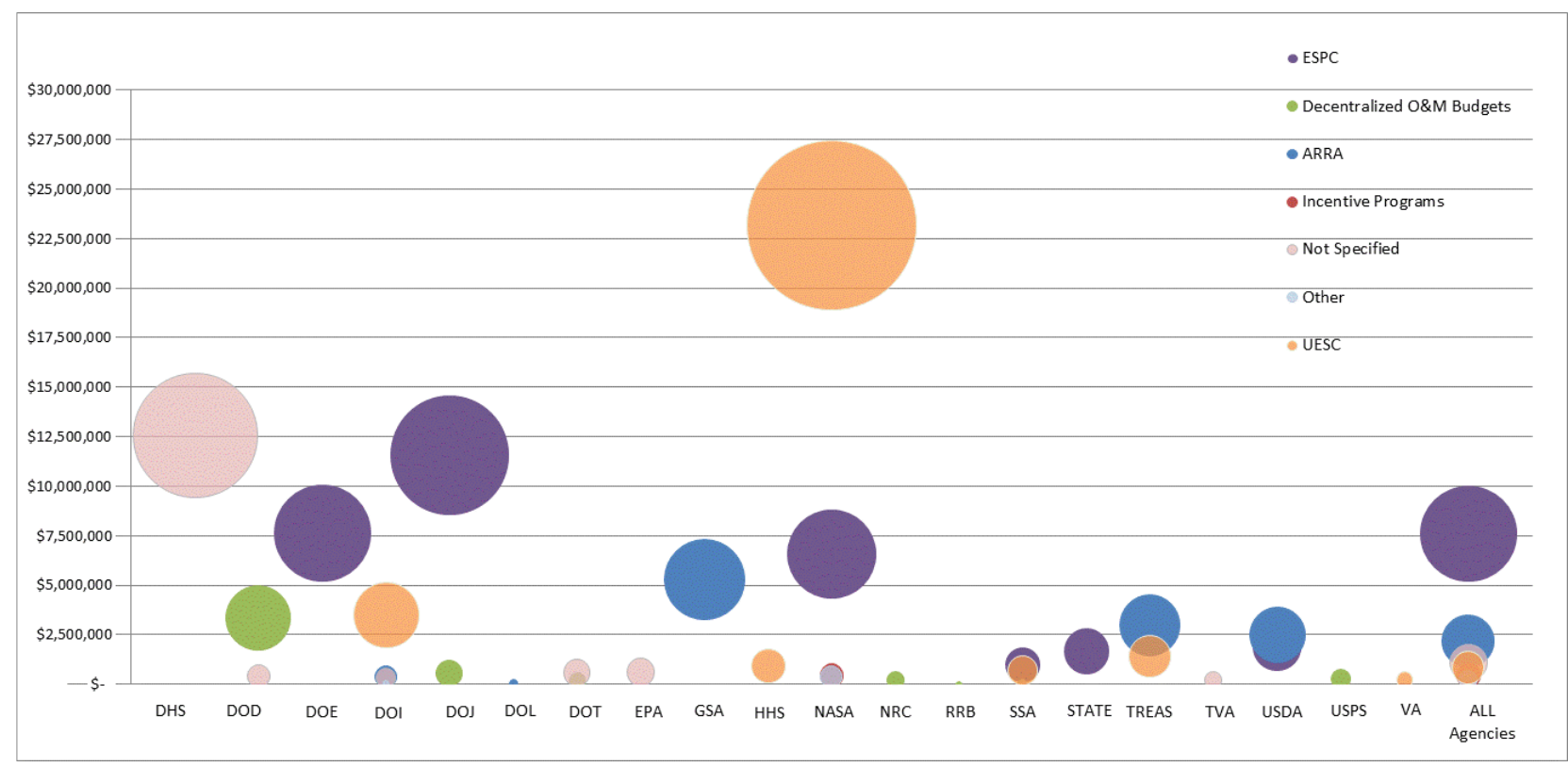

Figure 6.10. Average Project Size by Agency and Funding Source 


\subsection{Energy and Water Savings from Projects}

The implemented projects reported in CTS resulted in a total energy savings of 4,078,279 MMBtu government-wide. DOE projects represent $26 \%$ of all reported savings, followed by DOJ (18\%), GSA $(11 \%)$, and DOD (11\%). DOJ projects are making the greatest contribution to water savings, comprising $66 \%$ of all reported water savings investments. Fewer agencies have reported renewable electricity production or renewable thermal projects. DOE projects also represent the greatest portion of renewable output based on projects reported by federal agencies in CTS over the past four years. (See Table 6.2)

Table 6.2. Total Annual Energy Savings and Renewable Output from Projects in CTS

\begin{tabular}{|c|c|c|c|c|c|c|c|c|}
\hline Agency & $\begin{array}{c}\text { Total } \\
\text { Annual } \\
\text { Energy } \\
\text { Savings } \\
\text { (MMBtu) }\end{array}$ & $\begin{array}{c}\% \text { of } \\
\text { Total } \\
\text { Energy } \\
\text { Savings }\end{array}$ & $\begin{array}{c}\text { Total Annual } \\
\text { Renewable } \\
\text { Electricity } \\
\text { Output } \\
\text { (MMBtu) }\end{array}$ & $\begin{array}{c}\% \text { of Total } \\
\text { Renewable } \\
\text { Electricity } \\
\text { Output }\end{array}$ & $\begin{array}{c}\text { Total Annual } \\
\text { Renewable } \\
\text { Thermal } \\
\text { Output } \\
\text { (MMBtu) }\end{array}$ & $\begin{array}{c}\% \text { of Total } \\
\text { Renewable } \\
\text { Thermal } \\
\text { Output }\end{array}$ & $\begin{array}{c}\text { Total } \\
\text { Annual } \\
\text { Water } \\
\text { Savings } \\
\text { (thou. gal) } \\
\end{array}$ & $\begin{array}{c}\% \text { of } \\
\text { Total } \\
\text { Water } \\
\text { Savings }\end{array}$ \\
\hline $\begin{array}{l}\text { All } \\
\text { Agencies }\end{array}$ & $4,078,279$ & $100 \%$ & 359,643 & $100 \%$ & $1,350,859$ & & $1,140,147$ & $100 \%$ \\
\hline DHS & 213,920 & $5 \%$ & 21,685 & $6 \%$ & & & 17,799 & $2 \%$ \\
\hline DOD & 443,958 & $11 \%$ & & & 16 & $0.001 \%$ & 3,493 & $0.3 \%$ \\
\hline DOE & $1,076,883$ & $26 \%$ & 265,272 & $74 \%$ & $1,336,985$ & $99 \%$ & 173,983 & $15 \%$ \\
\hline DOI & 21,823 & $1 \%$ & 1,205 & $0.3 \%$ & 186 & $0.01 \%$ & 16,548 & $1 \%$ \\
\hline DOJ & 752,930 & $18 \%$ & & & & & 747,614 & $66 \%$ \\
\hline DOL & 24,642 & $1 \%$ & & & & & 3,458 & $0 \%$ \\
\hline DOT & 19,293 & $0.5 \%$ & 8,486 & $2 \%$ & & & 6,678 & $1 \%$ \\
\hline EPA & 41,327 & $1 \%$ & 61 & $0.02 \%$ & & & & \\
\hline GSA & 465,466 & $11 \%$ & 57,043 & $16 \%$ & & & & \\
\hline HHS & 73,091 & $2 \%$ & & & & & 878 & $0.1 \%$ \\
\hline NASA & 280,793 & $7 \%$ & 0.5 & $0.0001 \%$ & & & 125,879 & $11 \%$ \\
\hline NRC & 1,741 & $0.04 \%$ & & & & & & \\
\hline RRB & & & & & & & 130 & $0.01 \%$ \\
\hline SSA & 53,384 & $1 \%$ & 5,202 & $1 \%$ & 13,671 & $1 \%$ & 4,876 & $0.4 \%$ \\
\hline STATE & 44,502 & $1 \%$ & & & & & 1,194 & $0.1 \%$ \\
\hline TREASURY & 121,071 & $3 \%$ & 672 & $0.2 \%$ & & & 6,292 & $1 \%$ \\
\hline TVA & 33,361 & $1 \%$ & & & & & 10,085 & $1 \%$ \\
\hline USDA & 54,220 & $1 \%$ & & & & & & \\
\hline USPS & 325,034 & $8 \%$ & & & & & 5,171 & $0.5 \%$ \\
\hline VA & 30,840 & $1 \%$ & & & & & 16,069 & $1 \%$ \\
\hline
\end{tabular}

\subsection{Energy Conservation Measures Implemented}

This section examines the ECMs most frequently implemented as individual projects and bundles. For projects with a single ECM type, it evaluates the energy and cost savings associated with different ECMs. This provides insights into where the most opportunities for energy efficiency have been identified thus far and what their relative impacts have been.

\subsubsection{ECMs Implemented by Type}

Projects entered into CTS had 20 different parent ECM types available to characterize the activities. Table 5.2 in the previous section lists these categories with a corresponding short name used in this analysis and subsequent graphs and tables. Several of the parent ECM types have subcategories with more specific ECM descriptions, which are listed in Appendix B. Agencies had the option of entering these 
more detailed descriptions in CTS; however they were not used consistently across agencies, with less than $10 \%$ of the projects identifying sub-ECM categories. Therefore the overall ECM analysis uses the parent ECM categories, and the subcategories are used where appropriate.

Agencies identified over 2,800 ECMs in the 794 valid projects ${ }^{16}$ entered in CTS. Lighting, HVAC, EMCS, and Water and Sewer Conservation Systems are the four most common ECM types. Figure 6.11 below shows the count of ECMs identified by type in CTS.

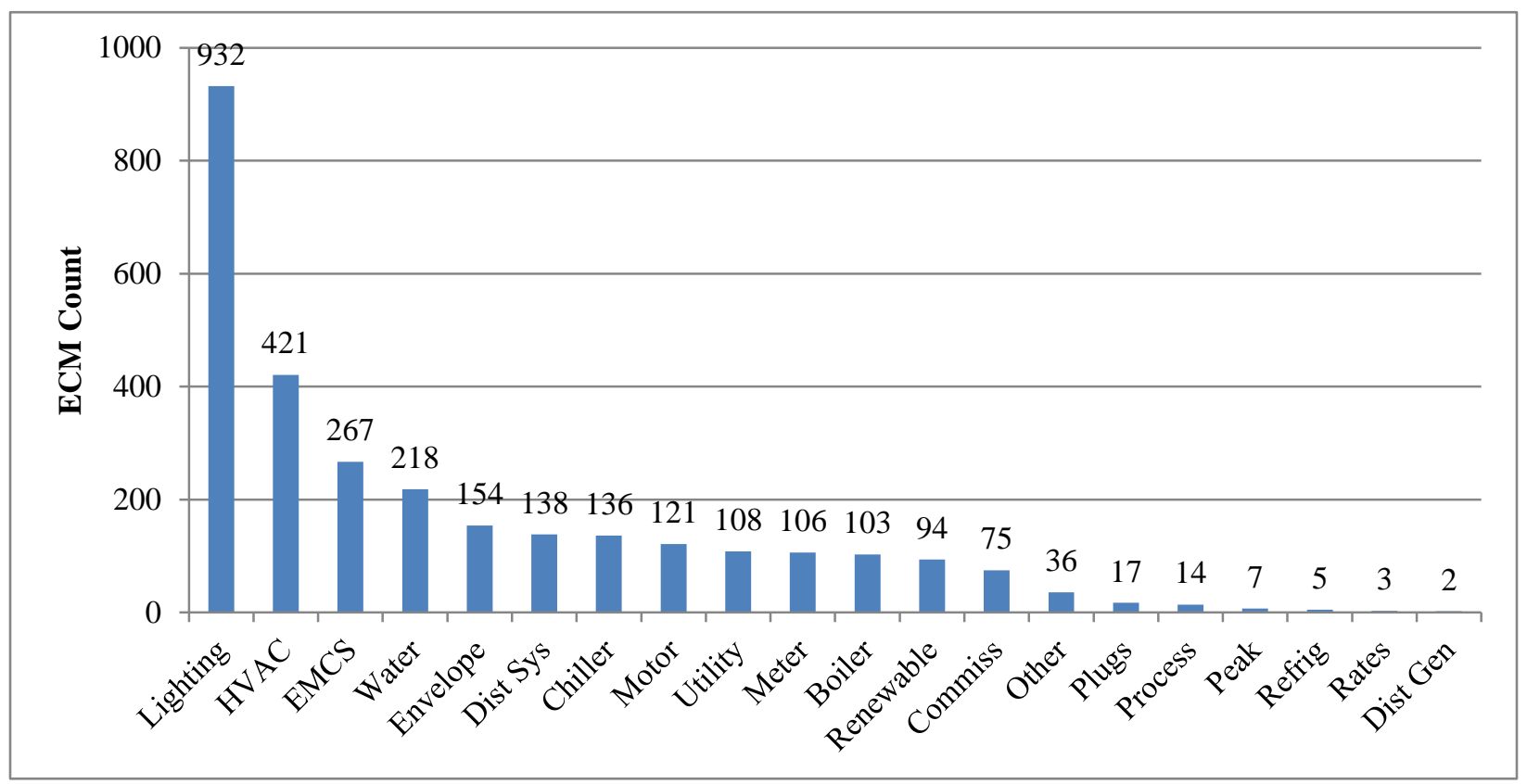

Figure 6.11. Sums of ECMs Implemented by Category

The types of ECMs that the agencies are implementing vary. Figure 6.12 illustrates the diversity of ECM types within the agencies' project portfolios. The percentage of ECM types is displayed in the stacked bar graphs. For example, all of NRC's projects are energy and utility distribution system projects while DOJ and DOE had a more even split of ECM types within their implemented projects.

\footnotetext{
${ }^{16}$ Projects are valid when the following information has been entered in CTS at a minimum: project has been initiated (contract awarded date), implementation cost, annual energy savings, and the ECM type.
} 


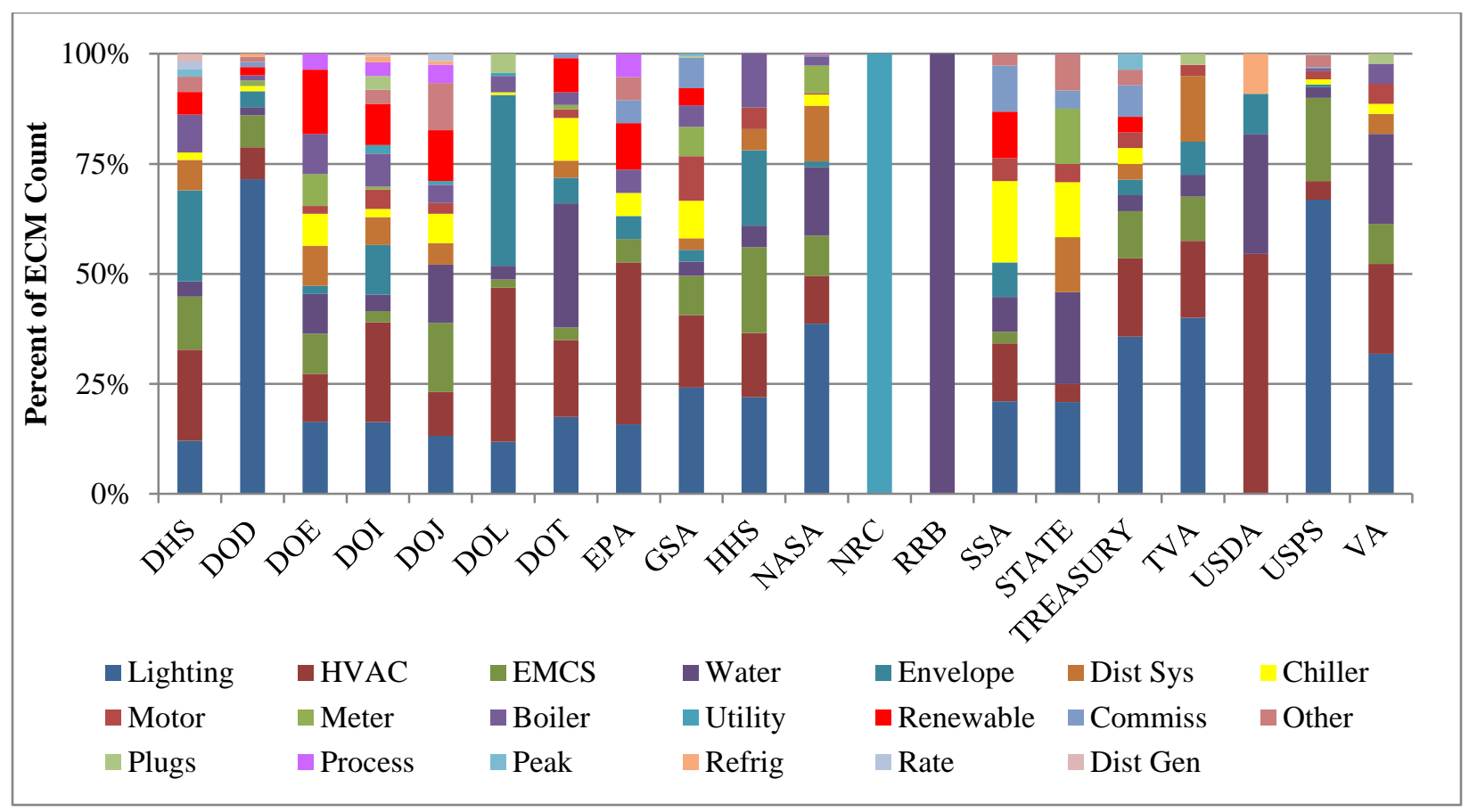

Figure 6.12. Type of ECMs Implemented by Agency

The table below shows the 10 most common ECMs at the 10 agencies with the highest number of ECMs in CTS (Table 6.3). A calculation was performed for each agency to show the percentage of total ECMs by category with respect to the agency's total ECM count. For several agencies with high ECM counts, such as GSA and USPS, Lighting is the most common ECM identified; for others, such as DOL and DOI, HVAC, EMCS, Envelope and Water projects are the most common.

Table 6.3. Percent of Agency's Total Count of ECMs for the Top 10 ECM Categories ${ }^{17}$

\begin{tabular}{|c|c|c|c|c|c|c|c|c|c|c|}
\hline Agency & Lighting & HVAC & EMCS & Envelope & Water & Chiller & Boiler & Commiss & Meter & Motor \\
\hline GSA & $24 \%$ & $16 \%$ & $9 \%$ & $3 \%$ & $3 \%$ & $8 \%$ & $5 \%$ & $7 \%$ & $7 \%$ & $10 \%$ \\
\hline NASA & $39 \%$ & $11 \%$ & $9 \%$ & $1 \%$ & $16 \%$ & $2 \%$ & $2 \%$ & $0 \%$ & $6 \%$ & $0 \%$ \\
\hline USPS & $67 \%$ & $4 \%$ & $19 \%$ & $1 \%$ & $3 \%$ & $1 \%$ & $1 \%$ & $0 \%$ & $0 \%$ & $2 \%$ \\
\hline DOD & $72 \%$ & $7 \%$ & $7 \%$ & $4 \%$ & $2 \%$ & $1 \%$ & $1 \%$ & $1 \%$ & $1 \%$ & $0 \%$ \\
\hline DOL & $12 \%$ & $35 \%$ & $2 \%$ & $39 \%$ & $3 \%$ & $1 \%$ & $4 \%$ & $0 \%$ & $0 \%$ & $0 \%$ \\
\hline DOI & $16 \%$ & $23 \%$ & $3 \%$ & $11 \%$ & $4 \%$ & $2 \%$ & $8 \%$ & $0 \%$ & $1 \%$ & $4 \%$ \\
\hline DOJ & $13 \%$ & $10 \%$ & $16 \%$ & $0 \%$ & $13 \%$ & $7 \%$ & $4 \%$ & $0 \%$ & $0 \%$ & $2 \%$ \\
\hline DOT & $16 \%$ & $18 \%$ & $3 \%$ & $6 \%$ & $29 \%$ & $10 \%$ & $3 \%$ & $1 \%$ & $1 \%$ & $2 \%$ \\
\hline DHS & $12 \%$ & $21 \%$ & $12 \%$ & $21 \%$ & $3 \%$ & $2 \%$ & $9 \%$ & $0 \%$ & $0 \%$ & $0 \%$ \\
\hline DOE & $16 \%$ & $11 \%$ & $9 \%$ & $2 \%$ & $9 \%$ & $7 \%$ & $9 \%$ & $0 \%$ & $7 \%$ & $2 \%$ \\
\hline
\end{tabular}

\footnotetext{
${ }^{17}$ Note that conditional formatting has been applied to each agency to identify the largest ECM categories. The darkest cells have the largest value for the agency, where the lightest colored cells have the smallest value.
} 


\subsubsection{Bundling of Projects}

EISA encourages agencies to bundle ECMs as a way to optimize the energy- and water-saving or environmental benefits of a project, while making sure that the overall investment is life-cycle cost-effective. Looking at all projects in CTS, the majority (72\%) have only one ECM type identified (Figure 6.13). ${ }^{18}$

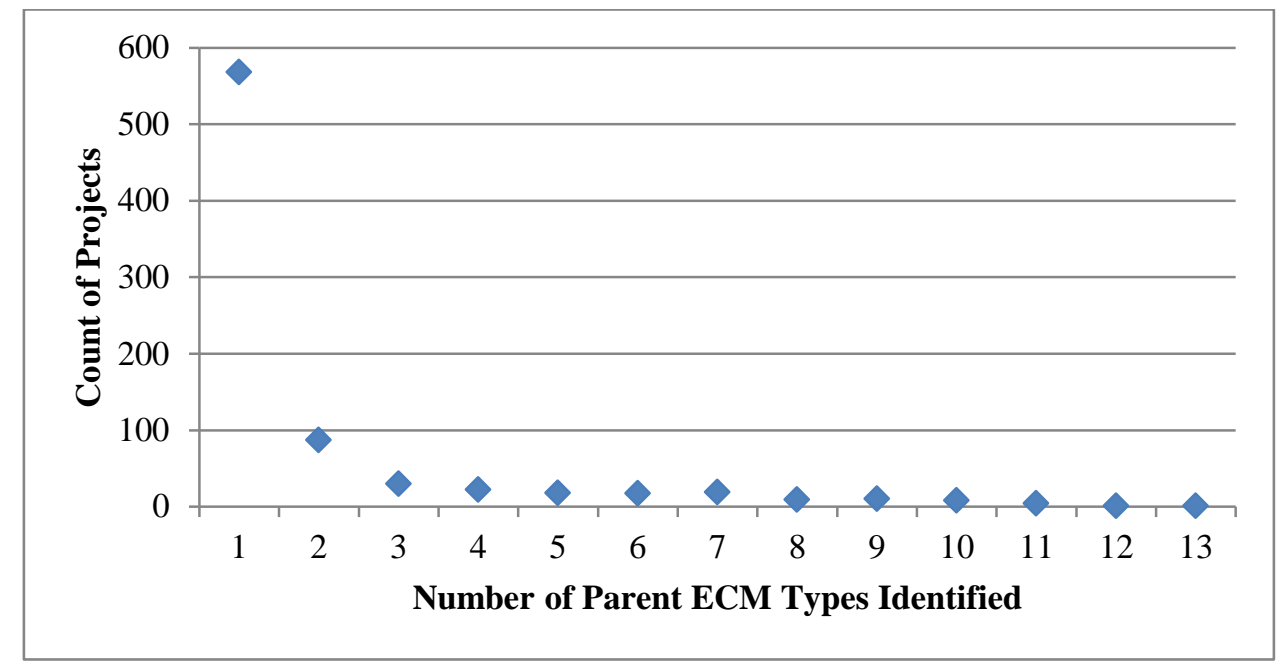

Figure 6.13. Number of Projects with One or More ECM Types

A comparison of the number of projects by agency to the number of projects with single parent ECMs shows that some agencies included several ECMs in each project while others did not. The red dots in Figure 6.14 indicate the total number of ECMs identified by the agencies. Projects in CTS had ECM counts ranging from 1 to 97 . As illustrated in Figure 6.14, GSA, NASA and USPS implemented the most ECMs and tended to bundle different ECM types into a single project.

\footnotetext{
${ }^{18}$ Because most agencies reported ECMs at the parent ECM level, this summary does not indicate whether multiple ECMs were bundled within a parent ECM category. For example, a project could include both daylighting and occupancy sensor ECMs and still be characterized as a single ECM type in this analysis.
} 


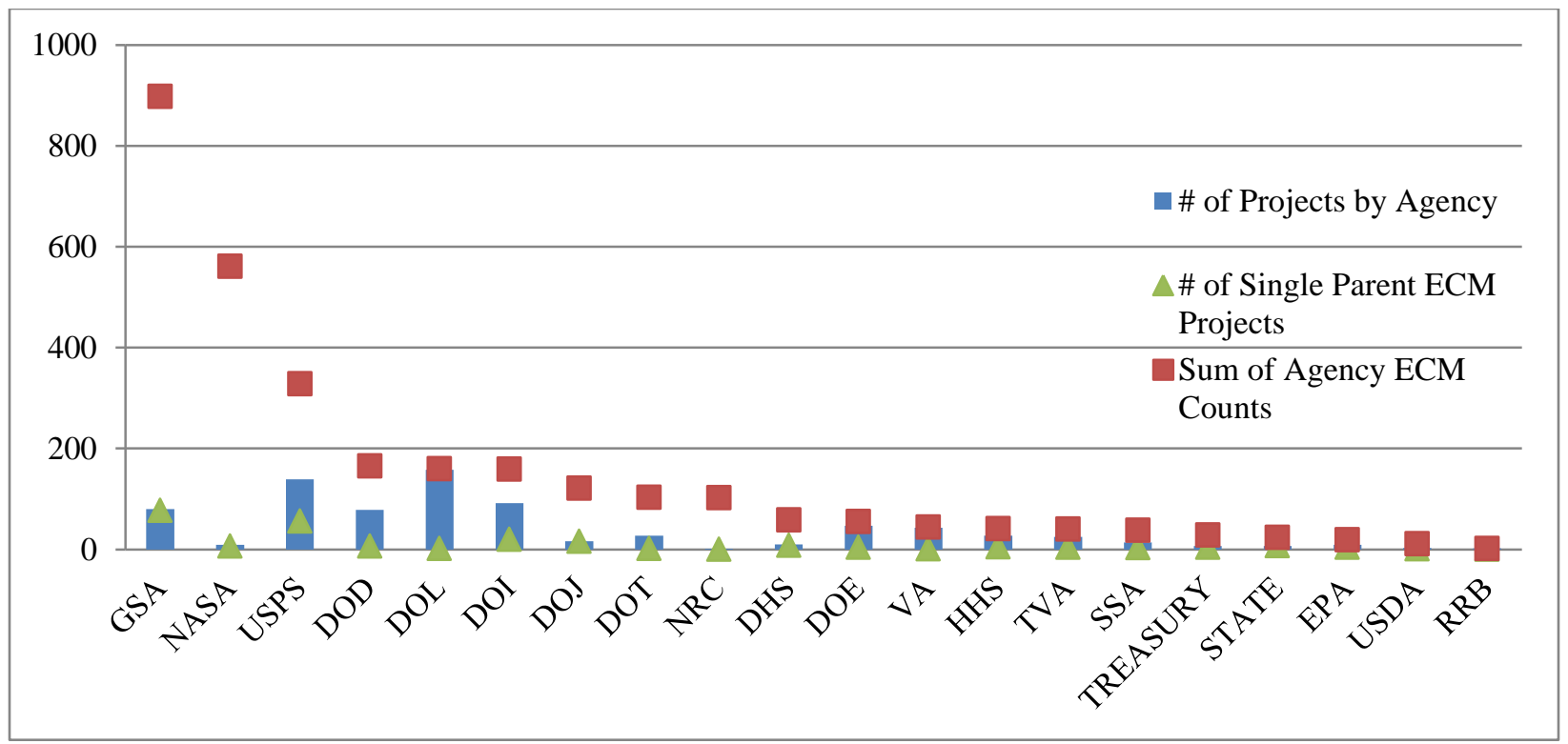

Figure 6.14. Number of Projects, Number of Single Parent ECM Projects, and Sum of ECMs by Agency

An alternative way of looking at the agency data is to evaluate how frequently they bundle their projects as a ratio of bundled projects to nonbundled projects. As shown in Table 6.4, DOJ and STATE bundled ECM types in every project entered in CTS. Six out of 20 agencies bundled ECMs in projects more than half of the time. Agencies with a larger number of projects (e.g., DOL, USPS and DOI) tended not to bundle the majority of their projects. ${ }^{19}$

\footnotetext{
${ }^{19}$ Note: This does not account for the cases where multiple ECM subcategories are bundled within the broad categories (e.g. daylighting and occupancy sensors within lighting).
} 
Table 6.4. Bundling of ECMs in Projects by Agency

\begin{tabular}{lr}
\hline \multicolumn{1}{c}{ Agency } & $\begin{array}{r}\text { \% of Agency's Projects } \\
\text { with Bundled ECMs }\end{array}$ \\
\hline DOJ & $100 \%$ \\
STATE & $100 \%$ \\
GSA & $96 \%$ \\
DHS & $80 \%$ \\
NASA & $67 \%$ \\
TREASURY & $57 \%$ \\
EPA & $44 \%$ \\
USPS & $40 \%$ \\
USDA & $33 \%$ \\
DOI & $22 \%$ \\
SSA & $21 \%$ \\
HHS & $19 \%$ \\
TVA & $16 \%$ \\
DOE & $9 \%$ \\
DOD & $8 \%$ \\
DOT & $7 \%$ \\
VA & $2 \%$ \\
DOL & $1 \%$ \\
RRB & $0 \%$ \\
NRC & $0 \%$ \\
\hline
\end{tabular}

The most common ECM bundle groups are Lighting improvements with EMCS, Lighting with HVAC, and HVAC with EMCS. Commissioning measures were frequently bundled with Lighting, HVAC, EMCS and Chiller plant retrofits. It is likely that agencies are adding Commissioning projects to Building Automation System upgrades, and Advanced Metering to larger capital projects during the project development phase. Agencies also appear to be taking advantage of more economical Lighting and EMCS projects to implement Water and Sewer Conservation system projects. Table 6.5 below highlights the top 25 most commonly bundled ECMs.

Table 6.5. Top 25 Most Commonly Bundled ECMs ${ }^{20}$

\begin{tabular}{ccccccccc}
\hline & EMCS & HVAC & Commiss & Meter & Boiler & Chiller & Motor & Water \\
\hline Lighting & 118 & 93 & 51 & 49 & 39 & 50 & 48 & 46 \\
HVAC & 88 & & 61 & 55 & 45 & 57 & 47 & \\
EMCS & & & 57 & 53 & 43 & 55 & 49 & 36 \\
Chiller & & & 39 & & 39 & & 37 & \\
Commiss & & & & 54 & & & 36 & \\
\hline
\end{tabular}

\subsubsection{Energy Savings by Implemented ECM}

Projects with a single ECM type identified can be analyzed for their relative contribution to total energy savings. Because a single savings value is entered in CTS for projects and is not attributed to individual ECMs, there is significant uncertainty around analysis of energy savings by ECM type for

\footnotetext{
${ }^{20}$ Note: The most frequent bundles are shaded in dark green and the less frequent bundles are lighter in color. The number in the cell refers to the number of projects that have both ECMs in the matrix.
} 
projects with bundled ECMs. Analysis of single-ECM projects provides the most accurate estimated savings ranges.

Table 6.6 and Table 6.7 show the reported amounts of energy avoided through energy efficiency ECMs. Projects implemented with a single ECM type account for $45 \%$ of the energy savings reported in CTS but account for the majority of projects. This suggests that single-ECM projects have a lower savings amount per project than projects with more than one ECM. Bundled projects tend to be larger in size. On average each project with a single ECM saved 3,600 MMBtu, while bundled projects saved over 14,000 MMBtu each.

Table 6.6. Energy Savings Grouped by Number of ECM Types per Project

\begin{tabular}{lrrrr}
\hline & $\begin{array}{c}\text { Energy } \\
\text { Savings } \\
\text { (MMBtu) }\end{array}$ & $\begin{array}{c}\text { Percent of } \\
\text { Total } \\
\text { Savings } \\
\text { Reported }\end{array}$ & $\begin{array}{c}\text { Number of } \\
\text { Projects with } \\
\text { Energy Savings }\end{array}$ & $\begin{array}{c}\text { Energy Savings } \\
\text { Per Project } \\
\text { (MMBtu) }\end{array}$ \\
\hline Projects with One ECM Type & $1,928,494$ & $45 \%$ & 541 & 3,565 \\
Projects with Two ECM Types & 419,754 & $10 \%$ & 81 & 5,182 \\
Projects with Three or More ECM Types & $1,948,958$ & $45 \%$ & 135 & 14,437 \\
Total CTS Project Energy Savings & $4,297,206^{21}$ & & 757 & 5,677 \\
\hline
\end{tabular}

An alternative way to look at these savings values is to compare the number of ECMs identified within each project to the energy-savings estimates. In Table 6.7 below, the projects with more than three ECM types have a lower savings per ECM value than the projects with only one or two ECMs identified. This means that the bundled projects are including several ECMs with smaller individual energy savings, which is expected.

Table 6.7. Energy Savings per ECM Group by Number of ECMs

\begin{tabular}{lcrr}
\hline & $\begin{array}{c}\text { Energy } \\
\text { Savings } \\
\text { (MMBtu) }\end{array}$ & $\begin{array}{c}\text { Number of ECMs } \\
\text { with Energy Savings }\end{array}$ & $\begin{array}{c}\text { Energy Savings Per } \\
\text { ECM } \\
\text { (MMBtu) }\end{array}$ \\
\hline Projects with One ECM Type & $1,928,464$ & 840 & 2,296 \\
Projects with Two ECM Types & 419,754 & 233 & 1,802 \\
Projects with Three or More ECM Types & $1,948,958$ & 1,807 & 1,079 \\
Total CTS Project Energy Savings & $4,297,206$ & 2,880 & 1,492 \\
\hline
\end{tabular}

Figure 6.15 below depicts the energy savings for all ECM types in projects with only one ECM type. The ECMs that account for the largest amount of estimated annual savings are Lighting, EMCS, Renewable Energy projects with an energy-savings component, and Chilled Water, Hot Water, and Steam Distribution systems. Together, these four single-ECM project types account for two-thirds of the energy savings of single projects in CTS. This means that these types of ECMs are implemented more independently because they are either cost-effective by themselves or there is a higher ease of implementation to fund and execute these types of projects on their own.

\footnotetext{
${ }^{21}$ Note that the totals have been adjusted based on quality checks of the data. A few renewable ECMs reported their data as energy savings rather than renewable energy production. The values have been corrected in this analysis.
} 


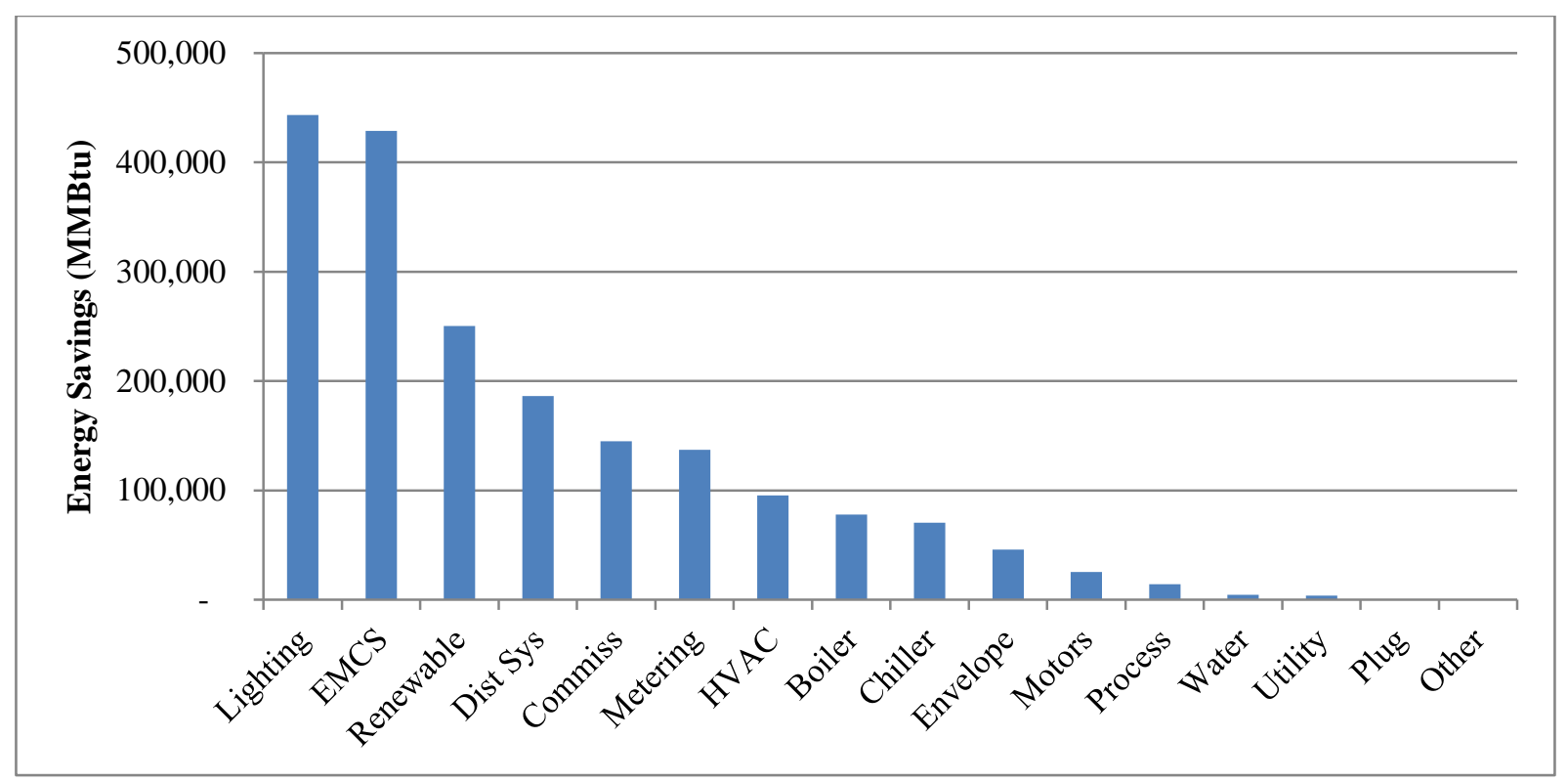

Figure 6.15. ECM Savings by Category for Projects with a Single ECM Type

\subsubsection{Renewable Energy Output by Implemented ECM}

Renewable energy ECMs account for a third of the total energy avoided by projects. There were far fewer renewable energy projects than energy efficiency projects, and on average the renewable projects generated nearly 35,000 MMBtu per project. Most of the projects produced renewable electricity, with one large biomass project producing $70 \%$ of the total energy savings realized by all federal projects. Without this large project, the overall average annual generation per project is $21,000 \mathrm{MMBtu}$.

Table 6.8. Annual Renewable Energy Output Summary

\begin{tabular}{lccc}
\hline & Renewable Electricity & Renewable Thermal & Total Renewable $^{22}$ \\
\hline Renewable Output & $\begin{array}{l}105,400,520 \mathrm{KWh} \\
(359,627 \mathrm{MMBtu})\end{array}$ & $1,350,859 \mathrm{MMBtu}$ & $1,710,485 \mathrm{MMBtu}$ \\
$\begin{array}{l}\text { Number of Projects } \\
\begin{array}{l}\text { MMBtu of Production per } \\
\text { Project }^{24}\end{array}\end{array}$ & 42 & 13 & $53^{23}$ \\
\hline
\end{tabular}

The renewable energy projects were reviewed in more detail to determine the specific types of projects that were implemented. Information from the project titles and notes was assembled to create Table 6.9, with a portion of the project types unable to be determined (noted as nonspecified RE). DOE's large biomass project makes up the bulk of the renewable output, with nonspecified renewable energy and photovoltaic projects generating the next largest amounts.

\footnotetext{
${ }^{22}$ Adjustments were made to these totals. Based on the project details provided in CTS it was determined that one project had renewable energy output inadvertently entered in the energy savings fields. 16MMBtu of renewable energy project savings were moved to renewable thermal energy output fields.

${ }^{23}$ Two projects have both renewable electricity output and renewable thermal output.

${ }^{24}$ This is calculated by dividing the renewable output by the number of projects.
} 
Table 6.9. Renewable Energy Output by Project Type

\begin{tabular}{lrr}
\hline \multicolumn{1}{c}{ Project Type } & $\begin{array}{c}\text { Sum of Renewable Energy Output } \\
\text { (MMBtu) }\end{array}$ & \multicolumn{2}{c}{$\begin{array}{c}\text { Percent of Renewable Energy } \\
\text { Contribution }\end{array}$} \\
\hline Biomass & $1,450,021$ & $85 \%$ \\
Nonspecified RE & 192,734 & $11 \%$ \\
Photovoltaic & 51,907 & $3 \%$ \\
Biogas & 15,056 & $<1 \%$ \\
Solar Transpired Wall & 503 & $<1 \%$ \\
Solar Hot Water & 179 & $<1 \%$ \\
Wind & 62 & $<1 \%$ \\
Ground-Coupled Heat Pump & 24 & $<$ \\
Grand Total & $\mathbf{1 , 7 1 0 , 4 8 6}$ & \\
\hline
\end{tabular}

\subsubsection{Cost of Implementing ECMs by Type}

Projects that had multiple ECMs bundled represented over half of the implementation cost reported in CTS. The values in Table 6.10 show all of the projects with the exception of the $\$ 137 \mathrm{M}$ biomass project and ECMs as part of larger maintenance projects with zero implementation costs, so as not to skew the averages. On average each project with a single ECM cost $\$ 660 \mathrm{k}$, while bundled projects were over $\$ 5 \mathrm{M}$ each.

Table 6.10. Implementation Costs Grouped by Number of ECM Types per Project

\begin{tabular}{lrrrr}
\hline & $\begin{array}{c}\text { Total } \\
\text { Implementation } \\
\text { Cost }(\$ \mathbf{M})\end{array}$ & $\begin{array}{c}\text { Percent of } \\
\text { Total Cost } \\
\text { Reported }\end{array}$ & $\begin{array}{c}\text { Number of } \\
\text { Projects with } \\
\text { Implementation } \\
\text { Cost }\end{array}$ & $\begin{array}{c}\text { Average Cost } \\
\text { per Project } \\
(\$ \mathrm{k})\end{array}$ \\
\hline Projects with One ECM Type & 372.1 & $30 \%$ & 561 & 663 \\
Projects with Two ECM Types & 153.0 & $12 \%$ & 86 & 1,780 \\
Projects with Three or More ECM Types & 712.0 & $58 \%$ & 136 & 5,235 \\
Total CTS Project Costs & $1,237.2$ & & 783 & 1,580 \\
\hline
\end{tabular}

The ECMs in which the largest investments were made were Chilled Water, Hot Water, and Steam Distribution Systems; Lighting Improvements; Building Envelope; Renewable Energy; and HVAC, as shown in Figure 6.6. Together, these five project types account for $70 \%$ of the implementation cost. As noted previously, these results are only for projects with one ECM type because only an overall implementation cost is entered into CTS by project. Projects that are bundled do not break out the costs by ECM type. Note that the large DOE biomass project $(\$ 137 \mathrm{M})$ was also taken out of this figure and accounts for the majority of the investment in renewable energy projects. 


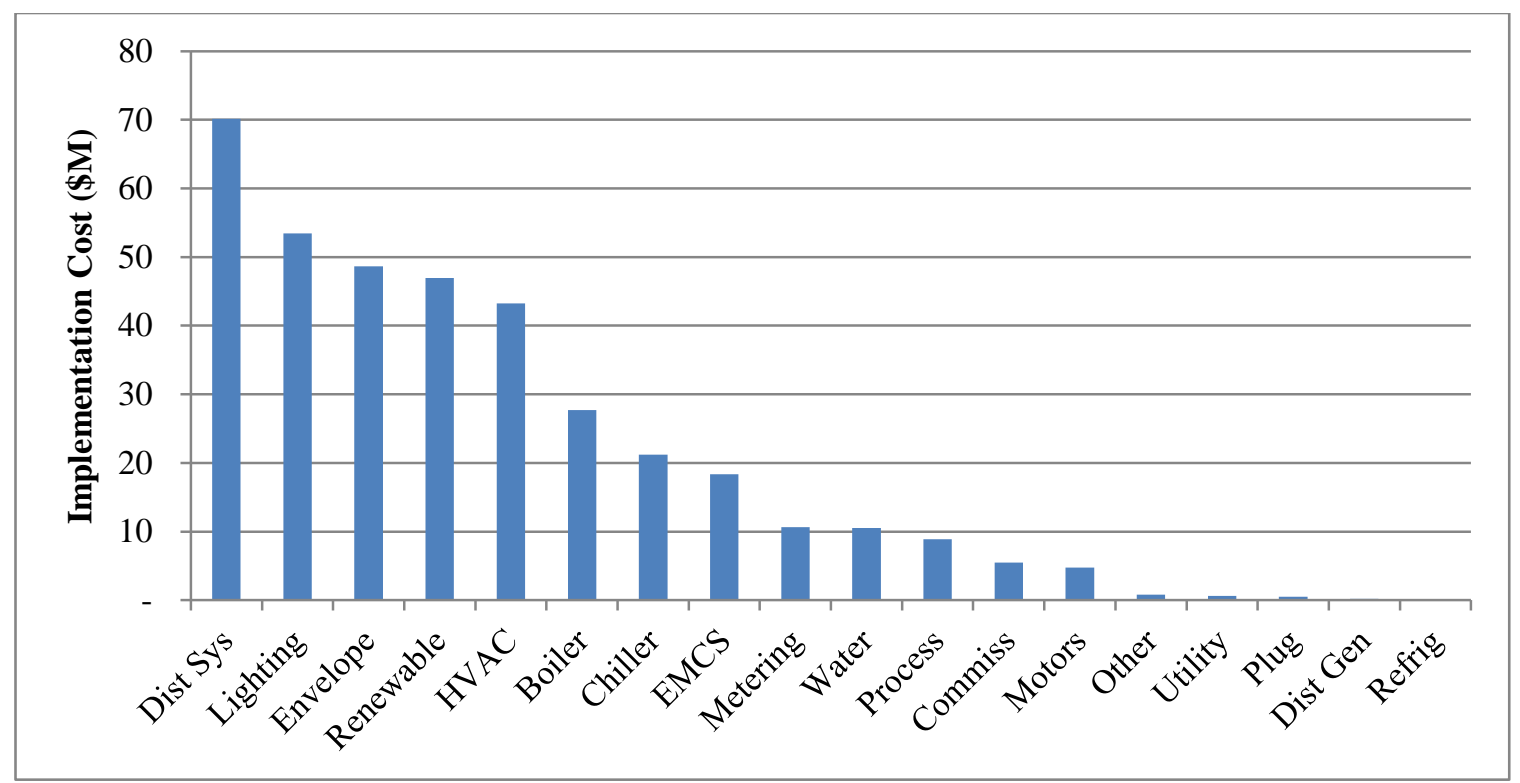

Figure 6.16. Total Implementation Cost by Category for Projects with a Single ECM Type

As shown in Figure 6.17, the ECMs that have the largest average implementation cost per project are Distribution Systems, Renewable Energy, Advanced Metering, Commissioning, Boiler and Chiller Plants, and Process Improvements. On average, these projects cost over $\$ 1 \mathrm{M}$ each, while the others generally cost between $\$ 100,000$ and $\$ 500,000$ each.

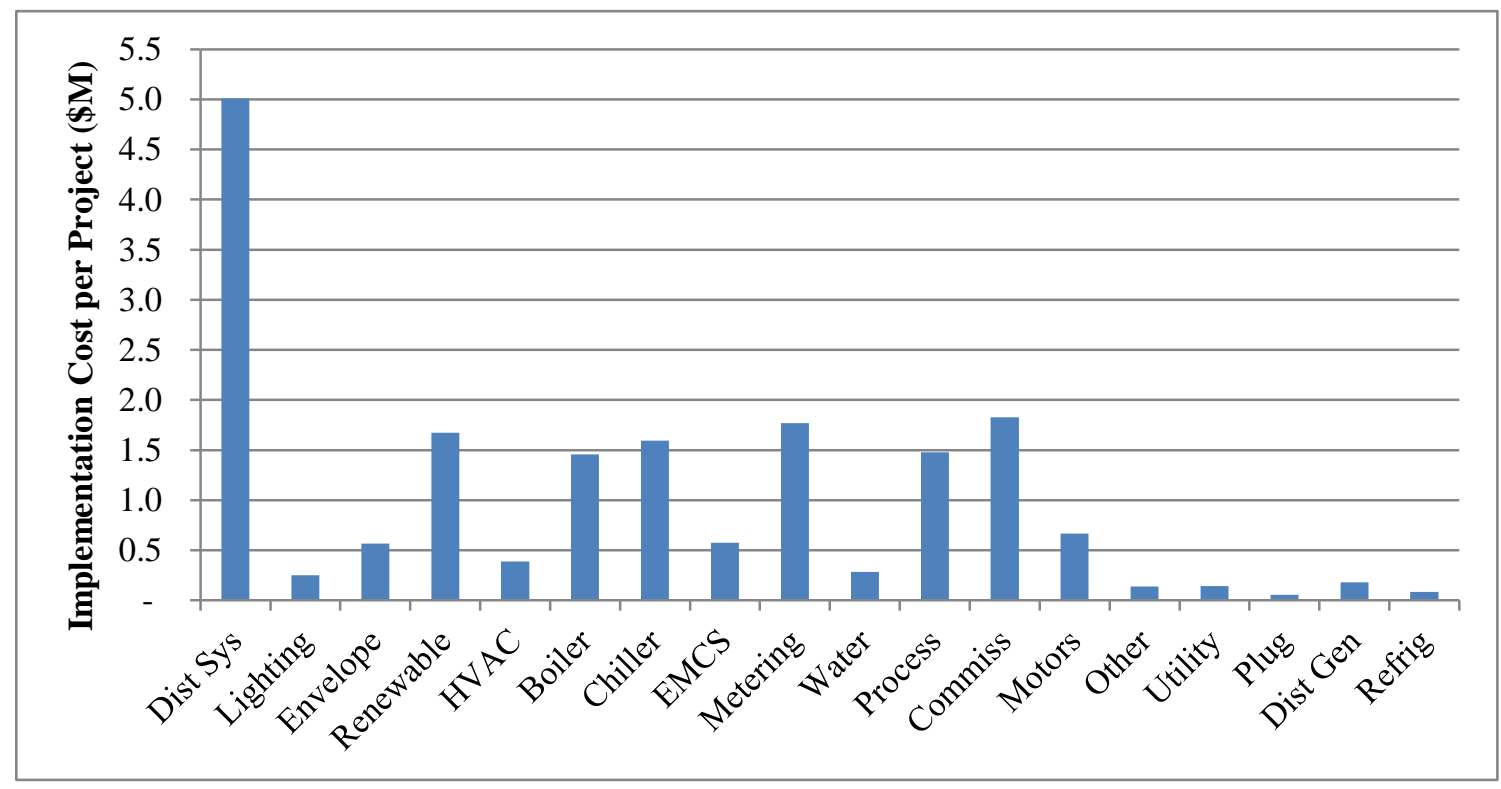

Figure 6.17. Average Implementation Cost per ECM for Projects with a Single ECM Type

\subsubsection{Water Conservation Measures Implemented}

This section examines projects in CTS that reported implementing a water savings ECM. The projects were analyzed to determine water savings by ECM type. Analysis of the available data presented some challenges. There is a broad range of potential water conservation measures that could be implemented 
under the umbrella of Water and Sewer Conservation. The potential water savings for these measures also varies significantly. The lack of specific information on the nature of the water conservation measure implemented limits the research team's ability to establish meaningful average savings.

A total of 77 projects reported in CTS included water savings. Nine projects were removed from the analysis due to obvious data quality issues that could not be resolved through follow-up with the agencies (e.g., reported annual water savings were greater than annual water use). The remaining 69 projects shown in Table 6.11 were broken down by the project information provided in CTS. The category "Plumbing ECM" is a combination of two water sub-ECMs included in CTS: low-flow faucets and showerheads, and low-flow plumbing equipment. Only 13 of the ECMs could be identified as a specific project type from the data provided in CTS, either because the agency specified what the sub-ECM was or by reviewing the project details. A majority of the water savings were simply identified by the parent ECM "Water and Sewer Conservation Systems" with no additional description. Water savings were also recorded under projects with predominantly energy-savings ECMs, including HVAC, Refrigeration, Boiler, Chiller, and Distribution Systems.

Table 6.11. Water Savings by ECM Type

\begin{tabular}{lrrrrr}
\hline & $\begin{array}{c}\text { Number of } \\
\text { Projects }\end{array}$ & $\begin{array}{c}\text { Total Water } \\
\text { Savings } \\
\text { (k gal) }\end{array}$ & $\begin{array}{c}\text { Median } \\
\text { Water } \\
\text { Savings } \\
\text { (k gal) }\end{array}$ & $\begin{array}{c}\text { Average } \\
\text { Water Savings } \\
\text { (k gal) }\end{array}$ & $\begin{array}{c}\text { Percent of } \\
\text { Total } \\
\text { Water } \\
\text { Savings }\end{array}$ \\
\hline Plumbing ECM & 12 & 31,858 & 52 & 2,655 & $3 \%$ \\
Irrigation ECM & 1 & 39 & N.A. & N.A. & $0 \%$ \\
General Water and Sewer ECMs & 36 & 895,697 & 4,647 & 24,880 & $80 \%$ \\
Energy ECMs with Water Savings & 19 & 187,861 & 1,187 & 9,887 & $17 \%$ \\
Totals & 68 & $1,115,455$ & 5,058 & 16,404 & \\
\hline
\end{tabular}

Determining cost savings for water projects was also difficult due to the fact that many projects with reported water savings were bundled with energy ECMs. Of the 69 projects listed above, only 12 reported water savings with no energy savings. The total implementation cost for these 12 projects was $\$ 8,701,470$ and the average was $\$ 725,123$. The lowest implementation cost of $\$ 0$ came from an ECM that was bundled into a maintenance project. Excluding this maintenance project, the cost of projects ranged from $\$ 2,500$ to $\$ 5,735,445$.

\subsubsection{Energy and Water Evaluation Estimate Relative to Implemented Projects}

The total evaluated energy savings was compared to the estimated project savings, and $18 \%$ of the evaluated (potential) energy savings from both efficiency projects and renewable projects has been implemented to date, if it is assumed that the implemented projects were identified in the agency's evaluations. About $8 \%$ of the total evaluated (potential) water savings has been implemented in projects, if it is assumed that those water savings opportunities were identified in the evaluations.

\subsection{Annual Savings per Dollar Invested}

The estimated annual energy and water savings per dollar invested provides one measure of return on investment for energy efficiency and water savings projects. This metric reveals the relative value of 
savings. This section evaluates energy savings per dollar invested overall, by ECM type, by agency, and by funding source. It also examines savings per dollar invested in water ECM projects.

\subsubsection{Annually Recurring Energy Savings per Dollar Invested}

Figure 6.18 shows the distribution of values of energy saved (Btu) per dollar invested for the projects entered into CTS that have energy savings and implementation costs identified. ${ }^{25}$ Energy projects that included water savings, which may have been bundled in the total costs, were excluded from this analysis. Over $90 \%$ of these projects save less than 10,000 Btu per dollar invested. Across all the available data, the mean and median values of Btu per dollar invested are 5,340 and 4,887, respectively. Note that any projects that were calculated to save over 50,000 Btu per dollar invested were omitted from this analysis because the integrity of the data was questionable.

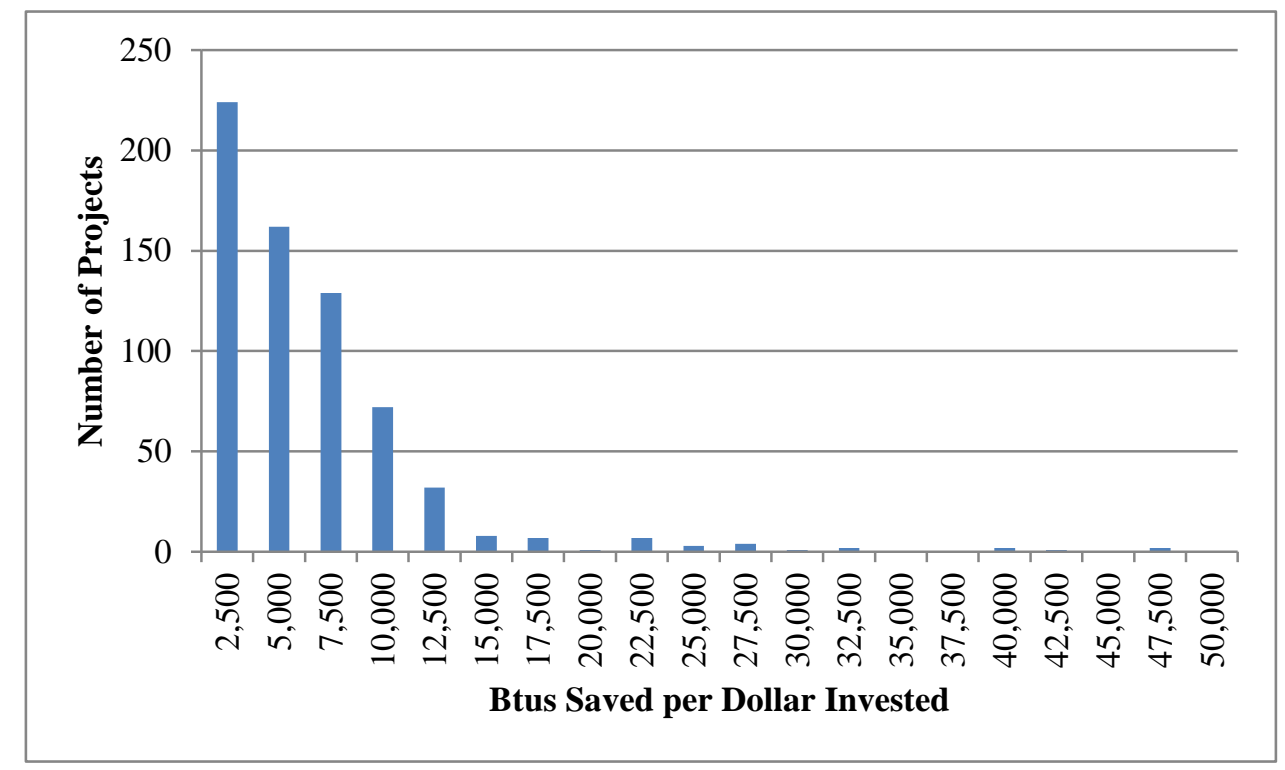

Figure 6.18. Annual Energy Savings (Btu) per Dollar Invested for All Energy Projects

\subsubsection{Energy Savings per Dollar Invested by ECM}

In order to establish the average energy savings per dollar invested associated with a particular ECM, all single-ECM projects were examined. As shown in Figure 6.19, the economics of lighting projects (in terms of savings per dollar invested) are consistently better than other ECM types reported. Of all singleECM projects, 88 percent save less than 10,000 Btu per dollar invested. Furthermore, the mean and median savings across all single-ECM projects of Btu per dollar invested are 6,389 and 5,000, respectively. The mean savings are much higher than the median savings because a few single-ECM projects with very high savings per dollar invested pull the mean upward.

Because there is significant variability within ECM types, it is useful to see how widely the savings vary. Figure 6.19 gives the minimum and maximum savings per dollar invested by ECM as well as the average savings per dollar by ECM. A wide range in minimum and maximum savings reveals that the

\footnotetext{
${ }^{25}$ There were six observations that had annual savings per dollar over 40,000 Btu. The research team did not receive clarification from agencies on the reason for these unusually high ratios.
} 
average Btu per dollar invested is not representative for that particular ECM. Those with less variability may be more useful to use as a basis for estimating future potential savings levels prior to conducting a more rigorous energy saving audit. For example, because ECMs such as Lighting and HVAC have relatively low variability for the number of projects implemented, they are more likely to accurately characterize the Btu savings per dollar as opposed to ECMs such as Metering and Plug Loads, which have few observations and more variability. Furthermore, the Boiler ECM has just 17 observations, most of which are less than 10,000 Btu saved per dollar invested, but the few very high-savings observations significantly influence the mean. Table 6.12 gives the number of observations and average (mean) Btus saved per dollar invested by ECM for single-ECM projects.

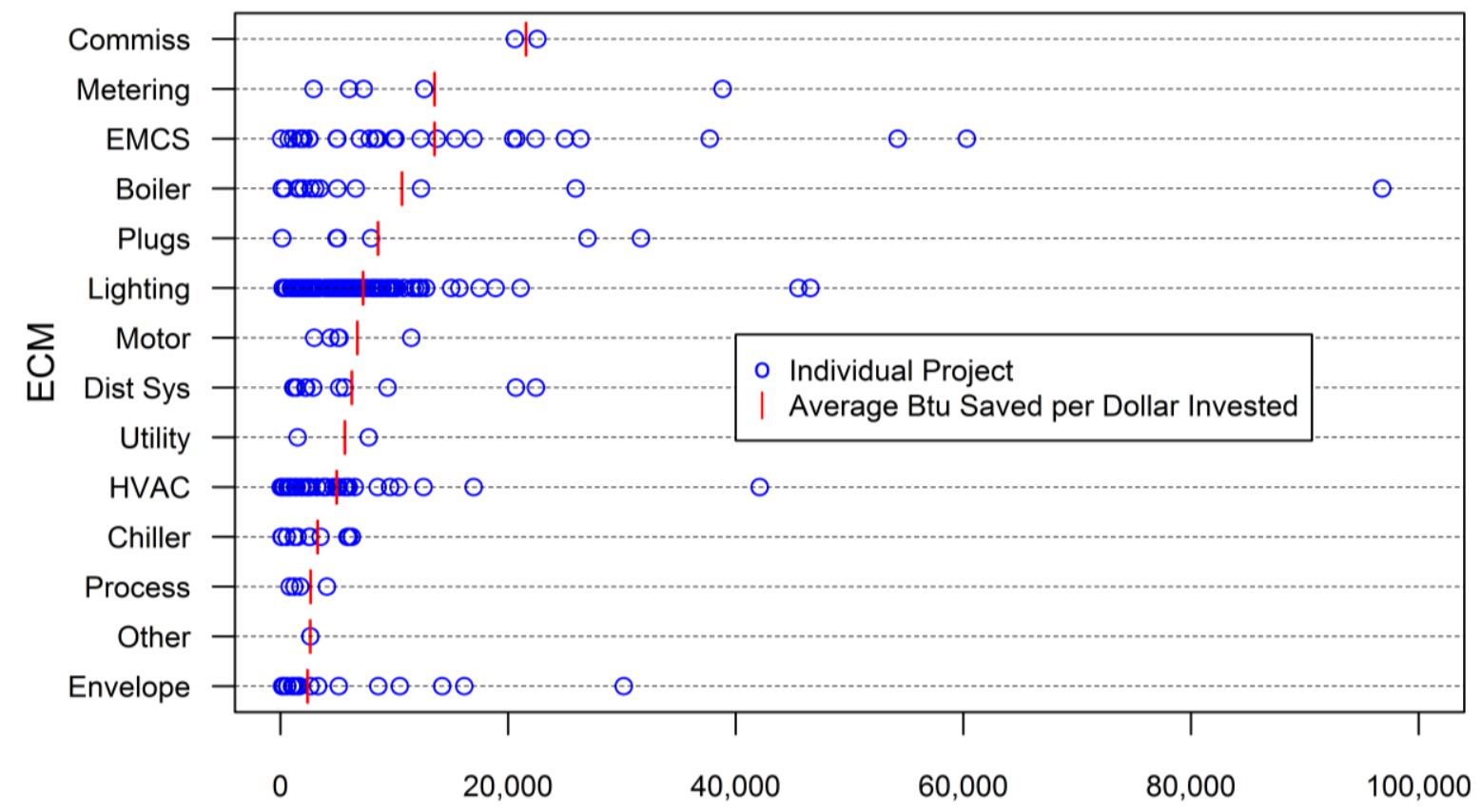

Btu Saved per Dollar Invested

Figure 6.19. Distribution of Savings per Dollar Invested by ECM Type 
Table 6.12. Btus Saved per Dollar Invested for Single-ECM Projects

\begin{tabular}{lrr}
\hline ECM Type & $\begin{array}{c}\text { Number } \\
\text { of Projects }\end{array}$ & $\begin{array}{c}\text { Average Btus } \\
\text { Saved per Dollar } \\
\text { Invested }\end{array}$ \\
\hline Commiss & 2 & 21,574 \\
Metering & 5 & 13,583 \\
EMCS & 31 & 13,535 \\
Boiler & 17 & 10,674 \\
Plugs & 9 & 8,564 \\
Lighting & 191 & 7,257 \\
Motor & 6 & 6,758 \\
Dist Sys & 13 & 6,269 \\
Utility & 3 & 5,659 \\
HVAC & 99 & 4,929 \\
Chiller & 13 & 3,269 \\
Process & 6 & 2,661 \\
Other & 1 & 2,615 \\
Envelope & 83 & 2,382 \\
\hline
\end{tabular}

Because energy savings are estimated for projects and not for individual ECMs, it is not possible to establish the Btus saved per dollar invested for projects with multiple ECMs. However, some general observations about bundled ECMs within projects can be made. Table 6.13 shows the average and range of Btus saved per dollar invested for all projects reported in CTS with two or more ECMs bundled, where the first column indicates the presence of the listed ECM within the project bundle. That is, Boiler ECMs are bundled within 41 projects with other ECMs, and those projects save an average of 2,402 Btu per dollar invested.

Table 6.13. Btus Saved per Dollar Invested for Bundled Projects by ECM Presence within Project

\begin{tabular}{lrrrrr}
\hline \multicolumn{1}{c}{ ECM Type } & $\begin{array}{c}\text { Number } \\
\text { of Projects }\end{array}$ & Minimum & Maximum & \multicolumn{1}{c}{ Average } & $\begin{array}{c}\text { Standard } \\
\text { Deviation }\end{array}$ \\
\hline Process & 5 & 2,262 & 77,269 & 19,921 & 32,169 \\
Refrig & 2 & 4,652 & 27,442 & 16,047 & 16,115 \\
Utility & 3 & 4,169 & 7,738 & 6,548 & 2,060 \\
Lighting & 174 & 137 & 77,269 & 6,533 & 9,023 \\
Rates & 3 & 97 & 7,800 & 5,015 & 4,271 \\
Other & 18 & 1,526 & 9,641 & 4,841 & 2,332 \\
Dist Sys & 34 & 559 & 17,059 & 4,494 & 3,934 \\
Plugs & 3 & 2,068 & 7,867 & 4,426 & 3,048 \\
EMCS & 136 & 157 & 23,858 & 4,403 & 3,774 \\
HVAC & 115 & 157 & 77,269 & 4,000 & 7,729 \\
Motor & 56 & 208 & 17,059 & 3,376 & 3,385 \\
Chiller & 57 & 234 & 9,641 & 2,835 & 2,166 \\
Envelope & 33 & 60 & 11,866 & 2,492 & 2,749 \\
Commiss & 65 & 137 & 23,858 & 2,482 & 3,237 \\
Boiler & 41 & 234 & 7,800 & 2,402 & 1,645 \\
Peak & 5 & 1,324 & 3,343 & 2,326 & 877 \\
Meter & 60 & 60 & 6,830 & 2,190 & 1,632 \\
\hline
\end{tabular}


This analysis suggests that bundled ECM projects with Energy-Related Process improvements and Refrigeration had the highest average savings per dollar invested. Projects containing lighting and Energy/Utility Distribution System ECMs also had higher Btus per dollar invested than projects with most other ECM types. Metering, Peak Shaving, Boiler Improvements, Commissioning and Envelope bundled projects had comparatively lower savings per dollar invested.

\subsubsection{Energy Savings per Dollar Invested by Agency}

There are a number of factors that may contribute to differences in the average energy savings per dollar invested by agency, including the function of the buildings in an agency's covered facility portfolio, local and regional factors such as climate, the number of projects, and the particular ECMs selected by agencies. As shown in Figure 6.20 and Table 6.14, energy savings per dollar invested varies by agency from approximately 2,000 Btu per dollar invested to 14,000 Btu per dollar invested. The USDA had the highest savings per dollar invested as shown in Figure 6.20. This value is based on two single-ECM projects for Refrigeration and Building Envelope improvements. The lowest savings per dollar shown, for GSA, is based on GSA's portfolio of over 70 projects with varying ECMs, many of which are EMCS and Metering ECMs. This analysis does not include the monetary costs associated with water projects or renewable generation systems.

Like the breakdown of savings by ECM, there is variability within agencies' energy conservation projects. Figure 6.20 gives the distribution of savings per dollar by agency, with the average savings per dollar overlaid. In general, agencies with higher average savings also vary more in terms of savings per dollar. This is because there are high outliers, which pull the mean upward. Note that while the USDA has the highest average savings per dollar invested, there are only two observations on which this statistic is based. Considering the number of observations, variation, and values of data shown, agencies such as USPS and DOD consistently save more Btus per dollar invested. 


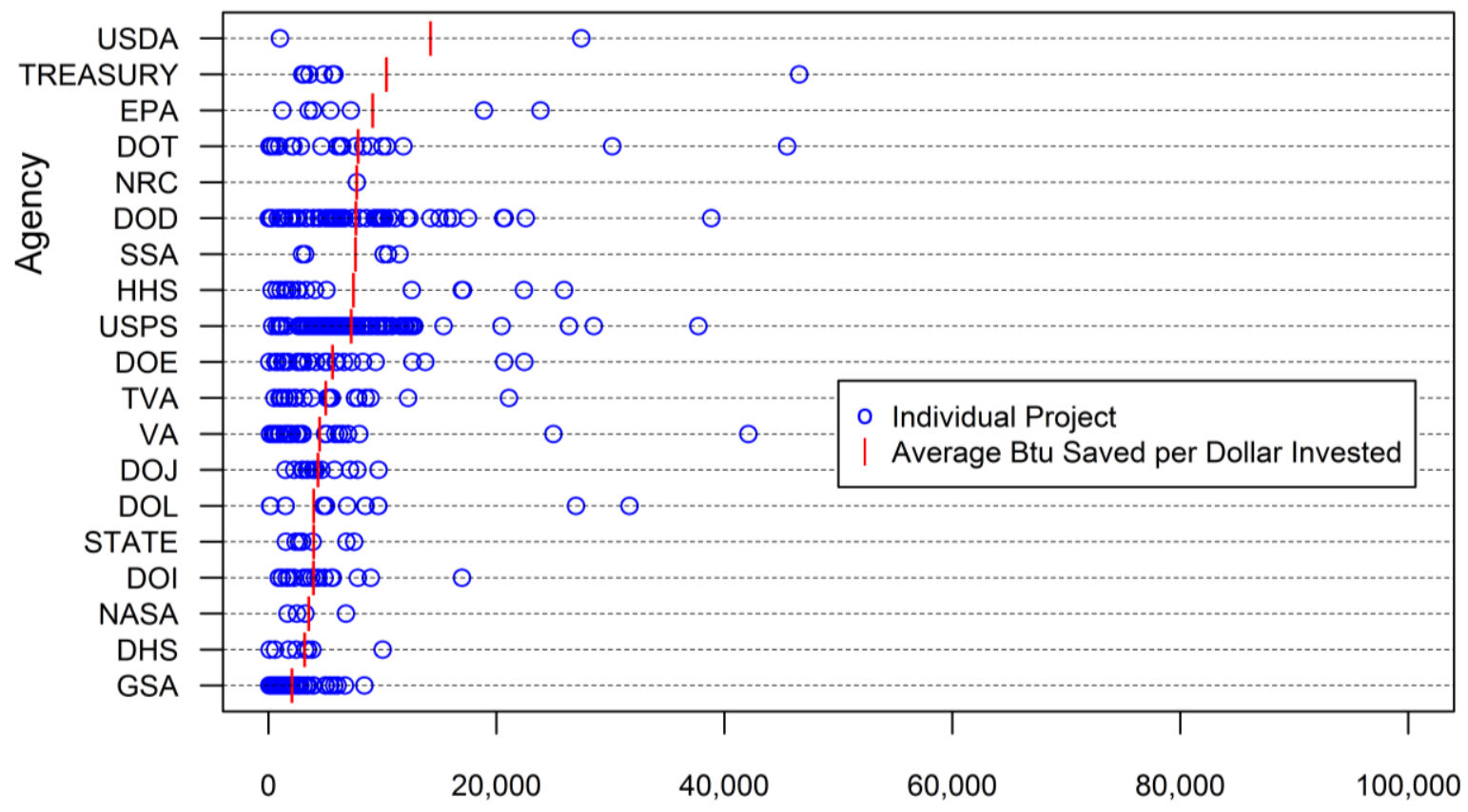

Btu Saved per Dollar Invested

Figure 6.20. Distribution of Savings per Dollar Invested by Agency

Table 6.14. Btus Saved per Dollar Invested by Agency

\begin{tabular}{lrr}
\hline \multicolumn{1}{c}{ Agency } & $\begin{array}{c}\text { Number } \\
\text { of Projects }\end{array}$ & \multicolumn{2}{c}{$\begin{array}{c}\text { Average Btus Saved } \\
\text { per Dollar Invested }\end{array}$} \\
\hline USDA & 2 & 14,223 \\
TREASURY & 7 & 10,353 \\
EPA & 7 & 9,145 \\
DOT & 21 & 7,877 \\
NRC & 1 & 7,738 \\
DOD & 67 & 7,677 \\
SSA & 5 & 7,644 \\
HHS & 18 & 7,462 \\
USPS & 138 & 7,253 \\
DOE & 31 & 5,615 \\
TVA & 25 & 5,029 \\
VA & 34 & 4,490 \\
DOJ & 16 & 4,344 \\
DOL & 155 & 3,960 \\
STATE & 7 & 3,960 \\
DOI & 28 & 3,949 \\
NASA & 4 & 3,540 \\
DHS & 8 & 3,168 \\
GSA & 75 & 2,065 \\
\hline
\end{tabular}

\subsubsection{Energy Savings per Dollar Invested by Funding Source}

Project funding sources can influence the types of projects implemented, and therefore the economics of those projects. Figure 6.21 and Table 6.15 illustrate the overall energy savings (Btu) per dollar invested 
by funding source. Note that the results shown in this figure include only those projects that had a single source of funding, and do not include financing costs for performance contracts. Direct ARRA funding is the only funding source that does not have several high outliers.

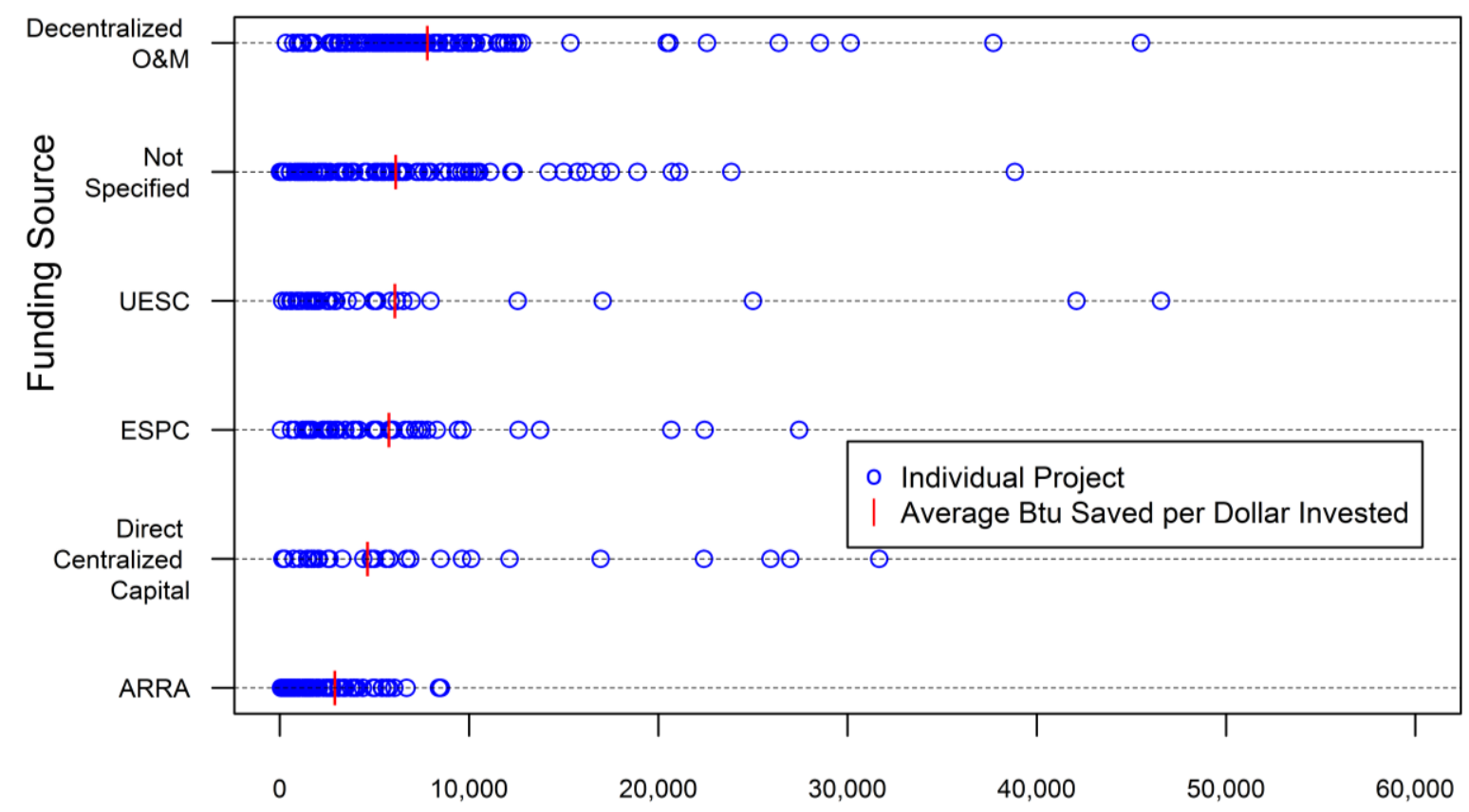

Btu Saved per Dollar Invested

Figure 6.21. Distribution of Savings per Dollar Invested by Funding Source for Projects with One Funding Source ${ }^{26}$

Table 6.15. Btus Saved per Dollar Invested by Funding Source

\begin{tabular}{lrr}
\hline \multicolumn{1}{c}{ Funding Source } & $\begin{array}{c}\text { Number of } \\
\text { Projects }\end{array}$ & $\begin{array}{c}\text { Average Btus } \\
\text { Saved per Dollar } \\
\text { Invested }\end{array}$ \\
\hline Decentralized O\&M & 156 & 7,793 \\
Not Specified & 123 & 6,121 \\
UESC & 42 & 6,078 \\
ESPC & 47 & 5,771 \\
Direct Centralized Capital & 102 & 4,634 \\
ARRA & 165 & 2,908 \\
\hline
\end{tabular}

\subsubsection{Water Savings per Dollar Invested}

A total of 31 projects in the CTS database reported both an implementation cost and savings estimate for water only. These projects were analyzed to determine the water savings as a function of investment cost, as shown in Figure 6.22. The majority of the projects reported saved 10 gallons or less per dollar invested to implement the project. Projects reporting savings of 10 to 100 gallons per dollar invested were

\footnotetext{
${ }^{26}$ Because "Incentive Program" and "Other" funding sources only occurred in conjunction with other funding sources, they are not represented in this figure.
} 
identified simply as Water and Sewer Conservation Systems, with no further details on the nature of the investments made; the exception was one project titled "Domestic Water Conservation," probably referring to an interior plumbing project, which saved just over 20 gallons per invested dollar. The one project that reported over 100 gallons saved per dollar invested was a project to eliminate a once-through cooling system with its associated water use. The high gallons saved per dollar invested in this case are considered reasonable since water use in this particular project was completely eliminated.

Figure 6.22 shows the count of projects with different levels of water savings per dollar invested. Given the relatively small number of water projects available for analysis and the water reporting information, meaningful conclusions regarding which types of water projects tend to save the most water per invested dollar cannot be made.

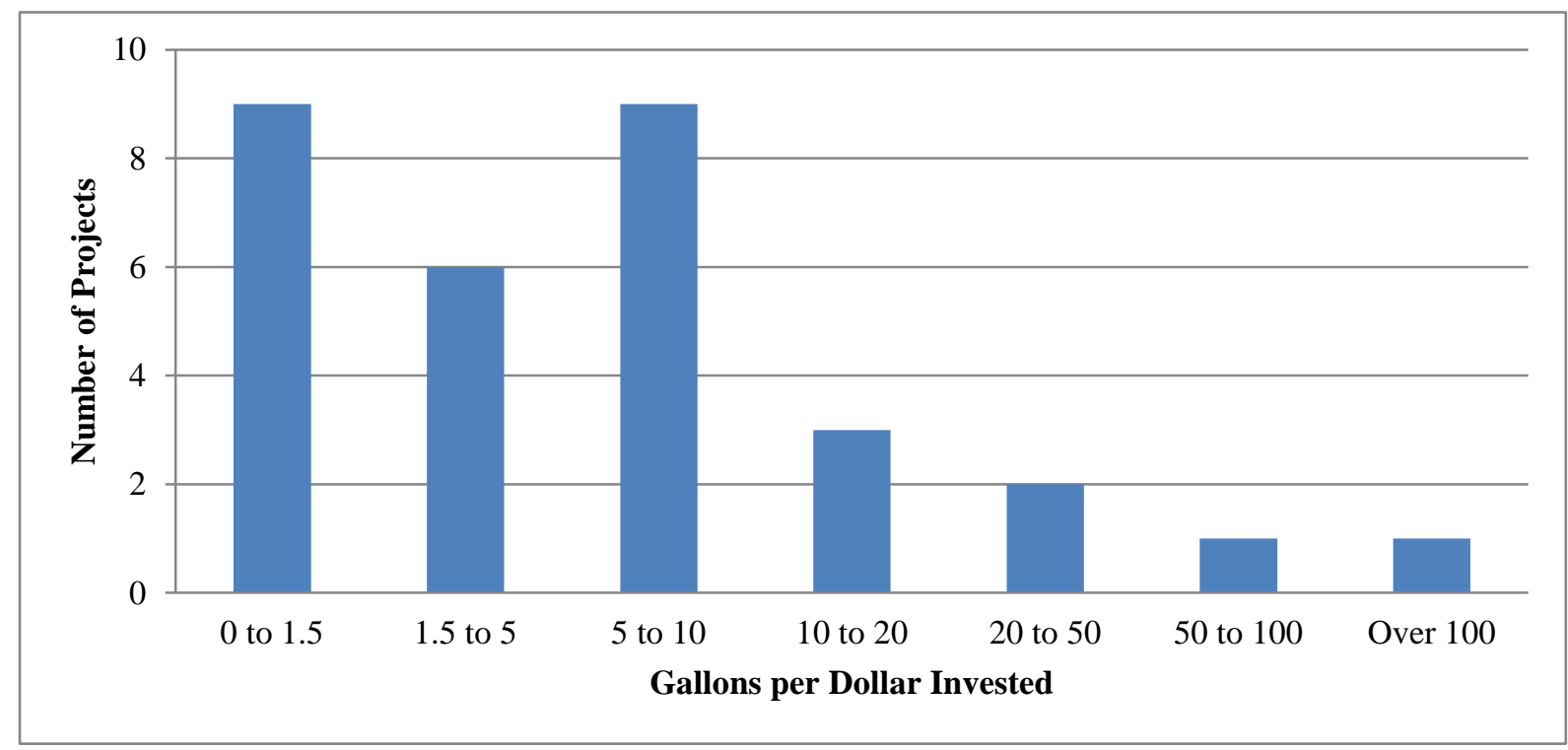

Figure 6.22. Number of Projects versus Range of Gallons Saved per Dollar Invested

\subsection{Savings Relative to Annual Energy and Water Use}

\subsubsection{Energy Savings as a Percent of Annual Energy Use}

While the goal of any energy conservation project is to maximize energy savings, examining savings relative to use provides a basis for normalizing those savings across ECMs and agencies. Several projects in CTS saved significant amounts of energy, but relative to the energy initially used by the facility the savings may not be as dramatic. One reason for this may be that many facilities have multiple buildings at their location and the projects may not have covered the entire facility.

Because energy use measurements are influenced by year-to-year differences in weather, energy use data reported in CTS was normalized to account for these differences each year in order to put energy-use and energy-savings estimates on a comparable basis. Table 6.16 gives the average annual energy savings relative to non-normalized and weather-normalized energy use by agency. This table illustrates the relatively small differences between the raw data and weather-normalized values. 
Table 6.16. Comparison of Average Annual Savings Relative to Non-Normalized and WeatherNormalized Energy Use

Average Annual Energy Savings Relative to Use for Non-Normalized and Weather-Normalized Use Data (\%)

\begin{tabular}{lrr}
\multicolumn{1}{r}{ Agency } & Non-Normalized & Weather-Normalized \\
\hline DOJ & 42.4 & 42.3 \\
NASA & 30.6 & 31.2 \\
USPS & 25.9 & 25.9 \\
DHS & 24.6 & 24.7 \\
TREASURY & 16.6 & 16.8 \\
USDA & 13.3 & 13.0 \\
GSA & 13.0 & 13.2 \\
STATE & 11.4 & 11.2 \\
DOT & 6.9 & 6.9 \\
TVA & 6.4 & 6.4 \\
EPA & 5.4 & 5.6 \\
NRC & 4.3 & 4.2 \\
HHS & 3.2 & 3.2 \\
SSA & 2.6 & 2.6 \\
DOE & 2.0 & 2.0 \\
DOI & 1.9 & 1.9 \\
DOD & 1.6 & 1.6 \\
VA & 0.9 & 1.0 \\
DOL & 0.5 & 0.5 \\
\hline
\end{tabular}

Figure 6.23 shows the percentage of energy savings relative to initial energy use for the projects entered into CTS. Over $60 \%$ of all projects analyzed saved less than $5 \%$ of the facility's annual energy use. The mean and median percentages of decreased energy consumption for all projects are $9.8 \%$ and $1.4 \%$, respectively. The mean is heavily influenced by the relatively few projects that have higher energy savings relative to use.

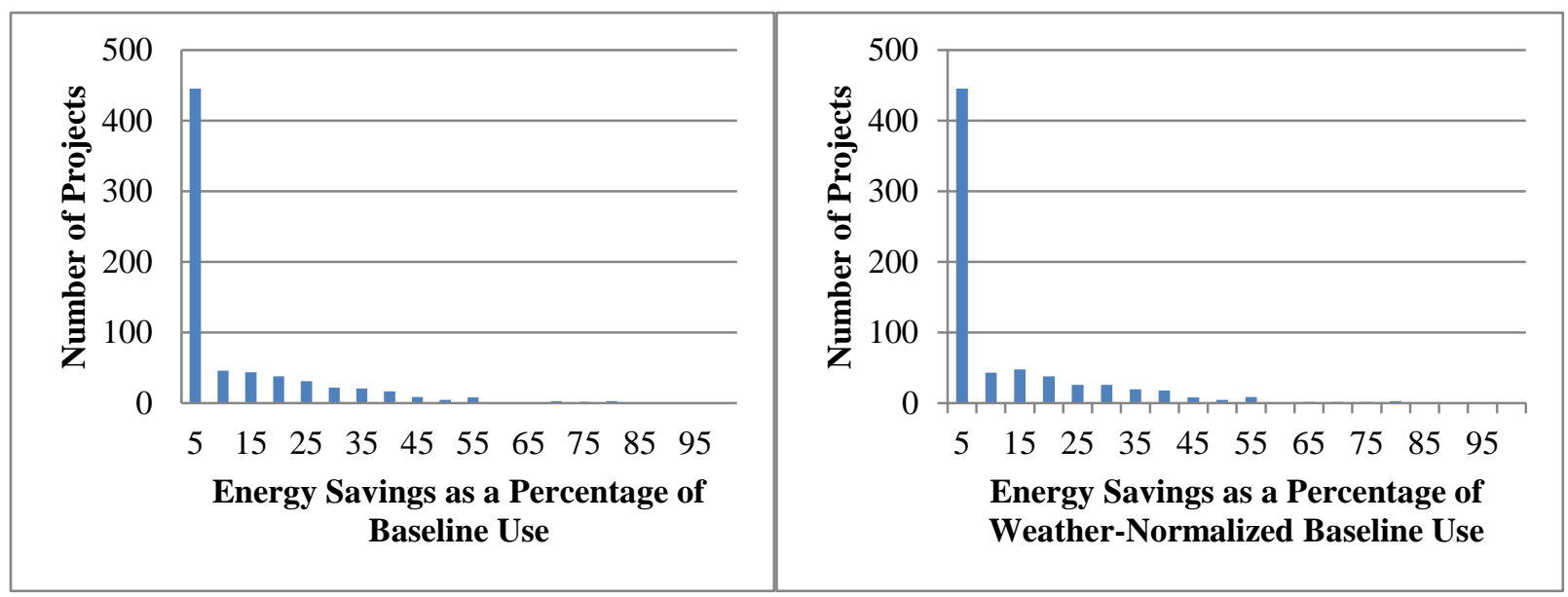

Figure 6.23. Energy Savings Relative to Annual Baseline (left) and Weather-Normalized (right) Energy Use for All Energy Projects 
As illustrated in Figure 6.23 there are no appreciable differences between the weather-normalized and non-normalized savings as a percentage of use. Henceforth, weather-normalized data are used in the analysis of energy savings as a percentage of use.

\subsubsection{Energy Savings Relative to Annual Energy Use by ECM}

Figure 6.24 shows the average percentage of energy savings relative to annual energy use overlaid on the distribution of all energy saving single-ECM projects. Note that there are numerous factors that influence savings relative to use values for single-ECM versus multiple-ECM projects.

Lighting ECMs have the highest ratio of energy savings relative to baseline energy use at $10 \%$, followed by EMCS. Plug Load ECMs had the lowest savings-to-use ratios at $0.2 \%$.

In general, ECMs with higher average savings also vary more widely across all single-ECM projects that implemented that ECM. For example, Lighting has the highest mean, but there are several projects with very high savings, which pull the overall mean upward. Savings over 50\% may reflect data quality issues that could not be resolved by agencies during quality checks by the research team. Table 6.17 gives the number of observations and mean percentage savings by ECM.

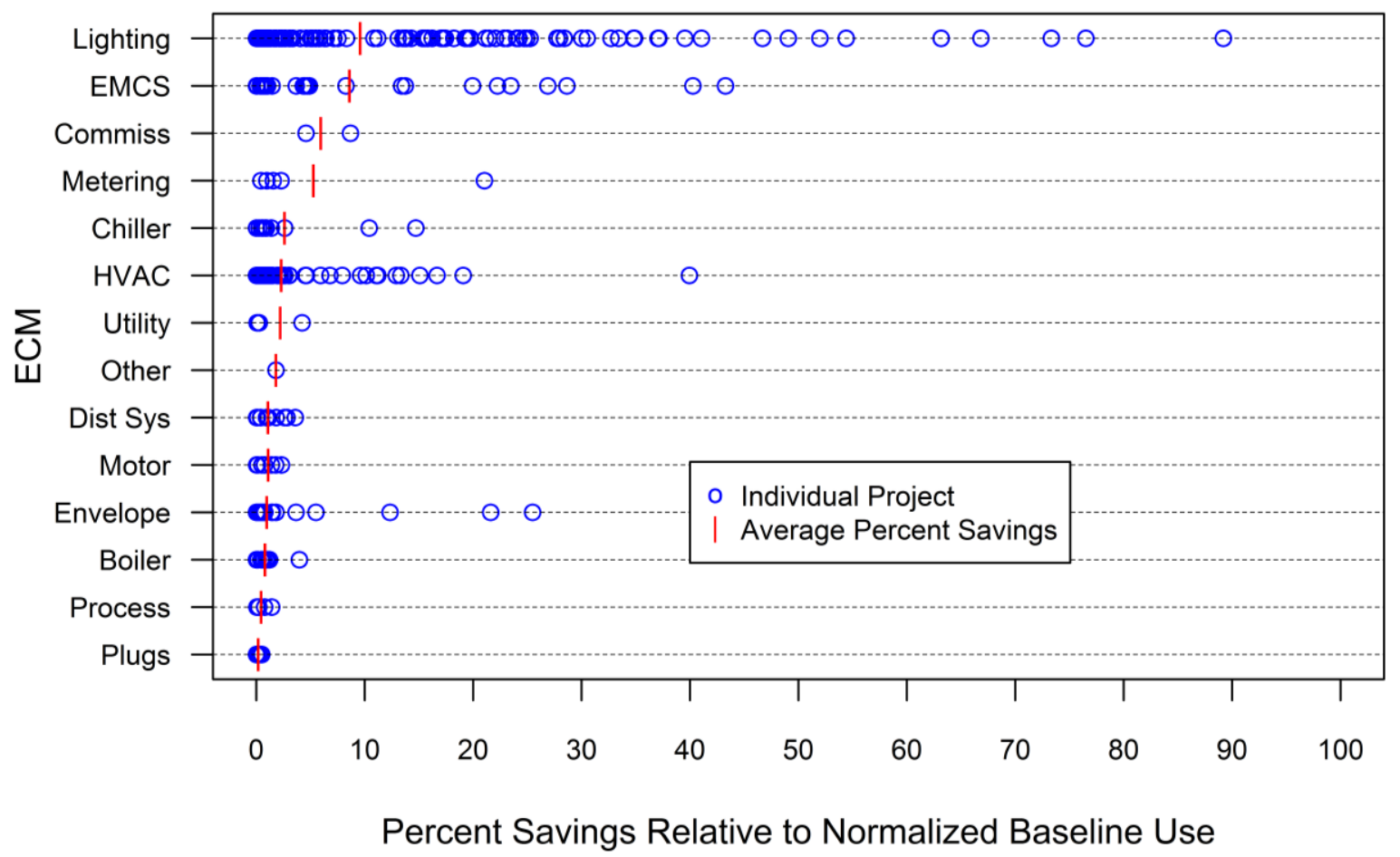

Figure 6.24. Distribution of the Ratio of Energy Savings to Energy Use by ECM Type 
Table 6.17. Energy Savings as a Percentage of Normalized Baseline Use for Single-ECM Projects

\begin{tabular}{lcc}
\hline ECM Type & $\begin{array}{c}\text { Number of } \\
\text { Projects }\end{array}$ & $\begin{array}{c}\text { Average Savings as a } \\
\text { Percent of Facility } \\
\text { Energy Use }\end{array}$ \\
\hline Lighting & 197 & 9.6 \\
EMCS & 32 & 8.6 \\
Commiss & 3 & 5.9 \\
Metering & 5 & 5.3 \\
Chiller & 13 & 2.6 \\
HVAC & 105 & 2.3 \\
Utility & 4 & 2.2 \\
Other & 1 & 1.8 \\
Dist Sys & 13 & 1.1 \\
Motor & 8 & 1.1 \\
Envelope & 87 & 1.0 \\
Boiler & 18 & 0.8 \\
Process & 6 & 0.4 \\
Plugs & 9 & 0.2 \\
\hline
\end{tabular}

\subsubsection{Energy Savings Relative to Annual Energy Use by Agency}

Because there are varying uses for different agencies' buildings, it is expected that agencies' savings as a percentage of baseline energy use may differ significantly among agencies. Figure 6.25 gives the distribution of energy savings as a percentage of use by agency, with averages overlaid, in the facilities where projects were implemented. Note that several agencies, including DOJ, NASA, USPS, and DHS, implemented projects that save, on average, over 20 percent of their facility baseline energy use. At the other end of the spectrum, many projects save only 5\% (or less) of their facility's baseline use energy use.

The agency with the highest savings as a percentage of baseline use was DOJ, which had only 13 implemented projects. The ECMs implemented were primarily Building Envelope, HVAC, and Lighting. In contrast, the agency with the lowest percentage of energy savings relative to baseline use-DOLrecorded 156 projects in CTS, but many of these projects were known to have used conservative estimates of energy savings when no project-level estimates were available. In general, agencies with higher average savings also vary more in terms of percent savings; however, this trend is not as distinct as it is for savings relative to use by ECM type. Note that while DOJ and DHS appear to have the highest percent savings, there are very few observations that support the average being so high. Conversely, although the percent savings shown for USPS are relatively variable, there is a significant amount of data that supports a relatively high average. Table 6.18 gives the number of observations and average values for the agencies in this analysis. 


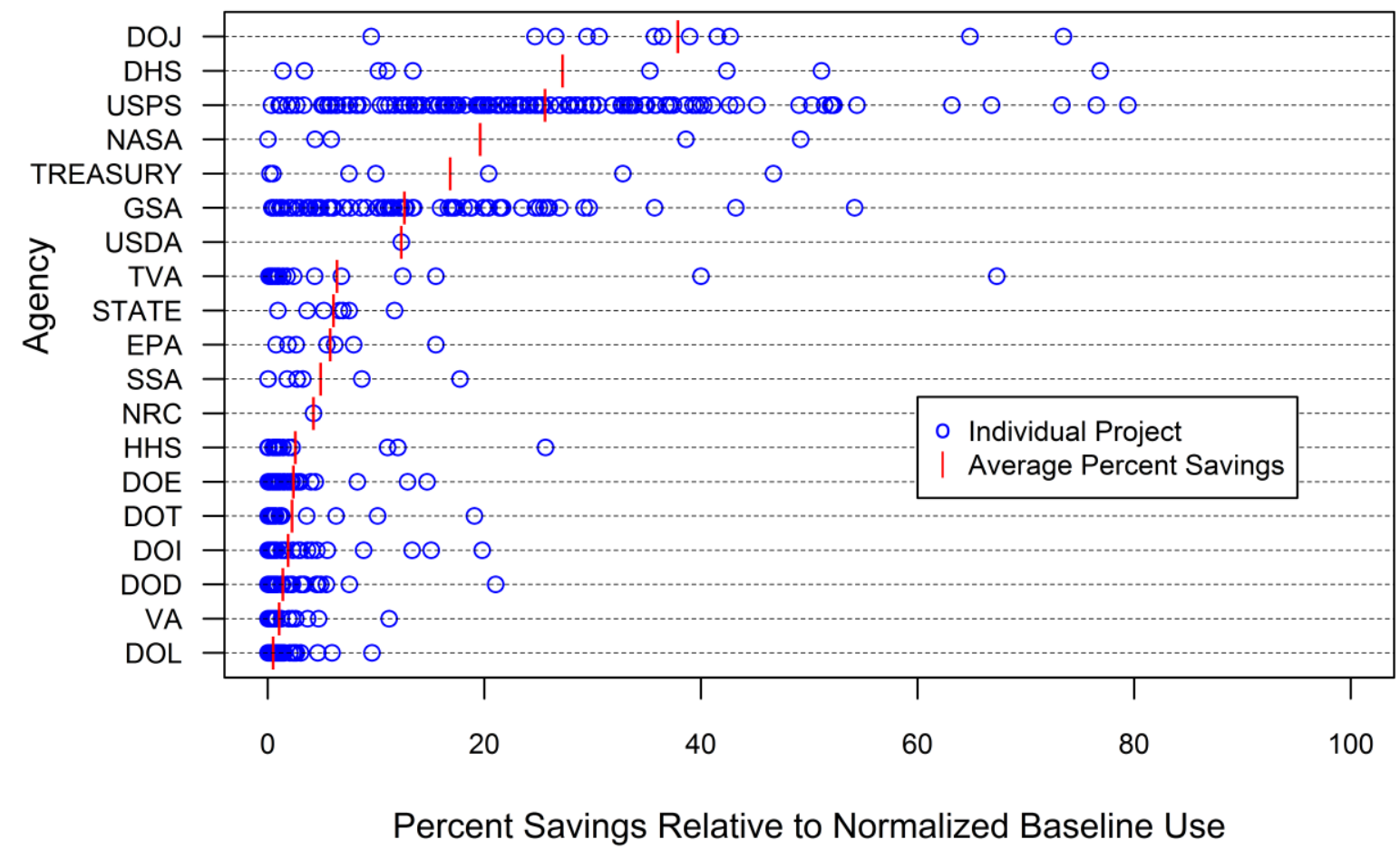

Figure 6.25. Distribution of Energy Savings Relative to Annual Normalized Baseline Energy Use, by Agency

Table 6.18. Percentage of Energy Savings Relative to Normalized Baseline Energy Use, by Agency

\begin{tabular}{lrr}
\hline Agency & $\begin{array}{c}\text { Number } \\
\text { of Projects }\end{array}$ & $\begin{array}{c}\text { Average Savings } \\
\text { as a Percent of } \\
\text { Energy Use }\end{array}$ \\
\hline DOJ & 12 & 37.9 \\
DHS & 9 & 27.2 \\
USPS & 138 & 25.6 \\
NASA & 5 & 19.6 \\
TREASURY & 7 & 16.9 \\
GSA & 78 & 12.6 \\
USDA & 1 & 12.3 \\
TVA & 25 & 6.4 \\
STATE & 7 & 6.1 \\
EPA & 7 & 5.8 \\
SSA & 7 & 4.9 \\
NRC & 1 & 4.2 \\
HHS & 25 & 2.5 \\
DOE & 32 & 2.4 \\
DOT & 21 & 2.2 \\
DOI & 52 & 1.9 \\
DOD & 71 & 1.4 \\
VA & 34 & 1.1 \\
DOL & 155 & 0.5 \\
\hline
\end{tabular}




\subsubsection{Water Savings Relative to Annual Water Use}

A subset of the implemented projects that reported water savings also reported annual water use. For the 42 projects for which both values were reported, the ratio of water savings to the baseline water use was evaluated. Figure 6.26 below shows the water savings as a percentage of the baseline water use for implemented projects. The average water savings across all 42 projects is $19.5 \%$ of total water use in those facilities.

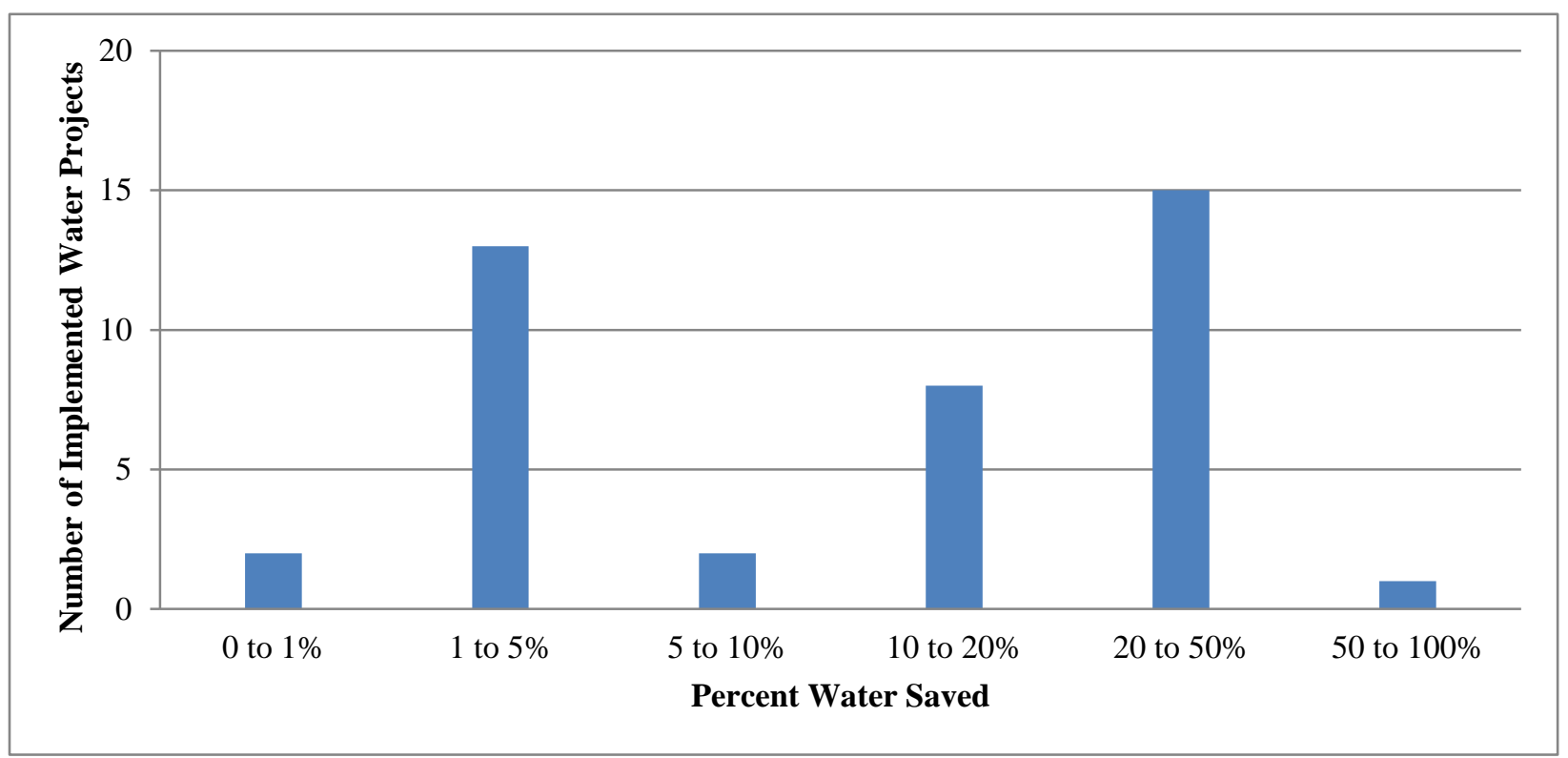

Figure 6.26. Water Savings Relative to Baseline Use

As noted above, it is difficult to draw conclusions about water savings based on the data currently available in CTS. The primary limitation is the lack of information regarding what type of water conservation project has been implemented. Recommendations are made at the end of this report suggesting possible enhancements to the reporting process for water ECMs. Reporting of data at the building level and occupancy information would also be useful for normalizing water savings across projects and agencies.

\subsection{Life-Cycle Cost Economics}

Life-cycle cost analysis is used to calculate several economic performance measures for evaluation of potential and implemented projects. This analysis examines the life-cycle cost (LCC), life-cycle benefit (LCB), net savings, savings-to-investment ratio (SIR), and adjusted internal rate of return (AIRR) for implemented projects with single-ECM types only.

In the context of this study, LCB represents the present value of future energy savings induced by the ECM. It is calculated as a product of annual cost of saved energy as of the base year (including produced thermal output and renewable electricity) and FEMP fuel-adjusted uniform present value factors, also referred to as fuel-adjusted escalation rates. Net savings is the difference between LCB and LCC, where LCC is calculated as a total cost of project implementation and financing. SIR uses the same inputs as net savings, but LCB is divided by LCC. In order for the project to be considered cost-effective, SIR should 
be greater than 1. Net savings and SIR are relative economic performance indicators and should be used only in a comparative context.

AIRR is another relative measure of cost-effectiveness. It shows annual percentage yield over the ECM lifetime. In order for the project to be cost-effective, the annual percentage yield should be higher than the discount rate. For this analysis, the DOE discount rate of $3 \%$ is assumed. If AIRR equals the discount rate, the project breaks even.

Additional assumptions about equipment lifetime and discount rate are necessary to calculate LCC. Agencies have the option of reporting LCC savings for projects in CTS; however these estimates were only provided for $44 \%$ of the projects in CTS. The missing values were filled in using the FEMP Handbook on $\mathrm{LCC}^{27}$ for discounting fuel-related savings, as well as recommendations by the National Institute of Standards and Technology (NIST). Several projects in CTS assumed a life of 40-49 years, which is an unusually long life for an ECM. Those entries were adjusted to assume a 30-year lifetime in order to comply with the NIST requirements regarding the discounting period (lack of specific details about each of those ECMs prevents equipment replacement tracking). For the entries where lifetime was not specified, average lifetime across the corresponding ECM was assumed.

LCC and LCB are estimated based on the weighted average that accounts for typical fuel shares across buildings as suggested by the 2003 Commercial Building Energy Consumption Survey (CBECS) ${ }^{28}$ Since electricity constitutes $52 \%$ of the sector energy consumption, followed by natural gas (33\%), the fuel prices and escalation rates were scaled accordingly. An average weighted price of $\$ 21.27$ per MMBtu was assumed for this analysis when an ECM could reduce either electricity or natural gas. An electricityspecific price of \$0.1012 per kWh was used for ECM's that would only save electricity, including Lighting, Chiller, Motor, and Plug Load ECMs. A natural gas price of \$7.87 per MMBtu was used for Boiler improvement projects. Discounting is implemented using the federal fuel-adjusted escalation rates, which are based on the DOE discount rate of 3\%. Additional results for high and low cases are included in Appendix C.

\subsubsection{Economic Performance Indicators by ECM}

Key results of the LCC analysis by ECM are presented in this section. The results were obtained first by averaging the LCC and LCB across similar ECMs. Averaged LCC and LCB were then used to derive the other standard economic indicators for each ECM type.

Several projects in CTS had significant financing costs; therefore results with and without the cost of financing (Table 6.19 and Table 6.20) and the comparative AIRR ranking (Table 6.21) are included below. Values in green are considered cost effective based on the criteria described below, whereas values in red are cost ineffective. The ECMs highlighted in red in the first table and green in the second reflect measures that are cost ineffective when financing costs are considered but cost effective when financing costs are excluded from the analysis.

\footnotetext{
${ }^{27}$ NIST Handbook 135, Life-Cycle Costing Manual for the Federal Energy Management Program, 1995 edition. Available at http://www.nist.gov/customcf/get_pdf.cfm?pub_id=907459.

${ }^{28}$ EIA - US Energy Information Administration Commercial Building Energy Consumption Survey (2003 Edition). Accessed at http://www.eia.gov/consumption/commercial/.
} 
Table 6.19. Average Economic Performance Indicators by ECM Type ${ }^{29}$ Including Financing Cost

\begin{tabular}{lrrrrr}
\hline ECM Type & \multicolumn{1}{c}{$\begin{array}{c}\text { Life-cycle } \\
\text { Benefit }(\$)\end{array}$} & $\begin{array}{c}\text { Location-Adjusted } \\
\text { Investment }(\$)\end{array}$ & $\begin{array}{c}\text { Net Savings } \\
(\$)\end{array}$ & $\begin{array}{c}\text { Savings-to- } \\
\text { Investment Ratio }\end{array}$ & $\begin{array}{c}\text { Adjusted Internal } \\
\text { Rate of Return }\end{array}$ \\
\hline Commiss & $8,441,711$ & $2,053,604$ & $6,388,107$ & 4.11 & $19 \%$ \\
EMCS & $4,423,204$ & $1,322,088$ & $3,101,117$ & 3.35 & $11 \%$ \\
Renewable & $134,663,627$ & $25,272,100$ & $109,391,572$ & 5.33 & $11 \%$ \\
Dist Gen & $1,140,968$ & 197,665 & 943,304 & 5.77 & $10 \%$ \\
Lighting & 632,577 & 332,605 & 299,972 & 1.90 & $7 \%$ \\
Meter & $8,472,775$ & $4,046,647$ & $4,426,128$ & 2.09 & $7 \%$ \\
Utility & 267,073 & 149,999 & 117,074 & 1.78 & $3 \%$ \\
Other & 4,987 & 5,358 & $(\$ 370)$ & 0.93 & $2 \%$ \\
Dist Sys & $16,171,604$ & $21,397,510$ & $(\$ 5,225,906)$ & 0.76 & $1 \%$ \\
Motor & $1,668,115$ & $2,284,258$ & $(\$ 616,143)$ & 0.73 & $-1 \%$ \\
Chiller & $2,793,226$ & $6,008,089$ & $(\$ 3,214,863)$ & 0.46 & $-4 \%$ \\
HVAC & 267,765 & 826,706 & $(\$ 558,940)$ & 0.32 & $-4 \%$ \\
Process & 874,087 & $5,578,280$ & $(\$ 4,704,193)$ & 0.16 & $-5 \%$ \\
Plugs & 15,707 & 49,117 & $(\$ 33,410)$ & 0.32 & $-6 \%$ \\
Envelope & 127,103 & 528,727 & $(\$ 401,625)$ & 0.24 & $-10 \%$ \\
Boiler & 536,381 & $5,476,869$ & $(\$ 4,940,489)$ & 0.10 & 3.05 \\
\hline Totals & $4,536,882,120$ & $1,486,601,443$ & $3,050,280,677$ & & $3.4 \%$ \\
\hline
\end{tabular}

Table 6.20. Average Economic Performance Indicators by ECM Type, Excluding Financing Cost

\begin{tabular}{lrrrrr}
\hline ECM Type & $\begin{array}{c}\text { Life-cycle Benefit } \\
(\$)\end{array}$ & $\begin{array}{c}\text { Location- } \\
\text { Adjusted } \\
\text { Investment }(\$)\end{array}$ & Net Savings (\$) & $\begin{array}{c}\text { Savings-to- } \\
\text { Investment } \\
\text { Ratio }\end{array}$ & $\begin{array}{c}\text { Adjusted } \\
\text { Internal Rate of } \\
\text { Return }\end{array}$ \\
\hline Commiss & $8,441,711$ & $2,053,604$ & $6,388,107$ & 4.11 & $19 \%$ \\
EMCS & $4,423,204$ & 575,150 & $3,848,054$ & 7.69 & $17 \%$ \\
Renewable & $134,663,672$ & $7,602,674$ & $127,060,998$ & 17.71 & $17 \%$ \\
Dist Gen & $1,140,968$ & 197,665 & 943,304 & 5.77 & $10 \%$ \\
Meter & $8,472,775$ & $2,219,330$ & $6,253,445$ & 3.82 & $10 \%$ \\
Lighting & 632,577 & 255,254 & 377,323 & 2.48 & $9 \%$ \\
Dist Sys & $16,171,604$ & $6,161,158$ & $10,010,446$ & 2.62 & $7 \%$ \\
Motor & $1,668,115$ & 754,762 & 913,353 & 2.21 & $7 \%$ \\
Utility & 267,073 & 149,999 & 117,074 & 1.78 & $6 \%$ \\
Chiller & $2,793,226$ & $1,838,027$ & 955,199 & 1.52 & $5 \%$ \\
Other & 4,987 & 5,358 & $(370)$ & 0.93 & $3 \%$ \\
Process & 874,087 & $1,606,136$ & $(732,049)$ & 0.54 & $1 \%$ \\
HVAC & 267,765 & 400,903 & $(133,138)$ & 0.67 & $0 \%$ \\
Boiler & 536,381 & $1,639,457$ & $(1,103,076)$ & 0.33 & $-4 \%$ \\
Plugs & 15,707 & 49,112 & $(33,405)$ & 0.32 & $-5 \%$ \\
Envelope & 127,103 & 528,727 & $(401,625)$ & 0.24 & $-6 \%$ \\
\hline Totals & $4,536,882,120$ & $534,961,041$ & $4,001,921,080$ & 8.48 & $17.6 \%$ \\
\hline
\end{tabular}

\footnotetext{
${ }^{29}$ Because there were only four water-only projects, the water ECM was not studied.
} 
Table 6.21. Comparative AIRR Ranking by ECM Type with and without Financing

\begin{tabular}{lcc}
\hline ECM Type & $\begin{array}{c}\text { AIRR Ranking } \\
\text { with Financing }\end{array}$ & $\begin{array}{c}\text { AIRR Ranking } \\
\text { without Financing }\end{array}$ \\
\hline Commiss & 1 & 1 \\
EMCS & 2 & 2 \\
Renewable & 3 & 3 \\
Dist Gen & 4 & 4 \\
Lighting & 5 & 6 \\
Meter & 6 & 5 \\
Utility & 7 & 9 \\
Other & 8 & 11 \\
Dist Sys & 9 & 7 \\
Motor & 10 & 8 \\
Chiller & 11 & 10 \\
HVAC & 12 & 13 \\
Process & 13 & 12 \\
Plugs & 14 & 15 \\
Envelope & 15 & 16 \\
Boiler & 16 & 14 \\
\hline
\end{tabular}

While traditional LCC is used to compare several alternative projects at one facility, this analysis is focused on comparing similar ECMs across multiple facilities, taking into account the geographic regions of the ECMs. As a result, the investment cost was scaled according to the regional pricing factors for a consistent comparison basis. Similarly, adjusted national fuel prices were used to derive the LCC and net savings estimates.

Net savings are estimated by subtracting total LCC (regionally adjusted) from the LCB. Out of the 16 ECM types analyzed in single-ECM projects, only seven had positive net savings on average (across all facilities and projects) when financing cost is taken into account. The Renewables ECM shows the highest net savings, because benefit calculation included annual thermal output, as well as annual renewable electricity output. When financing costs are excluded from the analysis, 10 out of $16 \mathrm{ECM}$ types have positive net savings. Distribution Systems, Motor, and Chiller ECMs have positive net savings once financing cost is removed from the analysis.

An SIR above 1 generally indicates that the project is cost-effective. For example, the SIR for Lighting is 1.90 (including financing), which implies that all projects of this ECM type return $\$ 1.90$ for every dollar invested. When financing cost is included, the most cost-effective ECMs based on the SIR are Distributed Generation and Renewables, followed by Commissioning and EMCS. The average SIR across all single-ECM projects combined is 2.4 when financing is taken into account and 6.9 when financing cost is removed from calculation.

The AIRR should be greater than the assumed discount rate (3\%) in order for the ECM to be considered cost-effective. When financing cost is included, AIRR is greater than the $3 \%$ discount rate for Commissioning, EMCS, Renewables, Distributed Generation, Lighting Metering, and Utility and ECMs. These are the same set of ECMs that have an SIR ratio above 1 and a positive net savings. Average AIRR rates for cases with and without financing across all analyzed ECMs are $8 \%$ and 14\%, respectively.

Excluding the financing cost from the total cost calculation had the most impact on Distribution Systems, Motor and Chiller ECMs, which switched from being cost-ineffective to cost-effective with an 
SIR of 2.62, 2.21 and 1.52 respectively, and an AIRR well above 3\%, as indicated in Table 6.20. HVAC, Process, Plug Load, Envelope, and Boiler ECMs appeared to be below desired levels of SIR and AIRR in both cases.

\subsubsection{Economic Performance Indicators by Agency}

A similar analysis was performed across ECMs, but grouped by agency. Economic performance results are presented below by agency, both with and without financing included in the total cost (Table 6.22 and Table 6.23). Note that no LCC analysis is presented for STATE or DOJ because they did not have single-ECM projects reported in CTS.

Table 6.22. Average Economic Performance Indicators by Agency, Including Financing Cost

\begin{tabular}{|c|c|c|c|c|c|}
\hline Agency & $\begin{array}{l}\text { Life-cycle Benefit } \\
(\$)\end{array}$ & $\begin{array}{c}\text { Location- } \\
\text { Adjusted } \\
\text { Investment }(\$)\end{array}$ & Net Savings (\$) & $\begin{array}{l}\text { Savings-to- } \\
\text { Investment } \\
\text { Ratio }\end{array}$ & $\begin{array}{c}\text { Adjusted } \\
\text { Internal Rate of } \\
\text { Return }\end{array}$ \\
\hline SSA & $9,198,311$ & 411,504 & $8,786,807$ & 22.35 & $22 \%$ \\
\hline TREASURY & $4,446,307$ & 467,954 & $3,978,353$ & 9.50 & $21 \%$ \\
\hline DHS & $42,722,588$ & $4,601,060$ & $38,121,529$ & 9.29 & $15 \%$ \\
\hline DOD & $1,615,882$ & 560,694 & $1,055,188$ & 2.88 & $10 \%$ \\
\hline USPS & 663,507 & 256,033 & 407,475 & 2.59 & $10 \%$ \\
\hline DOE & $111,621,052$ & $35,903,262$ & $75,717,789$ & 3.11 & $8 \%$ \\
\hline DOT & 663,984 & 344,013 & 319,971 & 1.93 & $7 \%$ \\
\hline NRC & 730,830 & 235,443 & 495,386 & 3.10 & $7 \%$ \\
\hline TVA & 336,150 & 183,066 & 153,084 & 1.84 & $7 \%$ \\
\hline VA & 306,770 & 241,510 & 65,260 & 1.27 & $4 \%$ \\
\hline HHS & 480,769 & 396,181 & 84,588 & 1.21 & $4 \%$ \\
\hline EPA & 766,254 & 728,374 & 37,880 & 1.05 & $3 \%$ \\
\hline DOI & 291,812 & 302,753 & $(10,941)$ & 0.96 & $3 \%$ \\
\hline DOL & 36,990 & 49,427 & $(12,437)$ & 0.75 & $1 \%$ \\
\hline USDA & $1,154,361$ & $2,866,569$ & $(1,712,208)$ & 0.40 & $0 \%$ \\
\hline GSA & $2,218,444$ & $9,946,937$ & $(7,728,493)$ & 0.22 & $-5 \%$ \\
\hline NASA & 16,693 & 59,664 & $(42,972)$ & 0.28 & $-9 \%$ \\
\hline Totals & $4,536,882,120$ & $1,486,601,443$ & $3,050,280,677$ & 3.05 & $10.39 \%$ \\
\hline
\end{tabular}


Table 6.23. Average Economic Performance Indicators by Agency, Excluding Financing Cost

\begin{tabular}{lrrrrr}
\hline \multicolumn{1}{c}{ Agency } & \multicolumn{1}{c}{$\begin{array}{c}\text { Life-cycle } \\
\text { Benefit }(\$)\end{array}$} & $\begin{array}{c}\text { Location- } \\
\text { Adjusted } \\
\text { Investment }(\$)\end{array}$ & $\begin{array}{c}\text { Net Savings } \\
(\$)\end{array}$ & $\begin{array}{c}\text { Savings-to- } \\
\text { Investment Ratio }\end{array}$ & $\begin{array}{c}\text { Adjusted } \\
\text { Internal Rate of } \\
\text { Return }\end{array}$ \\
\hline SSA & $9,198,311$ & 411,504 & $8,786,807$ & 22.35 & $22 \%$ \\
TREASURY & $4,446,307$ & 373,374 & $4,072,933$ & 11.91 & $22 \%$ \\
DHS & $42,722,588$ & $3,452,581$ & $39,270,007$ & 12.37 & $17 \%$ \\
DOE & $111,621,052$ & $10,258,075$ & $101,362,977$ & 10.88 & $15 \%$ \\
DOD & $1,615,882$ & 560,694 & $1,055,188$ & 2.88 & $10 \%$ \\
USPS & 663,507 & 256,033 & 407,475 & 2.59 & $7 \%$ \\
DOT & 663,984 & 344,013 & 319,971 & 1.93 & $7 \%$ \\
NRC & 730,830 & 235,443 & 495,386 & 3.10 & $7 \%$ \\
TVA & 336,150 & 183,066 & 153,084 & 1.84 & $4 \%$ \\
VA & 306,770 & 235,820 & 70,950 & 1.30 & $3 \%$ \\
HHS & 480,769 & 396,181 & 84,588 & 1.21 & $3 \%$ \\
EPA & 766,254 & 728,374 & 37,880 & 1.05 & $1 \%$ \\
DOI & 291,812 & 302,753 & $(10,941)$ & 0.96 & $0 \%$ \\
DOL & 36,990 & 49,427 & $(12,437)$ & 0.75 & $-5 \%$ \\
USDA & $1,154,361$ & $2,866,569$ & $(1,712,208)$ & 0.40 & $-9 \%$ \\
GSA & $2,218,444$ & $9,946,937$ & $(7,728,493)$ & 0.22 & $17.63 \%$ \\
NASA & 16,693 & 59,664 & $(42,972)$ & 0.28 & 8.48 \\
\hline Total & $4,536,882,120$ & $534,961,041$ & $4,001,921,080$ & & \\
\hline
\end{tabular}

Using the same assumptions as were applied to the ECM analysis, the project data was organized by agency to derive average economic performance indicators. When financing cost is taken into account, the agencies with the highest net savings are DOE, DHS, SSA and Treasury. Their average SIRs range between 3 and 22 dollars of return per dollar invested, with a SIR of 1 being generally a breaking point for cost-effectiveness.

For the case without financing, the SIR increases significantly for DOE (from 3.11 to 10.88), DHS (from 9.29 to 12.37), and Treasury (from 9.85 to 11.91). The highest increase in SIR is observed for DOE because of the biomass project with significant financing. Whether financing for the biomass project is taken into account or not, DOE is well above the SIR-based threshold for cost-effectiveness. In the case that includes the cost of financing, DOE is closely followed by NRC with a SIR of 3.10. The group with the next highest SIR consists of DOD with a SIR of 2.88 and USPS with a SIR of 2.59. It is followed by DOT, TVA, VA, HHS and EPA with SIRs ranging between 1.93 and 1.05. SIR ordering remains the same when financing is excluded from the computation. The SIR for the rest of the agencies is below 1 irrespective of financing.

As was noted in the ECM comparison, in order for the project to be considered cost-effective, AIRR should be equal or greater than the DOE FEMP discount rate of 3\%. When financing is taken into account, the agencies with the highest AIRRs are SSA (22\%), Treasury (21\%), DHS (15\%), DOD and USPS (both at 10\%), and DOE (8\%). They are followed by DOT, NRC and TVA (about 7\% each), VA and HHS (both at 4\%), and EPA (3\%). For the remaining agencies, AIRR is below the desired 3\% threshold with or without financing cost in the calculation.

Another potential issue that may be impacting the apparent cost-effectiveness of agency investment is individual projects that are very large and not cost-effective, which are skewing the agency average results. For example, the DOI has two projects with large losses that skew the results for the rest of the projects across the agency. It should also be noted that traditional LCC metrics are not suitable for all of 
the agencies. For example, for DOJ, the significant increase in prison population density is not taken into account by any of the standard comparative metrics. The population density data is not reported in the CTS to allow for normalization. EPA and GSA also have a small number of projects that drive down the average LCC results for the whole agency. Additional issues might arise from the fact that there was a group of entries removed from the analysis because either cost or savings data were missing.

\subsection{GHG Emissions Avoided}

Executive Order (E.O.) 13514 expanded the energy reduction and reporting requirements under EISA and other federal mandates by making GHG management a priority for federal agencies. This part of the analysis examines the impact that federal investments in energy efficiency projects have had on agency GHG emissions.

To calculate GHG emissions using estimated project energy savings, those savings estimates must be disaggregated by fuel source because GHG emission factors vary by fuel type. Because agencies have the option of entering estimated annual energy savings by fuel type or by the total MMBtu, savings estimates by fuel type are not available for all projects. Projects with estimated energy savings by fuel type represent $67 \%$ (2,865,950 MMBtu) of total estimated energy savings (see Table 6.24). Eight of the 19 agencies with energy savings reported all energy savings by fuel type, and as a result will have more accurate GHG savings estimates. For the $33 \%$ of energy savings that are not associated with a fuel source, the average energy consumption ratios for U.S. residential and commercial buildings in 2010 were applied to provide estimates of fuel use by major fuel source (e.g., electricity, natural gas, coal). ${ }^{30}$

\footnotetext{
${ }^{30}$ Estimates came from Table 1.1.1 of the U.S. Department of Energy's Building Energy Data Book 2011 (March 2012). Available at: http://buildingsdatabook.eren.doe.gov/TableView.aspx?table=1.1.1.
} 
Table 6.24.Estimated Annual Energy Savings (MMBtu) by Agency with Known and Unspecified Fuel Sources

\begin{tabular}{lrrrr}
\hline Agency & $\begin{array}{r}\text { Total Annual } \\
\text { Energy Savings }\end{array}$ & $\begin{array}{r}\text { Fuel Source } \\
\text { Known }\end{array}$ & $\begin{array}{r}\text { Fuel Source Not } \\
\text { Specified }\end{array}$ & $\begin{array}{c}\text { \% of Total Energy } \\
\text { Use with Fuel } \\
\text { Source Known }\end{array}$ \\
\hline All Agencies & $\mathbf{4 , 2 8 0 , 3 8 1}$ & $\mathbf{2 , 8 6 5 , 9 5 0}$ & $\mathbf{1 , 4 1 4 , 4 3 1}$ & $\mathbf{6 7 \%}$ \\
DHS & 213,920 & 30,736 & 183,184 & $14 \%$ \\
DOD & 443,974 & 31,128 & 412,846 & $7 \%$ \\
DOE & $1,076,883$ & $1,076,883$ & - & $100 \%$ \\
DOI & 21,823 & 6,587 & 15,236 & $30 \%$ \\
DOJ & 752,930 & 752,930 & - & $100 \%$ \\
DOL & 24,642 & - & 24,642 & $0 \%$ \\
DOT & 221,379 & 12,094 & 209,285 & $5 \%$ \\
EPA & 41,327 & - & 41,327 & $0 \%$ \\
GSA & 465,466 & - & 465,466 & $0 \%$ \\
HHS & 73,091 & 43,786 & 29,305 & $60 \%$ \\
NASA & 280,793 & 280,793 & - & $100 \%$ \\
NRC & 1,741 & 1,741 & - & $43 \%$ \\
SSA & 53,384 & 22,995 & 30,389 & $100 \%$ \\
STATE & 44,502 & 44,502 & - & $100 \%$ \\
TREASURY & 121,071 & 121,071 & - & $100 \%$ \\
TVA & 33,361 & 33,361 & - & $95 \%$ \\
USDA & 54,220 & 51,470 & 2,750 & $100 \%$ \\
USPS & 325,034 & 325,034 & - & $100 \%$ \\
VA & 30,840 & 30,840 & - & \\
\hline
\end{tabular}

Emission factors were then applied to those fuel savings estimates by fuel type based on established methodologies for federal GHG accounting. ${ }^{31}$ While most fuel types have a single emission factor regardless of where the fuel is combusted, electricity emissions vary depending on the region of the electric grid where the electricity was saved. Electricity savings were mapped to grid regions based on facility zip code when the fuel sources was specified, then the appropriate regional grid emission factors from EPA's eGRID database were applied. ${ }^{32}$

Based on this calculation, an estimated 485,070 metric tons of Scope 1 and $2 \mathrm{CO}_{2}$ equivalent $\left(\mathrm{MTCO}_{2} \mathrm{e}\right)$ were avoided by federal agencies as a result of energy efficiency investments reported in CTS since 2008. This represents approximately one percent of government-wide GHG emissions, which were estimated at 47.2 million $\mathrm{MTCO}_{2} \mathrm{e}$ based on FY 2011 reporting. ${ }^{33}$ As illustrated in Figure 6.27 and Figure 6.28 below, the majority of those emissions are the result of electricity savings (75\%), followed by natural gas savings (14\%).

\footnotetext{
${ }^{31}$ FEMP - Federal Energy Management Program. 2012. Federal Greenhouse Gas Accounting and Reporting Guidance. Revision 1: June 4, 2012. Available at: http://www.whitehouse.gov/sites/default/files/microsites/ceq/revised_federal_greenhouse_gas_accounting_and_repo rting_guidance_060412.pdf

${ }_{32}$ Emission factors from eGRID2012 were used. For more information on eGRID, go to: http://www.epa.gov/cleanenergy/energy-resources/egrid/index.html.

${ }^{33}$ Annual Energy/GHG Data Reports submitted to FEMP by federal agencies.
} 


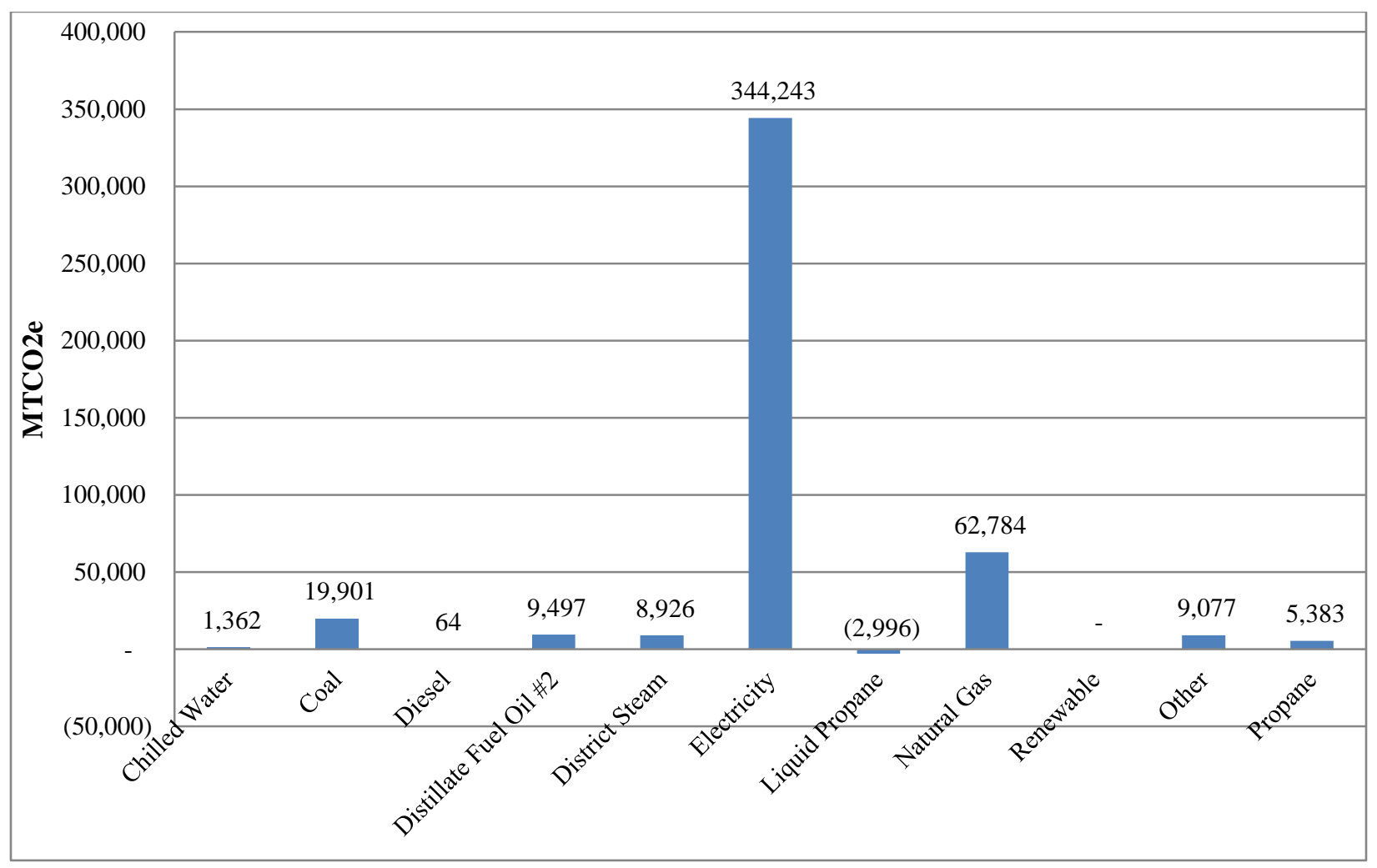

Figure 6.27. Estimated Annual Government-wide GHG Emissions Avoided by Fuel Source

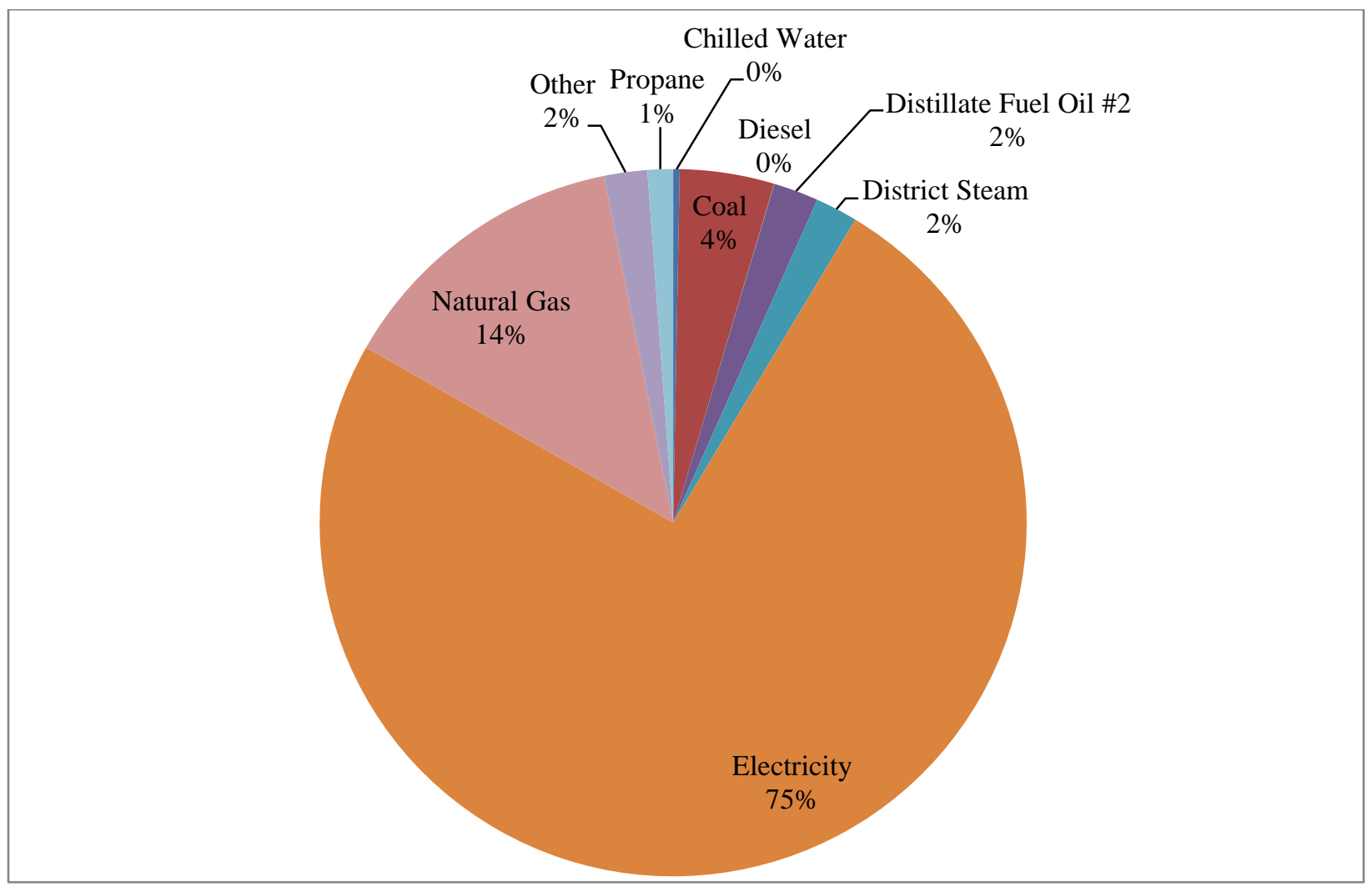

Figure 6.28. Estimated Proportion of Annual Government-wide GHG Emissions Avoided by Fuel Type 
Figure 6.29 below shows GHG emissions avoided by agency based on the reported fuel types. For the nine agencies that reported all project energy savings by fuel type (underlined in red), this represents total GHG emissions avoided by CTS projects. For the other agencies, this presents a partial picture of GHG emissions avoided. Estimates were made for the remainder in aggregate, so are not included in this figure by agency. While most agencies' avoided GHG emissions come predominantly from electricity savings, this figure shows that coal represents a substantial source of savings for DOE and natural gas represents a substantial portion of avoided emissions for DOJ. The major source of coal savings was from two large biomass and steam plant projects in the Southeast.

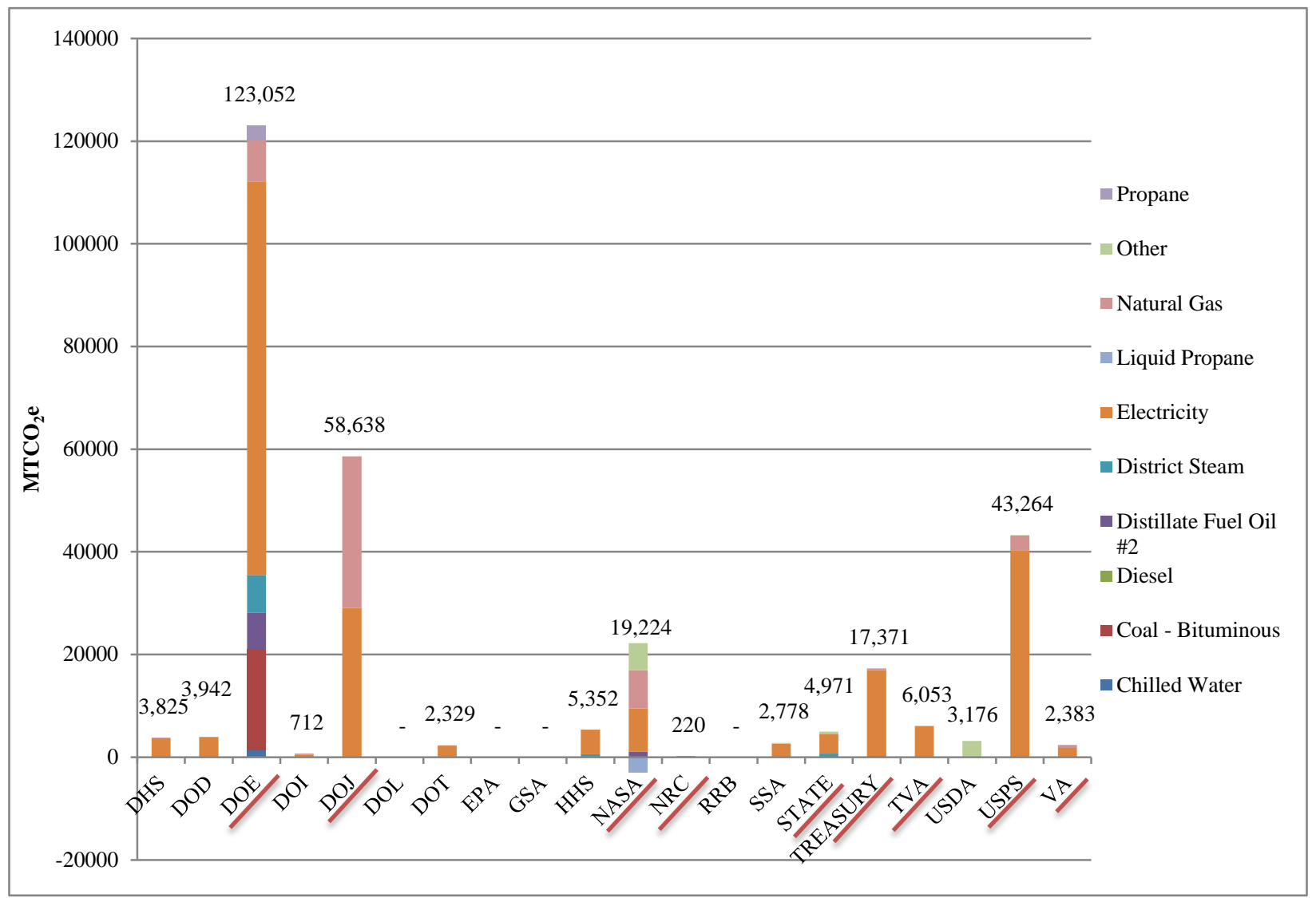

Figure 6.29. GHG Emissions Avoided by Agency for Projects with Known Fuel Sources. Red arrows indicate agencies with complete estimates of all avoided GHG emissions due to reporting by fuel type.

Because fuel types and regions of the grid differ in terms of their contributions to GHG emissions, energy savings from more carbon-intensive fuels will have a greater GHG reduction impact. Figure 6.28 below illustrates that while electricity represents $56 \%$ of energy savings, those savings represent a much greater proportion of total GHG emissions avoided (76\%). This is primarily because energy savings reflect site-delivered Btu for electricity rather than the Btu used to generate the electricity. Approximately $70 \%$ of Btus used to generate the delivered heat content of a $\mathrm{kWh}$ of electricity is lost during the conversion process and through transmission and distribution losses. A portion of electricity savings is also probably coming from coal-intensive grid regions, which may contribute to this difference. 
\% of Energy Savings

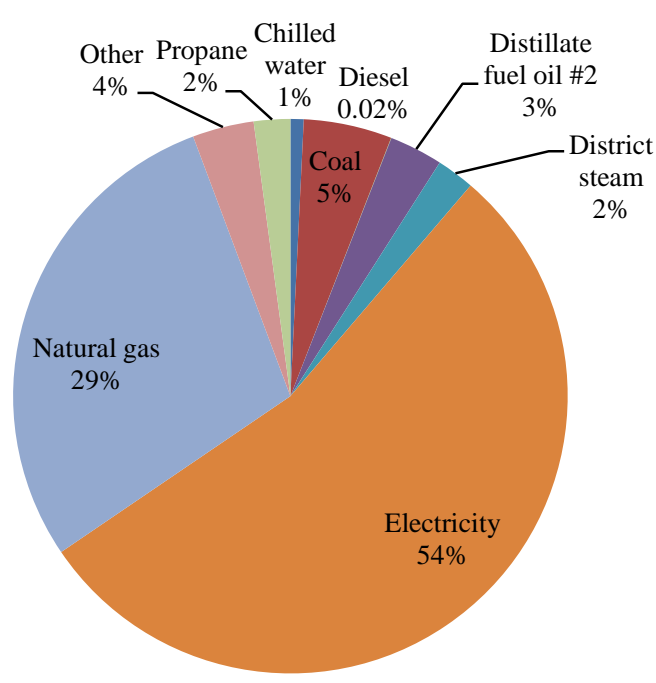

\% of GHG Emissions Avoided

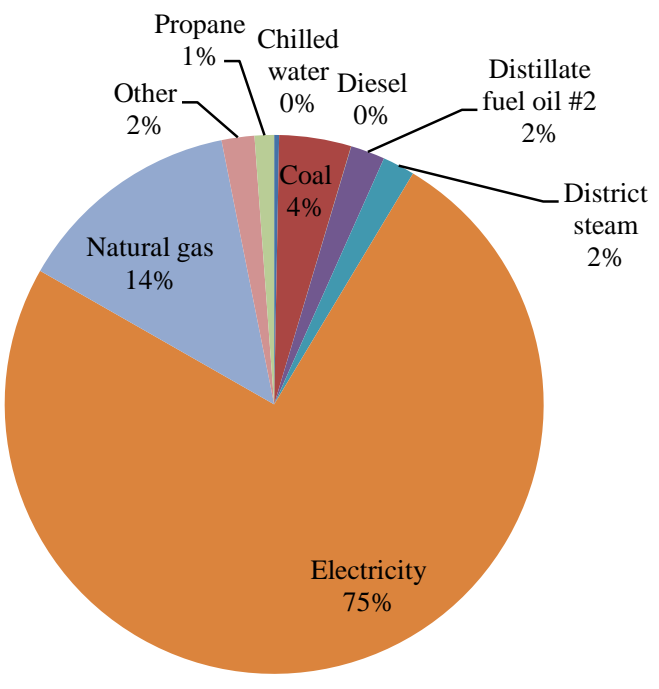

Figure 6.30. Comparison of Annual Estimated Energy Savings (left) and GHG Emissions Avoided (right) by Fuel Type as a Percentage of Total Annual Savings and Emissions Avoided (estimates are for savings reported by fuel source only)

Figure 6.31 summarizes electricity savings from projects reporting savings by fuel type against the eGRID subregion. Nearly a third of the 200,615 $\mathrm{MTCO}_{2} \mathrm{e}$ avoided by electricity savings (for projects that specified fuel sources only) were in the SERC Reliability Corporation (SERC) Tennessee Valley region, and $19 \%$ of the GHGs avoided came from a single $\$ 3.5$ million DOE project to deploy a building automation system in this region. This is a comparatively carbon-intensive subregion, which probably contributed to the high emissions avoided from electricity savings. Six of the 26 eGRID subregions did not have any project savings reported in CTS (HICC Miscellaneous, HICC Oahu, RFC Michigan, SERC Midwest, and NPCC Long Island). 


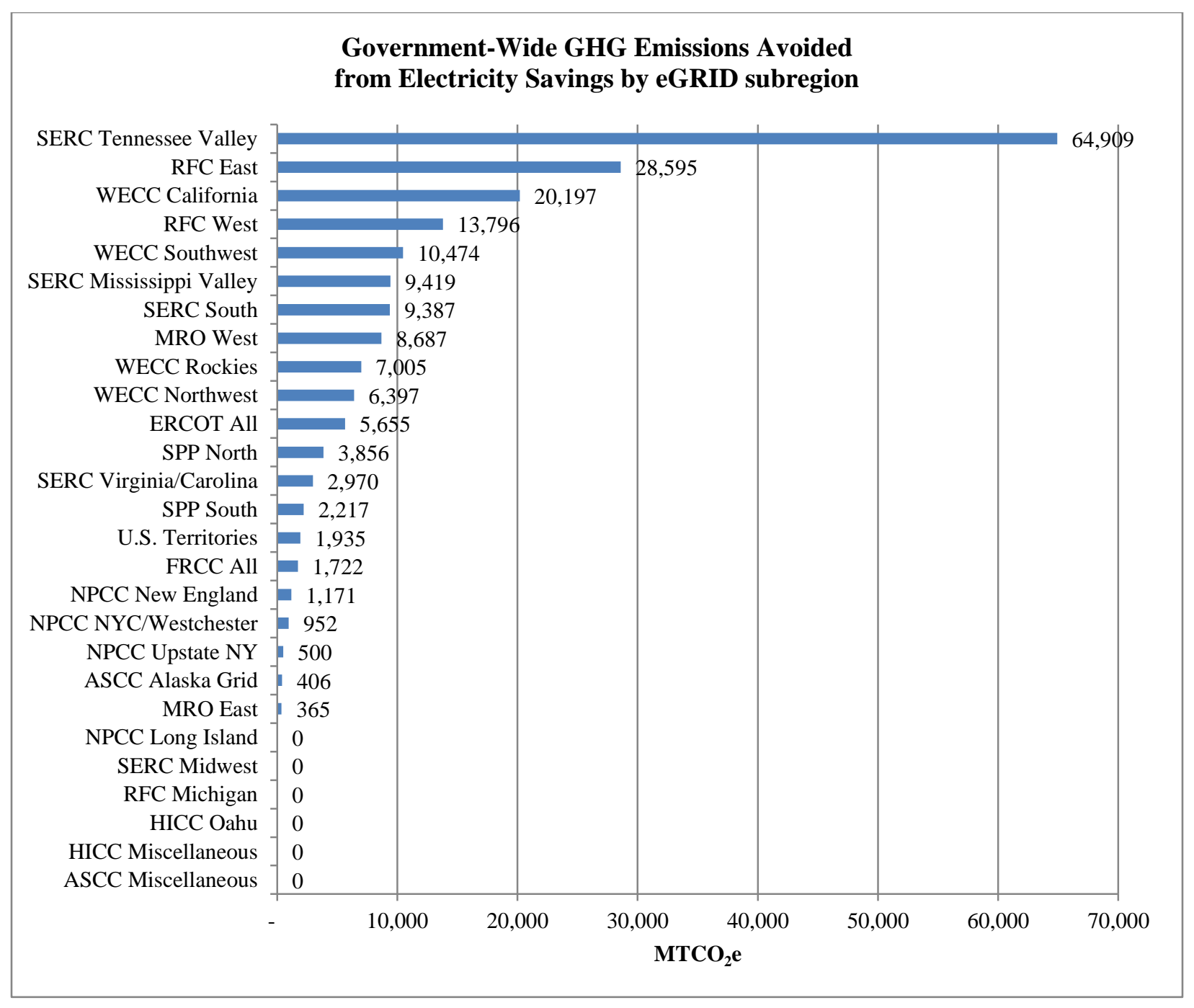

Figure 6.31. Government-wide GHG Emissions Avoided from Electricity Savings by eGRID Subregion $^{34}$

${ }^{34}$ Abbreviations are defined in the Acronyms and Abbreviations list, which follows the Executive Summary 


\subsection{Building Energy Performance}

Five specific energy use intensity (EUI) analyses were undertaken on the CTS. First, the reported average EUI for agency covered facilities in CTS was compared to typical EUI data for various building types and to the average EUI for agencies as included in FEMP's 2011 Report to Congress. ${ }^{35}$ Second, changes over time in EUI for covered facilities were examined, both for all facilities and by agency. Third, agency estimates of the EUI savings reduction expected from evaluations was examined. Fourth, EUI savings achieved in projects was examined. And fifth, the EUI reductions estimated in the evaluations and achieved in projects was compared to the FY 2011 agency average EUI.

\subsection{EUI Ranges by Agency}

In the first EUI analysis, EUI ranges by agency for covered facilities were determined. While facilities are not directly comparable to individual buildings, it would be expected that federal facilities would fall into the range of EUIs associated with the federal buildings that make up those facilities. While no source of federal building EUI data is known, commercial-sector building EUI data is available from DOE's Buildings Energy Data Book ${ }^{36}$, which lists commercial building EUIs by building type estimated from the 2003 CBECS. This table is simplified in Table 7.1 below by combining the vintage categories in Table 3.1.9 into a single upper and lower bound.

Table 7.1. Simplified Version of Table 3.1.9 of DOE's Building Energy Data Book-Commercial Building EUIs $\left(\mathrm{kBtu} / \mathrm{ft}^{2}\right)$

\begin{tabular}{lrr}
\hline Building Type & $\begin{array}{c}\text { Lower End of EUI } \\
\text { Range }\left(\mathrm{kBtu} / \mathrm{ft}^{2}\right)\end{array}$ & $\begin{array}{c}\text { Upper End of EUI } \\
\text { Range }\left(\mathrm{kBtu} / \mathrm{ft}^{2}\right)\end{array}$ \\
\hline Health Care & 84 & 255 \\
Food Sales & 197 & 206 \\
Lodging & 88 & 112 \\
Office & 88 & 94 \\
Mercantile & 80 & 104 \\
Education & 78 & 89 \\
Service & 62 & 86 \\
Food Service & 145 & 361 \\
Religious Worship & 40 & 47 \\
Public Order and Safety & 101 & 111 \\
Warehouse and Storage & 33 & 39 \\
Public Assembly & 62 & 120 \\
Vacant & 21 & 23 \\
Other & 125 & 205 \\
\hline
\end{tabular}

Table 7.2 shows the minimum, average, and maximum EUIs (in $\mathrm{kBtu} / \mathrm{ft}^{2}$ ) reported by each agency in CTS for FY 2011. Agencies are listed in terms of average EUI. The covered facility agency average EUI column was calculated based on the total agency energy usage and total agency square footage in CTS as

\footnotetext{
${ }^{35}$ Federal Energy Management Program. 2012. FY 2011 Federal Energy Management Report to Congress. Provided in E-mail message from Chris Tremper, Federal Energy Management Program, to Kathleen Judd and Emily Wendel, Pacific Northwest National Laboratory, October 24, 2012.

${ }^{36}$ DOE - U.S. Department of Energy. March 2012. Buildings Energy Data Book 2011. Table 3.1.9. Accessed at http://buildingsdatabook.eere.energy.gov/docs/xls_pdf/3.1.9.xlsx.
} 
reported in Table 4.1. The unadjusted and adjusted ${ }^{37}$ agency average EUI columns are taken from the 2011 FEMP Report to Congress. ${ }^{38}$

Table 7.2. Minimum, Average, and Maximum EUI $\left(\mathrm{kBtu} / \mathrm{ft}^{2}\right)$ Reported in FY 2011 by Agency

\begin{tabular}{|c|c|c|c|}
\hline Agency & $\begin{array}{c}\text { CTS Covered } \\
\text { Facility FY } 2011 \\
\text { Average EUI } \\
\left(\mathrm{kBtu} / \mathrm{ft}^{2}\right) \\
\end{array}$ & $\begin{array}{c}\text { Unadjusted } \\
\text { Agency FY } 2011 \\
\text { Average EUI } \\
\left(\mathrm{kBtu} / \mathrm{ft}^{2}\right) \\
\end{array}$ & $\begin{array}{c}\text { Adjusted } \\
\text { Agency FY } 2011 \\
\text { Average EUI } \\
\left(\mathrm{kBtu} / \mathrm{ft}^{2}\right) \\
\end{array}$ \\
\hline All Agencies & 120 & 109 & 105 \\
\hline DHS & 96 & 104 & 102 \\
\hline DOC & 181 & 209 & 204 \\
\hline DOD & 102 & 104 & 100 \\
\hline DOE & 282 & 181 & 175 \\
\hline DOI & 83 & 66 & 64 \\
\hline DOJ & 139 & 140 & 139 \\
\hline DOL & 101 & 99 & 97 \\
\hline DOT & 171 & 76 & 75 \\
\hline EPA & 348 & 320 & 311 \\
\hline GSA & 100 & 68 & 62 \\
\hline HHS & 414 & 324 & 277 \\
\hline HUD & 74 & 74 & 72 \\
\hline NARA & 118 & 131 & 128 \\
\hline NASA & 184 & 184 & 177 \\
\hline NRC & 118 & N.A. & N.A. \\
\hline OPM & 76 & 84 & 83 \\
\hline RRB & 97 & N.A. & N.A. \\
\hline SI & 166 & N.A. & N.A. \\
\hline SSA & 130 & 125 & 122 \\
\hline STATE & 119 & 98 & 96 \\
\hline TREASURY & 170 & 159 & 155 \\
\hline TVA & 65 & 54 & 54 \\
\hline USACE & 197 & 81 & 81 \\
\hline USDA & 184 & 69 & 67 \\
\hline USPS & 126 & 81 & 81 \\
\hline
\end{tabular}

Comparing Table 7.1 and Table 7.2 points out a number of interesting features of the federal facility data in CTS:

1. A number of agencies have average covered facility EUIs that are higher than most of the commercial building EUIs listed in Table 7.1. This fact points out that not all federal facilities (or buildings) are adequately covered in the CBECS data. Federal facilities may contain buildings with very high EUIs

\footnotetext{
${ }^{37}$ Adjustments are with regard to renewable energy purchases and source savings.

${ }^{38}$ FY 2011 Federal Energy Management Report to Congress. Provided in E-mail message from Chris Tremper, Federal Energy Management Program, to Kathleen Judd and Emily Wendel, Pacific Northwest National Laboratory, October 24, 2012.
} 
due to the presence of large computer loads, large industrial loads or research-related loads, and these types of buildings are not always included in surveys of "typical commercial buildings." The average EUI for HHS (home to National Institutes of Health laboratories) and EPA and DOE (laboratoryintensive agencies) are all near the top of the list. USACE also has very high EUIs because of a series of locks and pumping stations with higher energy usage and low square footage. NASA (another laboratory/industrial-assembly-intensive agency) and VA (hospital intensive) are also towards the top of the list.

2. There is generally good agreement between the covered facility EUIs in Table 7.2 and the average EUIs rolled up at the agency level and reported in the 2011 FEMP Report to Congress. Some agencies, including DOE, DOT, EPA, HHS and USACE, do have much higher covered facility EUIs than the agency average EUIs. This may be due to these agencies focusing on their higher-EUI facilities as part of their covered facilities.

\subsection{Covered Facility EUI Changes Over Time}

In the second EUI analysis, the facility footprint data was also examined for trends in reported energy consumption over the four years of entries. EUI changes from 2010 to 2011 and from 2008 to 2011 were examined. Only a subset $(n=827)$ of the 7,000 facilities had the same footprint across all four years and more than half of these are in the USPS's portfolio. This subset of facilities was then used to compare the reported energy use of the facility from year to year. Overall, only a quarter of these facilities showed an improvement in their energy use values. USPS has identified quality issues with their energy use data reported during this period, which may be contributing to these increases, and is in the process of correcting these values.

Specific agency EUI changes from 2008 to 2011 are shown in Figure 7.1 and changes from 2010 to 2011are shown in Figure 7.2. The facility count represents the number of facilities that had consistent footprint data from the comparison year to 2011. The green bars show the percentage of the agency's facilities with a reduced EUI and the red bars show the percentage of agency facilities with an increased EUI. Just 3,515 facilities had consistent footprint data from 2010 to 2011 and could be compared; only 827 facilities had consistent footprint data from 2008 to 2011. 


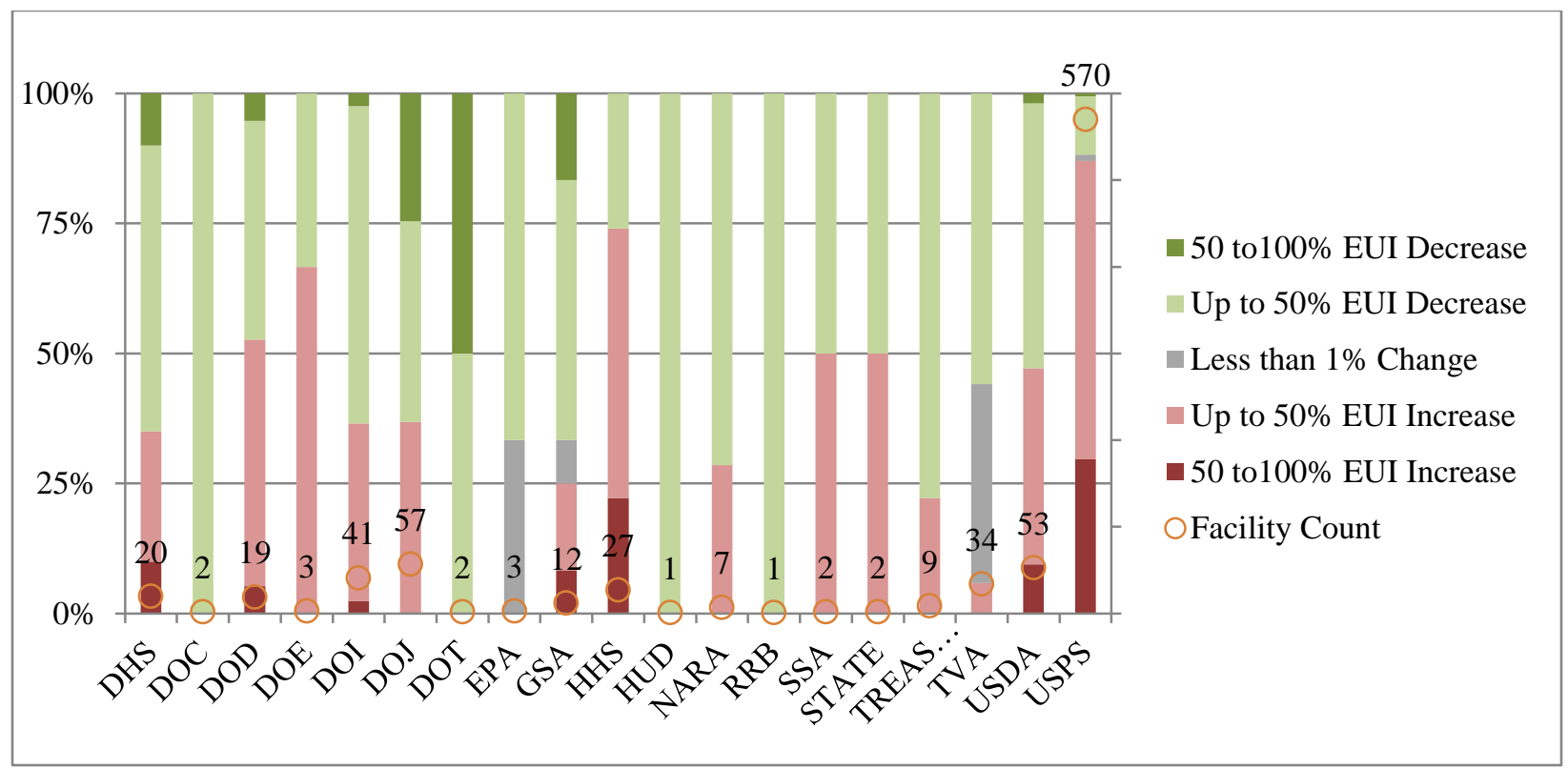

Figure 7.1. Comparison of EUI Changes from 2008 to 2011 by Agency

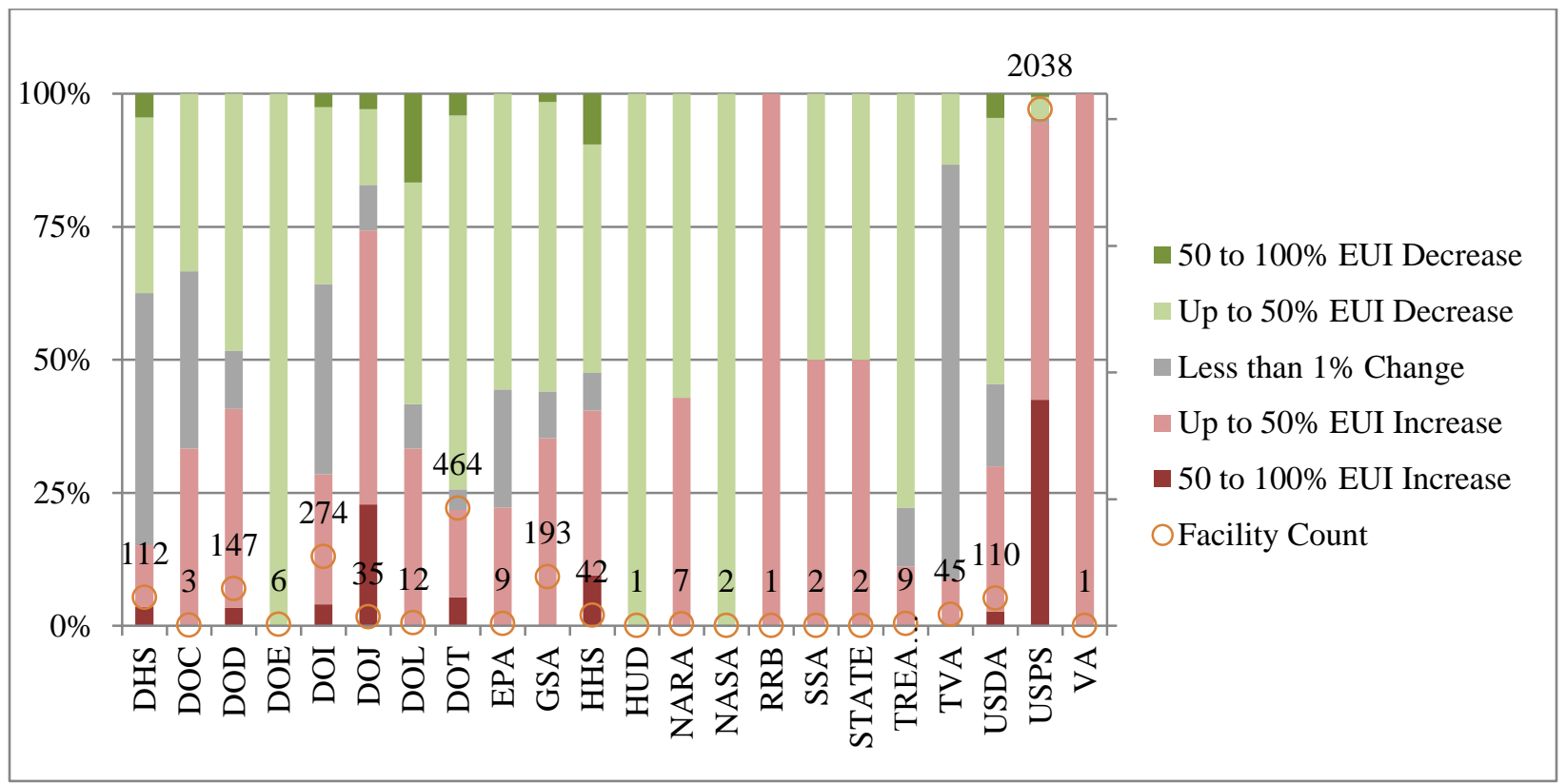

Figure 7.2. Comparison of EUI Changes from 2010 to 2011 by Agency

Overall, the EUI changes from year to year are fairly consistent except that the 2010 to 2011 comparison has a larger percentage of facilities with less than $1 \%$ change, which is expected for the tighter timeframe. Within each agency there is some variation of percentage of facilities with an EUI increase or decrease year to year. 


\subsection{Energy Savings per Square Foot for Evaluated ECMs}

In the third EUI analysis, estimates of EUI reductions were made based on the sum of energy savings potential reported for each agency's evaluated facilities (see Figure 7.3). Facilities that were not evaluated are not included in this estimate. EPA shows an EUI reduction of over 125, followed by DOE with an EUI reductions of over 75, while the Treasury Department and DOJ are the next highest with estimates over $50 \mathrm{kBtu} / \mathrm{ft}^{2}$.

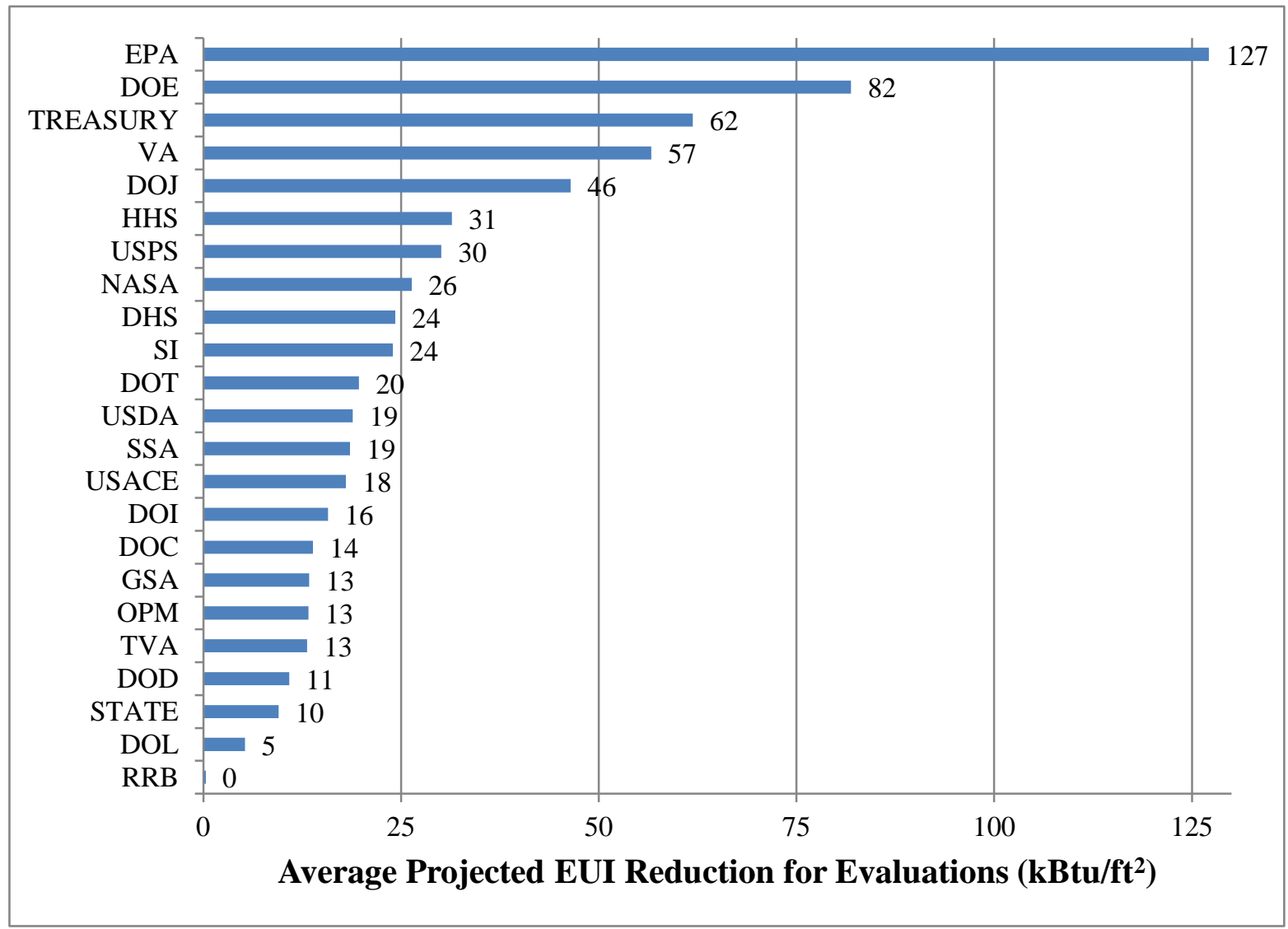

Figure 7.3. Average Projected EUI Reduction Estimates by Agency for Evaluated ECMs

\subsection{Energy Reduction per Square Foot for Implemented Projects}

In the fourth EUI analysis, estimates of reductions in EUI were made based on agency-estimated annual energy savings and renewable energy output from projects. The chart below shows the average potential reduction in EUI by agency in the covered facility in which the projects were done. DOJ's estimated annual energy savings per square foot of facility area was the highest at $49 \mathrm{kBtu} / \mathrm{ft}^{2}$. Many of DOJ's projects had high estimated savings amounts relative to the existing EUI of the covered facility; some projects were estimated to save more energy than the covered facility footprint energy usage. This also occurred in the DHS and NASA projects. Note that for DOL, when project-specific estimates were not available, conservative estimates of energy savings for ECM types were used by the agency, which may have contributed to their savings per square foot being unusually low. The average EUI savings are expected to be between 1 and 30\% depending on the type of retrofit and the existing facility energy 
consumption. ${ }^{39}$ This would equate to EUI savings between 1 and $36 \mathrm{kBtu} / \mathrm{ft}^{2}$ based on the agency average EUI of $120 \mathrm{kbtu} / \mathrm{ft}^{2}$ reported in Table 7.2 for "All Agencies." Of the agencies listed in

Figure 7.4, only DOJ is outside this range.

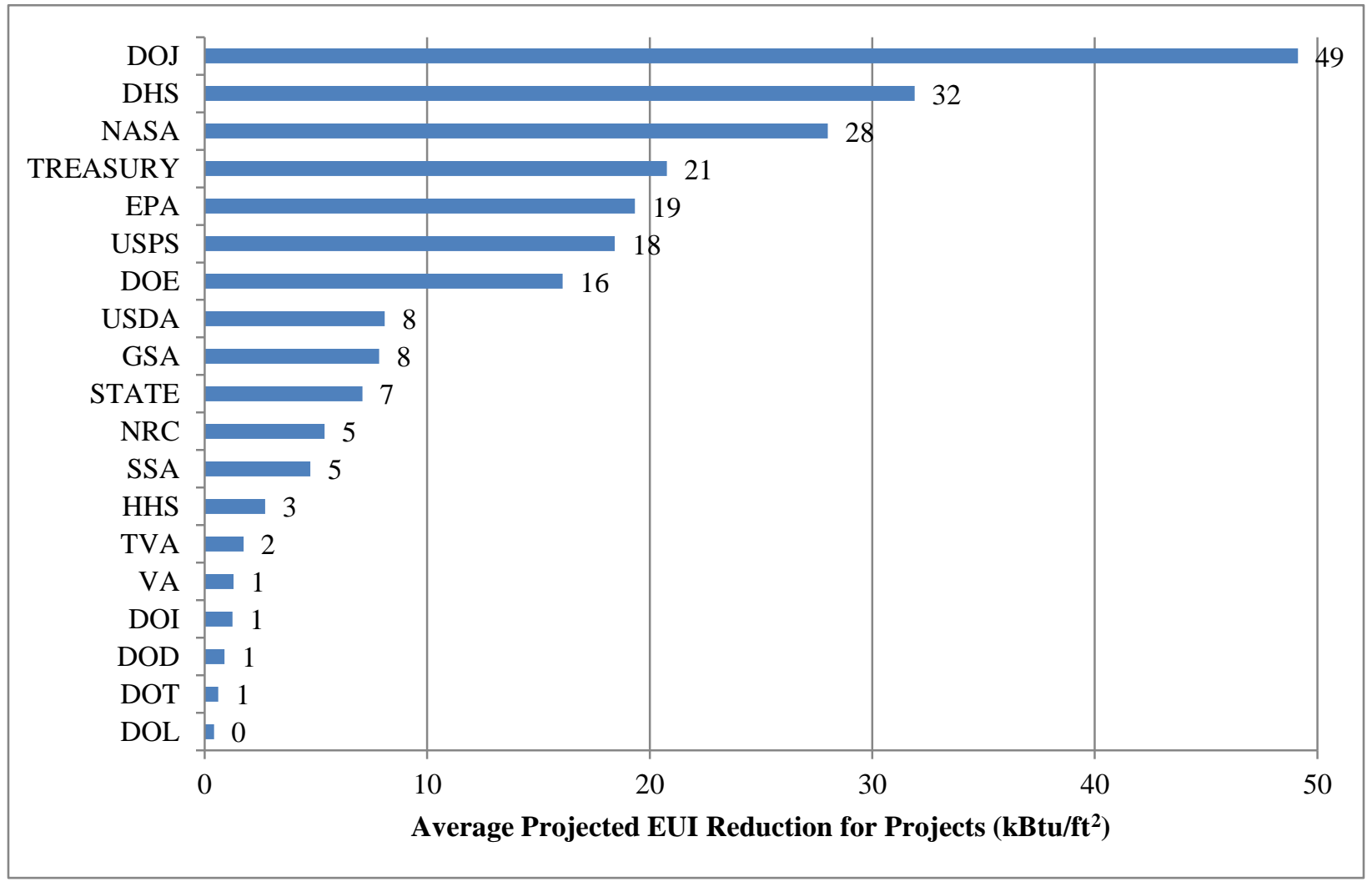

Figure 7.4. Average Projected EUI Reduction Estimates for Agencies for Active Projects

\subsection{Comparison of EUI Reductions to Facility EUls}

In the fifth and final EUI analysis, the average estimated EUI reduction from evaluations and the projected EUI reduction from projects were compared to the FY 2011 agency average EUI values. The results are shown in Table 7.3.

\footnotetext{
${ }^{39}$ PNNL- Pacific Northwest National Laboratory. 2011. Advanced Energy Retrofit Guides: Office Buildings. PNNL-20761. Pacific Northwest National Laboratory, Richland, Washington. Accessed at http://www.pnnl.gov/main/publications/external/technical_reports/pnnl-20761.pdf
} 
Table 7.3. Average EUI $\left(\mathrm{kBtu} / \mathrm{ft}^{2}\right)$ and Average EUI Reduction for Evaluations and Projects Reported in FY 2011 by Agency

\begin{tabular}{|c|c|c|c|c|c|}
\hline Agency & $\begin{array}{c}\text { Covered } \\
\text { Facility } \\
\text { FY2011 } \\
\text { Average EUI } \\
\left(\mathrm{kBtu} / \mathrm{ft}^{2}\right) \\
\end{array}$ & $\begin{array}{l}\text { Average EUI } \\
\text { Reduction } \\
\text { for } \\
\text { Evaluations }\end{array}$ & $\begin{array}{c}\text { Average EUI } \\
\text { Reduction for } \\
\text { Projects } \\
\left(\mathrm{kBtu} / \mathrm{ft}^{2}\right)\end{array}$ & $\begin{array}{l}\text { Average Percent } \\
\text { Reduction for } \\
\text { Evaluations }\end{array}$ & $\begin{array}{l}\text { Average Percent } \\
\text { Reduction for } \\
\text { Projects }\end{array}$ \\
\hline All Agencies & 120 & 18 & 6 & $15 \%$ & $5 \%$ \\
\hline DHS & 96 & 24 & 32 & $25 \%$ & $33 \%$ \\
\hline DOC & 181 & 14 & N.A. & $8 \%$ & N.A. \\
\hline DOD & 102 & 11 & 1 & $11 \%$ & $1 \%$ \\
\hline DOE & 282 & 82 & 16 & $29 \%$ & $6 \%$ \\
\hline DOI & 83 & 16 & 1 & $19 \%$ & $1 \%$ \\
\hline DOJ & 139 & 46 & 49 & $33 \%$ & $35 \%$ \\
\hline DOL & 101 & 5 & 0 & $5 \%$ & $0 \%$ \\
\hline DOT & 171 & 20 & 1 & $12 \%$ & $1 \%$ \\
\hline EPA & 348 & 127 & 19 & $36 \%$ & $5 \%$ \\
\hline GSA & 100 & 13 & 8 & $13 \%$ & $8 \%$ \\
\hline HHS & 414 & 31 & 3 & $7 \%$ & $1 \%$ \\
\hline HUD & 74 & N.A. & N.A. & N.A. & N.A. \\
\hline NARA & 118 & N.A. & N.A. & N.A. & N.A. \\
\hline NASA & 184 & 26 & 28 & $14 \%$ & $15 \%$ \\
\hline NRC & 118 & N.A. & 5 & N.A. & $4 \%$ \\
\hline OPM & 76 & 13 & N.A. & $17 \%$ & N.A. \\
\hline RRB & 97 & 0 & N.A. & $0 \%$ & N.A. \\
\hline SI & 166 & 24 & N.A. & $14 \%$ & N.A. \\
\hline SSA & 130 & 19 & 5 & $15 \%$ & $4 \%$ \\
\hline STATE & 119 & 10 & 7 & $8 \%$ & $6 \%$ \\
\hline TREASURY & 170 & 62 & 21 & $36 \%$ & $12 \%$ \\
\hline TVA & 65 & 13 & 2 & $20 \%$ & $3 \%$ \\
\hline USACE & 197 & 18 & N.A. & $9 \%$ & N.A. \\
\hline USDA & 184 & 19 & 8 & $10 \%$ & $4 \%$ \\
\hline USPS & 126 & 30 & 18 & $24 \%$ & $14 \%$ \\
\hline VA & 187 & 57 & 1 & $30 \%$ & $1 \%$ \\
\hline
\end{tabular}

As shown in Table 7.3, evaluated savings can range up to 36\% of the FY 2011 agency EUI (for EPA), while projected savings from projects range up to 35\% of the FY 2011 agency EUI (for DOJ). These numbers are consistent with typical estimates for retrofit projects, ranging up to $30 \%$ of existing building energy use.

For many agencies, there is a significant difference between EUI reduction estimates based on facility evaluations (audits) and EUI reduction estimates from implemented projects, with most agencies showing higher evaluation EUI reduction than project EUI reduction. However, three agencies (DHS, DOJ, and NASA) are achieving project EUI reductions higher than evaluation EUI reductions. The fact that most agencies have higher evaluation EUI reduction than project EUI reduction while some agencies have shown the reverse trend may be a matter of how agencies have chosen to implement projects in their covered facilities. Agencies could conceivably be choosing either to implement projects in facilities with higher-than-average evaluated savings or to implement easier and simpler projects that may have lowerthan-average savings. 



\subsection{Benchmarked Facilities}

Benchmarking data for the individual buildings that constitute covered facilities is reported in CTS to help agencies monitor annual performance, as well as to identify buildings with the greatest potential to benefit from energy- and water-saving projects. These buildings are benchmarked using either Energy Star Portfolio Manager or another benchmarking tool (e.g., Labs21) using monthly metering utility bills, occupancy, and other building characteristics. As shown in Table 8.1, a total of 1,419 individual buildings representing an estimated $11 \%$ of covered facility floor space and $20 \%$ of energy use in covered facilities have been benchmarked. ${ }^{40}$ The EPA is currently the only agency to have benchmarked all of its covered facility area. GSA, SSA, and STATE have over $90 \%$ of covered facility floor area benchmarked. While a relatively small percentage of DOE's floor area is benchmarked (19\%) this represents a substantial portion of its covered facility energy use (70\%).

Table 8.1. Benchmarked Buildings in CTS (FY 2011 data)

\begin{tabular}{|c|c|c|c|c|c|c|c|}
\hline Agency & $\begin{array}{l}\text { Number } \\
\text { of Bench- } \\
\text { marked } \\
\text { Buildings }\end{array}$ & $\begin{array}{l}\text { Covered } \\
\text { Facility } \\
\text { Gross } \\
\text { Square } \\
\text { Feet } \\
\text { (Thou.) }\end{array}$ & $\begin{array}{c}\text { Bench- } \\
\text { marked } \\
\text { Floor Space } \\
\left(\text { Thou. } \mathrm{ft}^{2}\right)\end{array}$ & $\begin{array}{l}\text { \% Floor } \\
\text { Space } \\
\text { Bench- } \\
\text { marked }\end{array}$ & $\begin{array}{c}\text { Covered } \\
\text { Facility } \\
\text { Energy Use } \\
\text { (MMBtu) }\end{array}$ & $\begin{array}{c}\text { Bench- } \\
\text { marked } \\
\text { Building Site- } \\
\text { Delivered } \\
\text { Energy Use } \\
\text { (MMBtu) }\end{array}$ & $\begin{array}{c}\% \text { Total } \\
\text { Covered } \\
\text { Facility } \\
\text { Energy } \\
\text { Use }\end{array}$ \\
\hline All Agencies & 1,419 & $2,784,721$ & 315,847 & $11 \%$ & $334,558,600$ & $66,961,094$ & $20 \%$ \\
\hline DHS & 68 & 37,066 & 2,691 & $7 \%$ & $3,583,200$ & 221,478 & $6 \%$ \\
\hline DOC & 14 & 11,694 & 5,993 & $51 \%$ & $2,112,800$ & $1,043,617$ & $49 \%$ \\
\hline DOD & 1 & $1,902,489$ & 9,311 & $0.5 \%$ & $194,868,100$ & $2,713,446$ & $1 \%$ \\
\hline DOE & 399 & 86,656 & 16,496 & $19 \%$ & $24,653,300$ & $17,133,437$ & $70 \%$ \\
\hline DOI & 23 & 46,518 & 1,877 & $4 \%$ & $3,842,400$ & 198,913 & $5 \%$ \\
\hline DOJ & & 53,087 & & $0 \%$ & $7,364,200$ & & $0 \%$ \\
\hline DOL & 16 & 17,495 & 2,465 & $14 \%$ & $1,771,800$ & 203,159 & $12 \%$ \\
\hline DOT & 3 & 16,411 & 210 & $1 \%$ & $2,817,400$ & 21,002 & $0.7 \%$ \\
\hline EPA & 16 & 2,840 & 2,840 & $100 \%$ & 989,200 & 989,208 & $100 \%$ \\
\hline GSA & 196 & 139,207 & 125,578 & $90 \%$ & $13,888,600$ & $12,942,878$ & $93 \%$ \\
\hline HHS & 129 & 22,133 & 16,742 & $76 \%$ & $9,165,200$ & $8,304,528$ & $91 \%$ \\
\hline HUD & & 1,441 & & $0 \%$ & 106,300 & & $0 \%$ \\
\hline NARA & & 3,492 & & $0 \%$ & 413,600 & & $0 \%$ \\
\hline NASA & 344 & 32,327 & 9,544 & $30 \%$ & $5,964,100$ & $1,065,242$ & $18 \%$ \\
\hline NRC & & 763 & & $0 \%$ & 90,200 & & $0 \%$ \\
\hline OPM & & 1,014 & & $0 \%$ & 77,000 & & $0 \%$ \\
\hline RRB & & 347 & & $0 \%$ & 33,600 & & $0 \%$ \\
\hline SI & & 6,105 & & $0 \%$ & $1,012,700$ & & $0 \%$ \\
\hline SSA & 7 & 6,320 & 5,754 & $91 \%$ & 820,700 & 576,184 & $70 \%$ \\
\hline STATE & 15 & 4,656 & 4,506 & $97 \%$ & 556,200 & 568,758 & $102 \%$ \\
\hline TREASURY & 10 & 8,861 & 7,229 & $82 \%$ & $1,485,600$ & $1,141,961$ & $77 \%$ \\
\hline TVA & 8 & 19,456 & 2,566 & $13 \%$ & $1,267,900$ & 170,089 & $13 \%$ \\
\hline USACE & & 147 & & $0 \%$ & $1,389,900$ & & $0 \%$ \\
\hline USDA & 56 & 17,968 & 2,221 & $12 \%$ & $3,302,900$ & 182,098 & $6 \%$ \\
\hline USPS & & 191,568 & & $0 \%$ & $24,117,300$ & & $0 \%$ \\
\hline VA & 114 & 154,661 & 99,825 & $64 \%$ & $28,864,400$ & $19,485,095$ & $68 \%$ \\
\hline
\end{tabular}

\footnotetext{
${ }^{40}$ While water use and water use intensity can be reported in Portfolio Manager, it is not reported for all sites, and at this time there are no established benchmark targets for water use intensity.
} 



\subsection{Limitations of Analysis}

There are a number of limitations to this analysis that should be kept in mind when drawing conclusions from the results shown in this document.

1. Underestimation of Investment and Savings - The current CTS data set is continually being updated and is not yet a comprehensive list of projects. Comparisons to efficiency investments reported in agency annual energy reports to FEMP suggest that the CTS data set underestimates the total investment and savings that will eventually occur. Some agencies are currently only reporting a subset of their projects, focusing on larger, third-party-funded projects first, and then entering other projects later.

2. ECM Definition - ECMs often refer to a technology implemented in a single building, but in CTS, ECMs may also refer to measures implemented in multiple buildings because covered facilities can comprise multiple buildings. This has implications for how this analysis can interpret the energy savings associated with specific ECMs.

3. Data Quality - While the CTS data was subjected to numerous data quality checks, no attempt was made to look at each of the approximately 7,000 facilities individually to make sure all the data was entered correctly. Data quality checks can find the "gross" errors, but may not find less obvious errors such as offsetting errors where two independent data parameters were both entered incorrectly yet the resulting calculation shows the facility data is within some predetermined range. For example, if both the square footage and energy usage are entered incorrectly, the resulting EUI may still be within range, even though the underlying data is incorrect.

4. Limited Building-Level Data - There is potentially much more analysis that could have been done on the CTS data if data had been entered at the building level rather than the facility level. However, requiring CTS data to be entered at the building level would have greatly increased the data-entry burden on agencies. The end result is that a number of analyses that can be done for benchmarked facilities (which are typically buildings) cannot be done for other facilities in CTS.

5. Limited Amount of Water Use Data - Interpretation of the results of the water analysis in this report should be made carefully. Water use is provided for a very limited number of facilities and limited data is reported on the nature of the water projects implemented.

6. Lack of Project Implementation Dates - CTS currently allows agencies to enter separate dates for project initiation and implementation. Project initiation refers to the project award or approval date and is a required field in CTS. Project implementation refers to the date the project was actually completed and is optional reporting. Throughout this analysis, project initiation was used as a surrogate for implementation since only $62 \%$ of projects reported actual implementation dates. It was therefore assumed that the year of initiation was the year projects were implemented and savings began to occur. 



\subsection{Conclusions and Recommendations}

CTS is a very large and complex data set of federal building energy usage. The creation of CTS represents an enormous effort on the part of federal agencies and FEMP. It also presents agencies and energy and water resource management professionals with an opportunity to gauge impact of their ECM investments at a scale and level of detail that were not previously available. Observations about the relative cost-effectiveness and energy-savings impact of past projects can help inform and justify future planning to achieve federal energy and water management goals most cost-effectively.

This report contains a snapshot of the contents of CTS as of the end of FY 2012. The contents may be quite different in future years as agencies continue to add and revise the data in CTS.

The data quality effort associated with this analysis also points out the need for ongoing data quality screening of CTS. Data-entry errors have been made in the past and will be made in the future. Tracking down and resolving these issues with agencies can be an extremely time-consuming task.

In the interest of supporting the continued improvement of the reporting process and increasing the potential value that federal agencies and their service providers gain from the information in CTS, the research team offers the following recommendations:

1. Automate some of the data quality checks discussed in this report so that agencies or others entering data into CTS receive immediate feedback that their entry (or entries) seems problematic.

2. Update the analyses found in this report on an annual basis to track changes in CTS.

3. Encourage agencies to enter baseline water usage for their covered facilities.

4. Revamp the water conservation ECMs available in the main ECM list beyond Water and Sewer Conservation Measures to expand the options available and make them more precise. The current category of water ECMs and its subcategories are not sufficient to accurately depict the water conservation projects being implemented by agencies. Consideration should be given to deleting the existing "Water and Sewer Conservation Measures" category and all water-related subcategories and adding the following ECM categories that are based on the FEMP Best Management Practices $(\mathrm{BMP}):^{41}$

a. Plumbing - includes toilets, urinals, faucets and showerheads (BMP \#s 6 and 7).

b. Landscaping and Irrigation - includes water-efficient landscaping and water-efficient irrigation (BMP \#s 4 and 5).

c. Industrial/Process Water - includes boiler/steam systems, single-pass cooling equipment, and cooling tower management (BMP \#s 8, 9, and 10).

d. Non-Plumbing Water Equipment - includes commercial kitchen equipment and laboratory/medical equipment (BMP \#s 11 and 12).

e. Other Water - includes water management planning; information and education programs; distribution system audits, leak detection, and repair; and alternate water sources (BMP \#s 1, 2, 3, and 13).

\footnotetext{
${ }^{41}$ Additional information on FEMPs Water Efficiency Best Management Practices is available at http://www1.eere.energy.gov/femp/program/waterefficiency bmp.html.
} 



\section{Appendix A}

\section{PNNL Program Plan for Savings Evaluation of EISA Federal}

Project Investments 



\section{Appendix A - PNNL Program Plan for Savings Evaluation of EISA Federal Project Investments}

Note: The program plan below was drafted prior to the analysis and was updated throughout the analysis as methodological changes were made.

This Program Plan details the tasks, methodology, timeline, and specific types of analyses to be completed by Pacific Northwest National Laboratory (PNNL) as part of a study to evaluate the energy, economic, and environmental savings resulting from Energy Independence and Security Act (EISA) 432 federal project investments. This document is also intended to meet the milestone for a detailed program plan for the investment impact study. Detail on project objectives, budget, and milestones can be found in the Statement of Work.

\section{Methodology}

The primary tasks in the development of the EISA 432 savings impact study are described below.

1. Data source review - While the Compliance Tracking System (CTS) is the primary source of data on implemented projects, ancillary data will be required to help establish assumptions about critical pieces of information that are missing from the CTS data set. These ancillary data sources will include:

a. Energy Savings Performance Contract (ESPC) Awarded Projects list

b. DOE's Commercial Initiative Reference Building Models - typical buildings based on analysis of the Commercial Building Energy Consumption Survey (CBECS)

c. DOE's Building Energy Codes Program Standard 90.1 Building Models - typical buildings based on DOE's reference buildings with refinements made by practicing engineers and architects associated with ASHRAE Standing Standard Product Committee 90.1

d. DOE Buildings Performance Database - for energy savings summaries and distributions

e. Federal Energy Management Program (FEMP) Annual Report to Congress - for overall agency energy use and energy expenditures

f. Agency and subagency budgets from the Office of Management and Budget - to estimate spending ratio for energy conservation measures (ECM)

g. Commercial and Institutional End-Uses of Water prepared by the Water Research Foundation water end-use benchmark data on specific building types

h. Federal Water Use Indices - typical water use per person by building type

2. Establish assumptions for missing data - Assumptions will primarily be used to establish energy use intensity (EUI) of buildings so that baseline energy use can be estimated when not reported. Assumptions may also be necessary establish corresponding greenhouse gas reductions and water savings. A preliminary review of available data in the CTS suggests that assumptions will need to be established for the following:

a. Building types - For projects in which it is not clear from the description what building types are involved, a default building type or building types will be developed for each agency. This may 
be based on the agency's most common "predominant use," and if that is not clear, a conservative assumption about the building's predominant use (e.g. Office building) may be used. Evaluation of available data on building type by agency will be used to inform these assumptions.

b. Building quantity - For projects in which the data or project titles do not convey how many buildings are covered by the project, it will be assumed that one building is impacted. If a project appears to be a campus or multi-building project, clarification may be sought from the Facility Energy Manager (FEM); this will depend on the number of projects that require follow-up.

c. Building floor area and physical geometry - For projects implemented in facilities where the building area affected is not known (i.e. no benchmarking to correspond with the project) or how the buildings are shaped, recently completed evaluations of CBECS and Residential Energy Consumption Surveys (RECS) for typical private sector construction will be used.

d. Fuel type ratio - Where it is not clear what fuel type (e.g. natural gas, propane, electricity) is being saved by the project, assumptions may be made based on geography and the nature of the ECM.

e. Type of water ECM - Where it is not clear from the project description what type of water project has been implemented, clarification will be sought from the project FEM.

f. Ratio of irrigation, industrial and domestic water use - Where it is not clear from the project description what type of water has been saved by a project, the project will be assumed to be a domestic water savings project.

3. Database development - An Excel ${ }^{\circledR}$-based database will be developed to support analysis at the project, ECM, agency and government-wide levels. The database will integrate data from the CTS and supplementary data sources described in Task 1 , as well as calculated values provided by the research team. ${ }^{42}$

The following practices will be established to provide data integrity and quality control:

a. The database administrator will maintain a master control copy of the data set. The administrator will check CTS for updates once weekly — or at a frequency that better corresponds with FEMP's planned updates - to make sure the most current data set is being analyzed.

b. All other team members will have "read" access only and will copy data from the master file to support analyses.

c. The master file will be backed up daily by the administrator.

d. Analysts will send data to be integrated into the master database to the administrator in xls or csv format. Data provided will include the unique identification, the calculated value, and a description of the calculation (e.g., EUI = total energy/gross square feet).

e. As noted in Task 6, if agency personnel request that PNNL make corrections to the reported data, such changes will be made in CTS and incorporated into the PNNL data set in the next CTS download.

f. The administrator will notify team members of specific structural or content changes that occur during database maintenance and regular CTS uploads.

4. Data preparation - Consolidate data from the CTS including evaluated projects, implemented projects, and benchmarking reports, and other sources as appropriate. Review entries with similar

\footnotetext{
${ }^{42}$ Excel is a registered trademark of Microsoft Corporation.
} 
titles and headings consolidate fields when they are clearly referring to the same source (e.g. DOE and Department of Energy).

5. Clarify definition of $\mathbf{E} \mathbf{C} \mathbf{M}^{43}$ - Agencies do not appear to be using a common definition of an "energy conservation measure" when it comes to counting the number of ECMs implemented as part of a project (e.g. some are counting individual fixtures, some counting a set of fixtures incorporated into a building). To help provide consistency, PNNL proposes to work with FEMP and with agencies to establish a common definition of an ECM along the lines of "a specific set of equipment and controls replacements, additions, or modifications made to an individual building," as well as supporting examples. Thus, installation of 200 occupancy sensors in one building would be one ECM; installation of 200 occupancy sensors in two separate buildings would be two ECMs. This will clarify analyses that look for the most commonly used ECMs and saving by ECM types.

6. Data quality check - Each agency's data reported in CTS will be checked for potential data-entry, calculation, or estimation errors prior to data analysis. Quality checks will be performed on the covered facility footprint, project, and evaluation data. Facility benchmark data has been entered by agencies at a slower rate due in part to data-entry and data-import challenges, and will not be included in the quality check. Specific data quality checks include:

a. Number of ECMs - The range of ECMs implemented per facility will be examined for project data. Those facilities with very large numbers of ECMs in a single project may suggest that the agency is not using a common definition of ECM. If so, PNNL will work with the agency to define an appropriate number of ECMs based on the common definition developed in Task 5. Agencies may have limited ability to change ECM-count audits, particularly if conducted by a third party. Therefore, evaluations will not be reviewed for high ECM counts.

b. Missing required data - If required data fields in CTS or other data that is key to the analysis of investments is missing, PNNL will contact the agency to help enter those values or remove the project from CTS, as appropriate. Examples include missing gross building area, project implementation cost, energy savings estimates for energy ECMs, water savings estimates for water ECMs, and renewable production estimates for renewable ECMs; PNNL will provide guidance to agencies on estimating savings for different ECM types using savings-per-dollarinvested ranges from past analyses and engineering judgment.

c. Energy use intensity - Facilities with EUIs greater than $500 \mathrm{kBtu} / \mathrm{ft}^{2}$ in any reporting year will be investigated further and followed up unless there is an obvious reason for the high EUI based on the agency mission or facility function (e.g. Federal Aviation Administration radar stations).

d. Energy savings per square foot - Projects with savings greater than $50 \mathrm{kBtu} / \mathrm{ft}^{2}$ will be flagged and investigated to check whether the types of ECMs implemented warrant such high savings levels. If there is no clear reason for the high savings levels, PNNL will contact the agency to determine whether savings estimates are appropriate.

e. Water savings per square foot - While there are no generally accepted ranges for water savings per square foot for buildings, projects will be checked for extreme outliers (e.g. > 100 gallons saved $/ \mathrm{ft}^{2}$ ) to determine whether such savings estimates are appropriate for the type of facility described.

f. Renewable energy production relative to energy use - There are no clear upper and lower limits to renewable energy production; however, projects with extremely large ratios of

\footnotetext{
${ }^{43}$ For consistency with language in EISA Section 432(f)(3)-(8) and the CTS, the abbreviation ECM represents both water and energy efficiency measures.
} 
renewable energy production to energy use will be checked to see whether the type of project described corresponds with such savings (e.g., from a large biomass project).

g. Energy savings per dollar invested -A FEMP analysis of federal ESPC projects found that the average annual energy savings per dollar invested in projects over a ten-year period was between 5,000 and 15,000 Btus per dollar invested. Because this range represents annual averages over multiple projects, this range will not be used to identify outliers, but will be used to validate rolled-up project averages by agency. However, projects with extremely low or high energy savings per dollar invested $(<100 \mathrm{Btu} / \$$ or $>100,000 \mathrm{Btu} / \$)$ will be examined further. Unusually low savings may be the result of projects bundling ECMs with broader maintenance projects and not separating the ECM cost from the total implementation cost, which can be difficult to do. If confirmed by the agency to be general maintenance projects, these will be flagged in the database and pulled from analyses that specifically look at savings per dollar invested.

h. Savings reported relative to estimated baseline use - If the savings reported for implemented projects at covered facilities represent a significant portion of energy or water use (e.g. $>20 \%$ ), or are greater than total energy use or water use at the facility, these projects will be flagged and investigated further. If there is no obvious reason for the high savings levels, (for example, due to the magnitude of changes or projects involving renewable energy or distributed generation systems), the agency will be contacted. Follow-up will typically occur only on projects with savings-to-use ratios greater than $50 \%$.

i. Evaluated area relative to gross area - The FEMP guidance in CTS requires that the evaluated area of a facility be less than the gross area reported as the covered facility footprint. Facilities with evaluated area greater than the gross area may be including energy and water savings potential from evaluations and projects that are not included in the agency's covered footprint. If a facility's evaluated area differs from the footprint by more than $10 \%$ in the year of the evaluation (or a subsequent year) then the agency will be contacted to correct the evaluated area or footprint as appropriate. Differences of less than $10 \%$ may be the result of auditors and facility managers using slightly different building areas for the same buildings.

j. Other anomalies - As other anomalies in each agency's data sets are discovered, PNNL will follow up with those agencies to make corrections as necessary. Examples include:

- Multiple projects with the same name and savings estimates appear at the same facility, indicating likely duplicate entries.

- Energy and water use spikes in one year that appear to be an order of magnitude off.

7. Agency follow-up - PNNL will e-mail the agency-level energy coordinator, copying the FEM contact if identified, with any issues that are identified during the quality check and offer to provide technical assistance as appropriate to establish the correct data in CTS.

8. Data corrections - When data is determined to have been entered incorrectly, the agency may correct the data in CTS or PNNL will make the correction if asked to do so by the agency. (Note that changes will be made in CTS directly, not to the PNNL data set.) These may include entering a rationale for the anomalous data in the "comments" field of CTS. For example, it may be noted that lower than expected energy savings were the result of an increase in mission tempo or occupancy at a given site. To support data quality, all requests and approvals must be by written (e-mail) correspondence. PNNL will request that the CTS Administrator create a field in the CTS for documenting any changes made by third parties, by whom they were made, and on what date. 


\section{Normalization}

a. Normalization of energy use data for weather - Energy use data was normalized by PNNL to account for the fact that the evaluation and measurement occurred in a particular year and reflects specific weather patterns of that year. Savings reported by agencies are estimated, which implies that the typical meteorological year (TMY) was used. To bring energy use data and savings estimates to a comparable basis, weather normalization was implemented.

Ideally, normalization for weather can be done when energy consumption for cooling and heating days is shown separately; then it can be scaled based on the ratio of cooling degree days (CDD) and heating degree days (HDD) of the data year to the CDD and HDD of the TMY, correspondingly.

Since only aggregate annual energy use is available in CTS, cooling and heating portions were approximated first. This was done based on the breakdown of energy consumption by end use for typical buildings estimated in CBECS 2003 as shown in Table A.1.

Table A.1. Energy Consumption by Census Division and End Use

\begin{tabular}{clrrr}
\hline $\begin{array}{c}\text { Census } \\
\text { Division } \\
\text { Number }\end{array}$ & Census Division & Heating & Cooling & Other \\
\hline 1 & New England & $54 \%$ & $3 \%$ & $43 \%$ \\
2 & Middle Atlantic & $46 \%$ & $4 \%$ & $50 \%$ \\
3 & East North Central & $50 \%$ & $3 \%$ & $47 \%$ \\
4 & West North Central & $43 \%$ & $5 \%$ & $52 \%$ \\
5 & South Atlantic & $22 \%$ & $13 \%$ & $65 \%$ \\
6 & East South Central & $33 \%$ & $8 \%$ & $59 \%$ \\
7 & West South Central & $19 \%$ & $17 \%$ & $64 \%$ \\
8 & Mountain & $37 \%$ & $7 \%$ & $56 \%$ \\
9 & Pacific & $21 \%$ & $9 \%$ & $70 \%$ \\
\hline
\end{tabular}

Once energy consumption was split out, it was scaled to account for difference in the HDD and CDD of the actual year versus the TMY. 2000-2011 National Oceanic and Atmospheric Administration (NOAA) state data ${ }^{44}$ for HDD and CDD was used to derive the adjustment factors between a specific year's energy use and the HDD and CDD for the TMY. The resulting weather-normalized expected energy use estimates were used as a basis for calculating energy-savings fraction. (See Task 10.1 below).

One limitation of this approach is that the weather-adjusted energy use estimates are developed based on a uniform split between heating and cooling, while the facilities within CTS probably have very heterogeneous heating and cooling loads even within each facility/building type.

While Portfolio Manager provides a weather-adjusted energy use estimate, only $4 \%$ of benchmarked buildings in CTS appear to "match" the building area of the corresponding covered facility. So it is not possible to use the weather-normalized data from the benchmark set.

\footnotetext{
${ }^{44}$ NOAA - National Oceanic and Atmospheric Administration, National Climatic Data Center, Historical Climatology Series 5-1, State Regional and National Monthly and Seasonal Heating Degree Days Weighted by Population. Accessed at http://www.ncdc.noaa.gov/oa/documentlibrary/hcs/hcs.html
} 
b. Normalization of water use and savings - Water savings for projects related to irrigation have the potential to be normalized based on historic weather data. However, only one project is readily identifiable as an irrigation project at this time. For building interior water use, ranges of water-use intensity based on occupant density are available for certain building types, but there are no established estimates of typical water use per occupant or per square foot when building types are not known. Benchmark data imported from Portfolio Manager identifies the building type, but lacks occupancy rates and is available for very few facilities with water projects. Due the limited data available for water projects in CTS, water use and savings estimates will not be normalized. Water savings will be totaled by agency and it will be noted that savings estimates would be slightly higher or lower if data were normalized.

10. Savings Impact Analysis - Specific analyses to be completed will include:

a. ECMs implemented - This analysis will be a simple count of ECMs implemented by facility, including analysis of those used most/least often, ECMs that are typically implemented alone or bundled with other ECMs, and aggregated by agency and building type. This analysis will provide FEMP an opportunity to see which ECMs agencies are focusing on and which ECMs some agencies may be missing.

b. Energy savings by ECM - This analysis will be a simple summation of the energy savings reported for each ECM and by agency. For single-ECM projects, reporting of energy savings by ECM will be simple. Bundled ECMs will first be analyzed as a separate group. Then, using the estimates from the single-measure projects, a suggested attribution of the bundled project savings to its component ECMs will be calculated. This analysis will allow FEMP to see which ECMs are generating the greatest total energy savings in the federal sector.

c. Water savings by ECM - Water-related projects will be assessed by plotting water saved against dollars invested in the project. This plot will show trends in relative water savings compared to the up-front capital expense of the project. This analysis will provide information on outliers in the data set that may indicate projects outside the normal range of savings. Also, this comparison may reveal "clusters" of relative savings that show trends in specific technology types. This analysis will allow FEMP to see which water-related ECMs are generating the most water savings in the federal sector.

d. Project funding by source - This analysis will be a simple summation of the reported project funding by source (e.g. ARRA, UESC, ESPC, appropriated funds) and by agency. This analysis will allow FEMP to see whether agencies are making full use of the project funding options available to them.

e. Project investment by agency and subagency - This analysis will be a summation of project investment by agency and subagency, coupled with a normalization of that total to the agency or subagency's reported budget. Note that it is not expected that all agencies or subagencies will spend the same normalized fraction of their budget on buildings. Some agencies may be more (or less) "building intensive" and be expected to spend a larger (or smaller) proportion of their allocated budgets on building energy efficiency. This analysis will provide FEMP with information on what fraction of agency budgets are being spent on this activity and which agencies tend to spend a larger (or smaller) fraction on this activity.

f. Project implementation cost by ECM - This analysis will establish the total and average cost of implementing individual ECMs or bundles of ECMs. This will help FEMP to understand the total investment levels by ECM and the relative cost of implementing those ECMs to support future planning efforts.

g. Average savings by building type - When the covered facility building type is known (i.e., when the benchmarked building area and energy use are equal to covered facility area and energy 
use, we can assume the covered facility is a single building), normalized energy savings per square foot and per dollar invested will be characterized by building type.

h. Average energy savings and savings ranges per dollar invested - This analysis will establish average savings per dollar invested overall and by individual ECM, as the data set allows. Ranges of savings by ECM (or for bundles of similar ECMs) will be established based on the data reported in the CTS, and percentiles and standard deviations will be used to provide an indication of uncertainty around those estimates.

i. Life-Cycle Cost Economics - This analysis will focus on providing return on investment, net savings, and average payback periods for individual ECMs, ECM bundles, subagencies, and agencies. Life-cycle cost and savings analysis will be implemented using the equipment lifetime data where it was reported in CTS, or alternatively, using lifetime assumptions for various energy measures from cost-effectiveness assumptions prescribed by the National Institute of Standards and Technology. In addition, the total implementation cost will be subject to regional cost inflator adjustment in order to perform LCC analysis on the comparable national scale. This analysis will allow FEMP to promote various ECMs or packages of ECMs to agencies as life-cycle costeffective.

j. Greenhouse Gas (GHG) emissions avoided - Zip codes will be associated with eGRID subregions and reported electricity savings will be multiplied by a $\mathrm{CO}_{2}$-equivalent emission factor for the region to estimate GHGs avoided. When facilities report total fuel savings from projects, rather than savings by fuel type, PNNL will apply fuel share ratios for standard commercial buildings from the National Energy Modeling System/Annual Energy Outlook by location. GHG emissions avoided will be estimated for each project and totaled by:

$\circ$ Federal government

$\circ$ Agency

- Subagency

- State or Region

- ECM type for single-ECM projects

k. Implemented project energy savings relative to evaluated project savings potential - An initial comparison of the most recent evaluated energy savings potential and implemented project savings will be made. This analysis may provide FEMP with a general indication of remaining potential projects that could be implemented cost-effectively, but it will be presented with several caveats. It will be noted that not all projects have been entered into CTS yet and that the results should not be construed as a complete representation of activities. It will also be noted that, due to the fluid nature of covered facility portfolios, not all initial savings identified will remain relevant to the agency.

1. Total implemented project energy and water savings relative to total agency energy and water use - This analysis will provide FEMP with information on the relative impact the agency projects have. As with many building-related activities, cumulative savings over time will be important as well.

11. CTS updates and process improvements -To facilitate and improve the quality of the EISA savings impact analyses, PNNL will recommend modifications to the CTS and the reporting process, and work with FEMP contractors to integrate aspects of PNNL's data set back into the CTS. 


\section{Timeline}

\begin{tabular}{|c|c|c|}
\hline Task & & Completion Date \\
\hline 1. & Data Source Review & $3 / 3 / 12$ \\
\hline 2. & Establish Assumptions for Missing Data & $3 / 3 / 12$ \\
\hline 3. & Database Development & $3 / 31 / 12$ \\
\hline 4. & Data Preparation/Cleanup & $4 / 30 / 12$ \\
\hline & Data Quality Check & $8 / 17 / 12$ \\
\hline 6. & Agency Follow-Up & $8 / 31 / 12$ \\
\hline & Data Corrections & ongoing \\
\hline \multicolumn{2}{|r|}{$\begin{array}{l}\text { Milestone: Compilation of Data Sets for Basis of Analysis } \\
\text { Complete }\end{array}$} & $8 / 30 / 12$ \\
\hline & Normalization of Energy and Water Use and Savings & $8 / 31 / 12$ \\
\hline \multicolumn{2}{|r|}{ Milestone: Analysis of Non-Project Savings Variables Complete } & $8 / 24 / 12$ \\
\hline & Savings Impact Analysis & $9 / 21 / 12$ \\
\hline & Extrapolation of Future Potential Energy Savings & $9 / 30 / 12$ \\
\hline & Extrapolation of Future Potential GHG Reductions & $9 / 30 / 12$ \\
\hline & Extrapolation of Future Potential Water Savings & 9/30/12 \\
\hline Mile & stone: Draft Savings Impact Study Complete & $9 / 30 / 12$ \\
\hline & $\begin{array}{l}\text { stone: Presentation Summarizing Key Findings / Deliver at } \\
\text { Conference or Webinar }\end{array}$ & $10 / 30 / 12$ \\
\hline Mile & stone: Final Savings Impact Report complete & $12 / 15 / 12$ \\
\hline
\end{tabular}




\section{Appendix B}

\section{List of ECM Types and Subtypes in CTS}





\section{Appendix B - List of ECM Types and Subtypes in CTS}

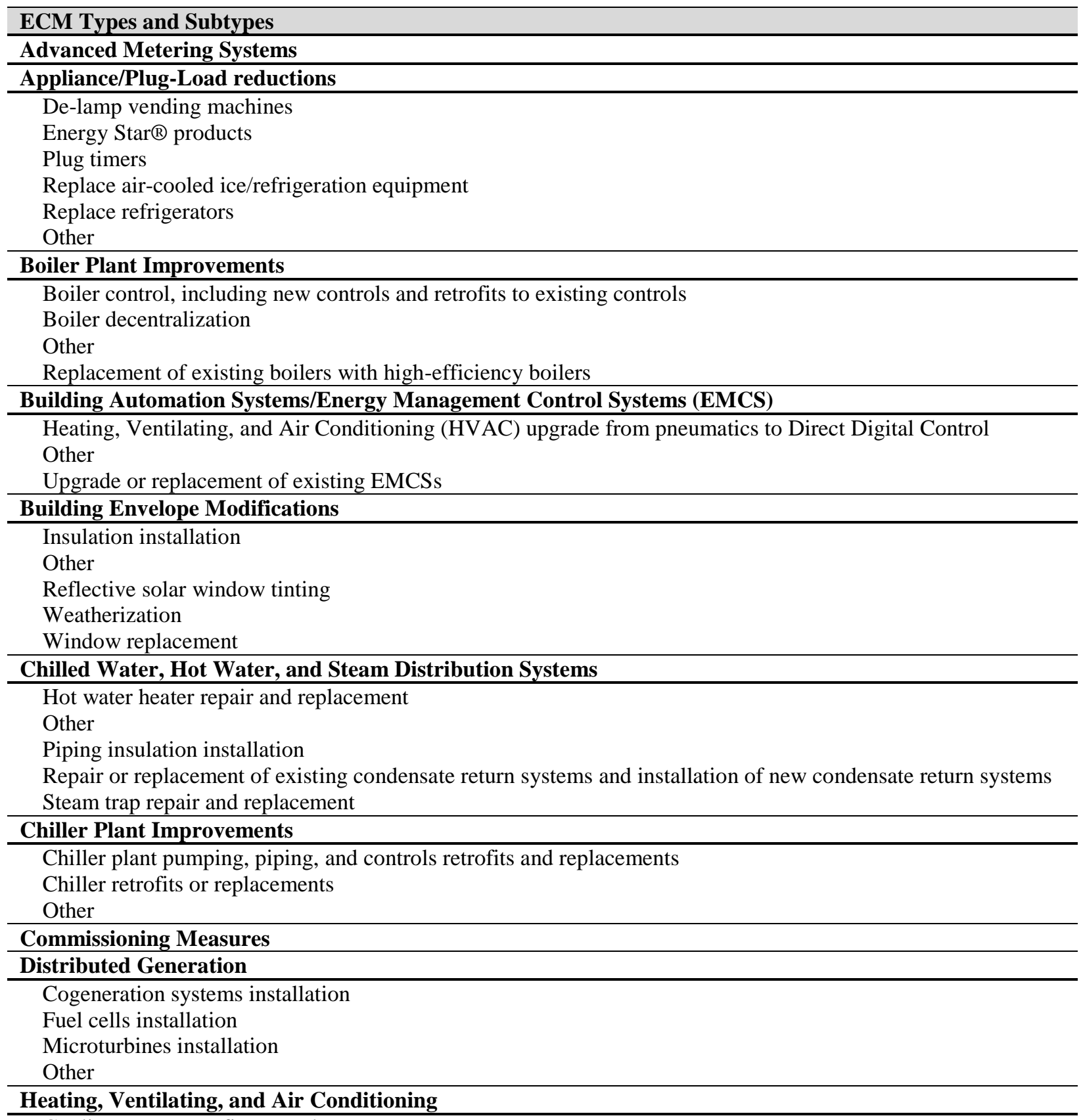

Cooling tower retrofits or replacements

Economizer installation

Fans and pump replacement or impeller trimming

HVAC damper and controller repair or replacement

Other

Packaged air conditioning unit replacements

Thermal energy storage

Variable air volume retrofit

Window air conditioning replacement with high-efficiency units 
ECM Types and Subtypes

Electrical Peak Shaving/Load Shifting

Gas cooling

Other

Thermal energy storage

Electric Motors and Drives

Motor replacement with high-efficiency motors

Other

Variable speed motors or drives

Energy Cost Reduction Through Rate Adjustments

Change to more favorable rate schedule

Energy service billing and meter auditing recommendations

Lower energy cost supplier(s) (where applicable)

Other

Energy Related Process Improvements

Industrial process improvement

Other

Production and/or manufacturing improvements

Recycling and other waste stream reductions

Energy/Utility Distribution Systems

Gas distribution systems installation

Other

Power factor correction

Power quality upgrades

Transformer installation

Lighting Improvements

Daylighting

Fiber optic lighting technologies

Intelligent lighting controls

Interior and exterior lighting retrofits and replacements

Light emitting diode technologies

Occupancy sensors

Other

Spectrally enhanced lighting

Other

Refrigeration

Other

Replacement of ice/refrigeration equipment with high-efficiency units

Renewable Energy Systems

Landfill gas, wastewater treatment plant digester gas, and coalbed methane power plant installation

Other

Passive solar heating installation

Photovoltaic system installation

Replacement of air conditioning and heating units with ground-coupled heat pump systems

Solar hot water system installation

Solar ventilation preheating system installation

Wind energy system installation

Wood waste and other organic waste stream heating or power plant installation

Water and Sewer Conservation Systems

Low-flow faucets and showerheads

Low-flow plumbing equipment

On-site sewer treatment systems

Other

Water-efficient irrigation 


\section{Appendix C}

High and Low LCC Results by ECM and Agency 



\section{Appendix C - High and Low LCC Results by ECM and Agency}

High and low LCC results are obtained based on using either electricity or natural gas rates to account for the uncertainty around the fuels saved in the different ECMs. The escalation rates for the LCC discounting by fuels are included below. Low case was calculated based on using the natural gas price, assuming that all savings on the ECMs where fuel type is not identified are attributed to natural gas. High case was calculated by attributing all generated savings to electricity, and applying electricity price and escalation factors.

Table C.1. Federal Energy Management Program Uniform Present Value Discount Factors Adjusted for Fuel Price Escalation by Fuel Type, Commercial Sector

\begin{tabular}{rrr}
\hline $\mathrm{N}$ & Electric & Natural Gas \\
\hline 1 & 0.96 & 0.95 \\
2 & 1.87 & 1.85 \\
3 & 2.75 & 2.70 \\
4 & 3.61 & 3.53 \\
5 & 4.43 & 4.33 \\
6 & 5.23 & 5.12 \\
7 & 6.01 & 5.89 \\
8 & 6.76 & 6.66 \\
9 & 7.49 & 7.41 \\
10 & 8.20 & 8.16 \\
11 & 8.89 & 8.90 \\
12 & 9.56 & 9.63 \\
13 & 10.22 & 10.35 \\
14 & 10.85 & 11.06 \\
15 & 11.47 & 11.77 \\
16 & 12.07 & 12.46 \\
17 & 12.65 & 13.14 \\
18 & 13.21 & 13.80 \\
19 & 13.76 & 14.45 \\
\hline 20 & 14.29 & 15.09 \\
21 & 14.81 & 15.71 \\
22 & 15.31 & 16.32 \\
23 & 15.80 & 16.93 \\
24 & 16.28 & 17.52 \\
25 & 16.74 & 18.11 \\
26 & 17.20 & 18.69 \\
27 & 17.63 & 19.26 \\
28 & 18.06 & 19.81 \\
29 & 18.48 & 20.36 \\
30 & 18.88 & 20.90 \\
\hline & & \\
& &
\end{tabular}


Table C.2. High and Low Average Life-Cycle Cost Results by Energy Conservation Measure, without Financing Cost

\begin{tabular}{|c|c|c|c|c|c|c|c|c|c|}
\hline \multirow[b]{2}{*}{$\mathrm{ECM}^{*}$} & \multicolumn{2}{|c|}{ Life-cycle Benefit (\$) } & \multirow{2}{*}{$\begin{array}{c}\text { Location- } \\
\text { Adjusted } \\
\text { Investment }(\$)\end{array}$} & \multicolumn{2}{|c|}{ Net Savings (\$) } & \multicolumn{2}{|c|}{$\begin{array}{c}\text { Savings-to-Investment } \\
\text { Ratio }\end{array}$} & \multicolumn{2}{|c|}{$\begin{array}{c}\text { Adjusted Internal Rate of } \\
\text { Return }\end{array}$} \\
\hline & Low & High & & Low & High & Low & High & Low & High \\
\hline Boiler & 536,381 & 536,381 & $5,476,869$ & $(\$ 4,940,489)$ & $(\$ 1,103,076)$ & 0.10 & 0.33 & $-10.20 \%$ & $-3.57 \%$ \\
\hline Chiller & $2,793,226$ & $2,793,226$ & $6,008,089$ & $(\$ 3,214,863)$ & $\$ 955,199$ & 0.46 & 1.52 & $-0.79 \%$ & $5.13 \%$ \\
\hline Commis s & $3,101,608$ & $11,748,270$ & $2,053,604$ & $\$ 1,048,004$ & $\$ 9,694,666$ & 1.51 & 5.72 & $7.34 \%$ & $22.63 \%$ \\
\hline Dist Gen & $1,140,968$ & $1,140,968$ & 197,665 & $\$ 943,304$ & $\$ 943,304$ & 5.77 & 5.77 & $10.48 \%$ & $10.48 \%$ \\
\hline Dist Sys & $6,248,601$ & $21,771,488$ & $21,397,510$ & $(\$ 15,148,909)$ & $\$ 15,610,329$ & 0.29 & 3.53 & $-2.10 \%$ & $8.51 \%$ \\
\hline EMCS & $1,696,409$ & $5,985,227$ & $1,322,088$ & $\$ 374,321$ & $\$ 5,410,077$ & 1.28 & 10.41 & $4.62 \%$ & $19.31 \%$ \\
\hline Envelope & 48,191 & 173,318 & 528,727 & $(\$ 480,536)$ & $(\$ 355,409)$ & 0.09 & 0.33 & $-11.47 \%$ & $-4.01 \%$ \\
\hline HVAC & 101,747 & 364,592 & 826,706 & $(\$ 724,958)$ & $(\$ 36,311)$ & 0.12 & 0.91 & $-9.86 \%$ & $2.38 \%$ \\
\hline Lighting & 632,577 & 632,577 & 332,605 & $\$ 299,972$ & $\$ 377,323$ & 1.90 & 2.48 & $7.36 \%$ & $9.20 \%$ \\
\hline Meter & $3,228,762$ & $11,514,548$ & $4,046,647$ & $(\$ 817,885)$ & $\$ 9,295,217$ & 0.80 & 5.19 & $1.84 \%$ & $11.84 \%$ \\
\hline Motor & $1,668,115$ & $1,668,115$ & $2,284,258$ & $(\$ 616,143)$ & $\$ 913,353$ & 0.73 & 2.21 & $1.45 \%$ & $7.02 \%$ \\
\hline Other & 1,899 & 6,780 & 5,358 & $(\$ 3,458)$ & $\$ 1,423$ & 0.35 & 1.27 & $-2.20 \%$ & $4.22 \%$ \\
\hline Plugs & 15,707 & 15,707 & 49,117 & $(\$ 33,410)$ & $(\$ 33,405)$ & 0.32 & 0.32 & $-4.54 \%$ & $-4.54 \%$ \\
\hline Process & 337,744 & $1,176,760$ & $5,578,280$ & $(\$ 5,240,536)$ & $(\$ 429,376)$ & 0.06 & 0.73 & $-7.93 \%$ & $1.73 \%$ \\
\hline Renewable & $125,273,289$ & $139,963,729$ & $25,272,100$ & $\$ 100,001,189$ & $\$ 132,361,054$ & 4.96 & 18.41 & $10.33 \%$ & $16.73 \%$ \\
\hline Utility & 104,199 & 357,154 & 149,999 & $(\$ 45,800)$ & $\$ 207,155$ & 0.69 & 2.38 & $1.14 \%$ & $7.57 \%$ \\
\hline Total & $3,978,214,976$ & $4,854,678,728$ & $534,961,041$ & $3,443,253,936$ & $4,319,717,687$ & 7.44 & 9.07 & $16.67 \%$ & $18.13 \%$ \\
\hline
\end{tabular}

* Abbreviations are defined in the Acronyms and Abbreviations list, which follows the Executive Summary. 
Table C.3. High and Low Average LCC Results by Agency, without Financing Cost

\begin{tabular}{|c|c|c|c|c|c|c|c|c|c|}
\hline \multirow[b]{2}{*}{ Agency* } & \multicolumn{2}{|c|}{ Life-cycle Benefit (\$) } & \multirow{2}{*}{$\begin{array}{c}\text { Location- } \\
\text { Adjusted } \\
\text { Investment (\$) }\end{array}$} & \multicolumn{2}{|c|}{ Net Savings (\$) } & \multicolumn{2}{|c|}{$\begin{array}{c}\text { Savings-to-Investment } \\
\text { Ratio }\end{array}$} & \multicolumn{2}{|c|}{$\begin{array}{c}\text { Adjusted Internal Rate of } \\
\text { Return }\end{array}$} \\
\hline & Low & High & & Low & High & Low & High & Low & High \\
\hline DHS & $42,490,856$ & $42,861,517$ & $3,452,581$ & $\$ 39,038,275$ & $\$ 38,260,458$ & 12.31 & 9.32 & $16.77 \%$ & $15.16 \%$ \\
\hline DOD & $1,030,964$ & $1,965,997$ & 560,694 & $\$ 470,270$ & $\$ 1,405,303$ & 1.84 & 3.51 & $7.18 \%$ & $11.80 \%$ \\
\hline DOE & $98,584,154$ & $118,979,005$ & $10,258,075$ & $\$ 88,326,079$ & $\$ 83,075,743$ & 9.61 & 3.31 & $14.14 \%$ & $8.76 \%$ \\
\hline DOI & 261,921 & 308,727 & 302,753 & $(\$ 40,832)$ & $\$ 5,974$ & 0.87 & 1.02 & $2.20 \%$ & $3.11 \%$ \\
\hline DOL & 20,730 & 46,737 & 49,427 & $(\$ 28,698)$ & $(\$ 2,690)$ & 0.42 & 0.95 & $-2.77 \%$ & $2.62 \%$ \\
\hline DOT & 591,600 & 706,643 & 344,013 & $\$ 247,587$ & $\$ 362,630$ & 1.72 & 2.05 & $6.31 \%$ & $7.42 \%$ \\
\hline EPA & 401,770 & 984,557 & 728,374 & $(\$ 326,603)$ & $\$ 256,183$ & 0.55 & 1.35 & $-0.35 \%$ & $4.74 \%$ \\
\hline GSA & $1,179,582$ & $2,841,266$ & $9,946,937$ & $(\$ 8,767,354)$ & $(\$ 7,105,670)$ & 0.12 & 0.29 & $-8.31 \%$ & $-3.80 \%$ \\
\hline HHS & 297,357 & 590,472 & 396,181 & $(\$ 98,824)$ & $\$ 194,291$ & 0.75 & 1.49 & $1.28 \%$ & $5.44 \%$ \\
\hline NASA & 6,133 & 23,231 & 59,664 & $(\$ 53,531)$ & $(\$ 36,433)$ & 0.10 & 0.39 & $-17.96 \%$ & $-6.27 \%$ \\
\hline NRC & 286,245 & 974,669 & 235,443 & $\$ 50,802$ & $\$ 739,226$ & 1.22 & 4.14 & $3.67 \%$ & $7.99 \%$ \\
\hline SSA & $8,775,203$ & $9,460,232$ & 411,504 & $\$ 8,363,699$ & $\$ 9,048,729$ & 21.32 & 22.99 & $21.26 \%$ & $21.75 \%$ \\
\hline TREASURY & $4,431,813$ & $4,454,997$ & 373,374 & $\$ 4,058,439$ & $\$ 3,987,043$ & 11.87 & 9.52 & $22.40 \%$ & $20.54 \%$ \\
\hline TVA & 316,350 & 347,672 & 183,066 & $\$ 133,284$ & $\$ 164,606$ & 1.73 & 1.90 & $6.39 \%$ & $6.98 \%$ \\
\hline USDA & 452,131 & $1,539,511$ & $2,866,569$ & $(\$ 2,414,438)$ & $(\$ 1,327,058)$ & 0.16 & 0.54 & $-3.15 \%$ & $0.89 \%$ \\
\hline USPS & 491,793 & 766,454 & 256,033 & $\$ 235,760$ & $\$ 510,421$ & 1.92 & 2.99 & $7.54 \%$ & $10.75 \%$ \\
\hline VA & 175,531 & 382,975 & 235,820 & $(\$ 60,289)$ & $\$ 141,465$ & 0.74 & 1.59 & $1.49 \%$ & $5.40 \%$ \\
\hline Total & $3,978,214,976$ & $4,854,678,728$ & $534,961,041$ & $3,443,253,936$ & $4,319,717,687$ & 7.44 & 9.07 & $16.67 \%$ & $18.13 \%$ \\
\hline
\end{tabular}

* Abbreviations are defined in the Acronyms and Abbreviations list, which follows the Executive Summary. 




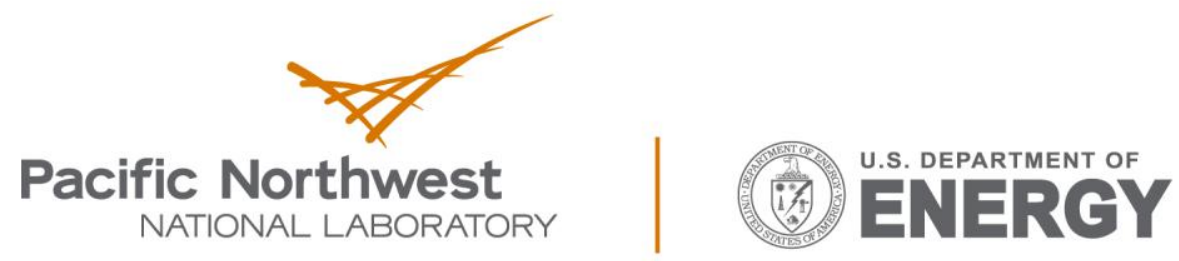

Proudly Operated by Battelle Since 1965

902 Battelle Boulevard

P.O. Box 999

Richland, WA 99352

1-888-375-PNNL (7665)

www.pnnl.gov 